\section{U.S. DEPARTMENT OF ENERGY}

\section{Office of}

ENERGY EFFICIENCY \& RENEWABLE ENERGY

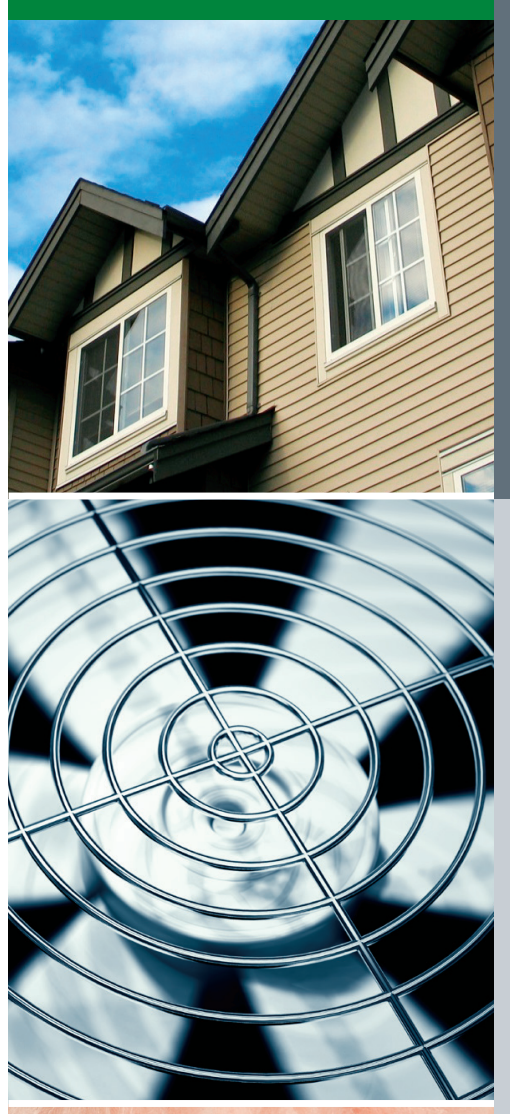

Field and Laboratory Testing of Approaches to Smart Whole-House Mechanical Ventilation Control

January 2018

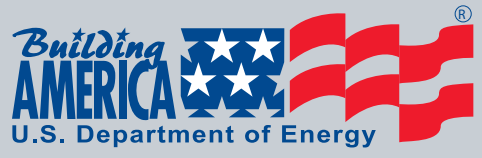




\section{NOTICE}

This report was prepared as an account of work sponsored by an agency of the United States government. Neither the United States government nor any agency thereof, nor any of their employees, subcontractors, or affiliated partners makes any warranty, express or implied, or assumes any legal liability or responsibility for the accuracy, completeness, or usefulness of any information, apparatus, product, or process disclosed, or represents that its use would not infringe privately owned rights. Reference herein to any specific commercial product, process, or service by trade name, trademark, manufacturer, or otherwise does not necessarily constitute or imply its endorsement, recommendation, or favoring by the United States government or any agency thereof. The views and opinions of authors expressed herein do not necessarily state or reflect those of the United States government or any agency thereof.

Available electronically at SciTech Connect www.osti.gov/scitech

Available for a processing fee to U.S. Department of Energy and its contractors, in paper, from:

U.S. Department of Energy

Office of Scientific and Technical Information

P.O. Box 62

Oak Ridge, TN 37831-0062

OSTI www.osti.gov

Phone: 865.576.8401

Fax: 865.576.5728

Email: reports@osti.gov

Available for sale to the public, in paper, from:

U.S. Department of Commerce

National Technical Information Service

5301 Shawnee Road

Alexandria, VA 22312

NTIS www.ntis.gov

Phone: 800.553.6847 or 703.605 .6000

Fax: 703.605.6900

Email: orders@ntis.gov 


\title{
Field and Laboratory Testing of Approaches to Smart Whole-House Mechanical Ventilation Control
}

\author{
Prepared for: \\ U.S. Department of Energy's Building America Program \\ Office of Energy Efficiency and Renewable Energy \\ Prepared by: \\ Eric Martin, Karen Fenaughty, and Danny Parker \\ Florida Solar Energy Center \\ 1679 Clearlake Rd. \\ Cocoa, FL 32922 \\ and \\ Michael Lubliner and Luke Howard \\ Washington State University \\ January 2018
}

Martin, E.; Fernaughty, K.; Parker, D.; Lubliner, M.; Howard, L. 2018. Field and Laboratory Testing of Approaches to Smart Whole-House Mechanical Ventilation Control. Golden, CO; National Renewable Energy Laboratory. DOE/EE-1701. https://www.osti.gov/scitech/biblio/1416954field-laboratory-testing-approaches-smart-whole-house-mechanical-ventilation-control. 
This material is based on work supported by the U.S.

Department of Energy's Office of Energy Efficiency and

Renewable Energy (EERE) within the Building Technologies

Office (Award Number EE0007056).

The work presented in this EERE Building America report does not represent performance of any product relative to regulated minimum efficiency requirements.

The laboratory and/or field sites used for this work are not certified rating test facilities. The conditions and methods under which products were characterized for this work differ from standard rating conditions, as described.

Because the methods and conditions differ, the reported results are not comparable to rated product performance and should only be used to estimate performance under the measured conditions. 


\section{FOREWORD}

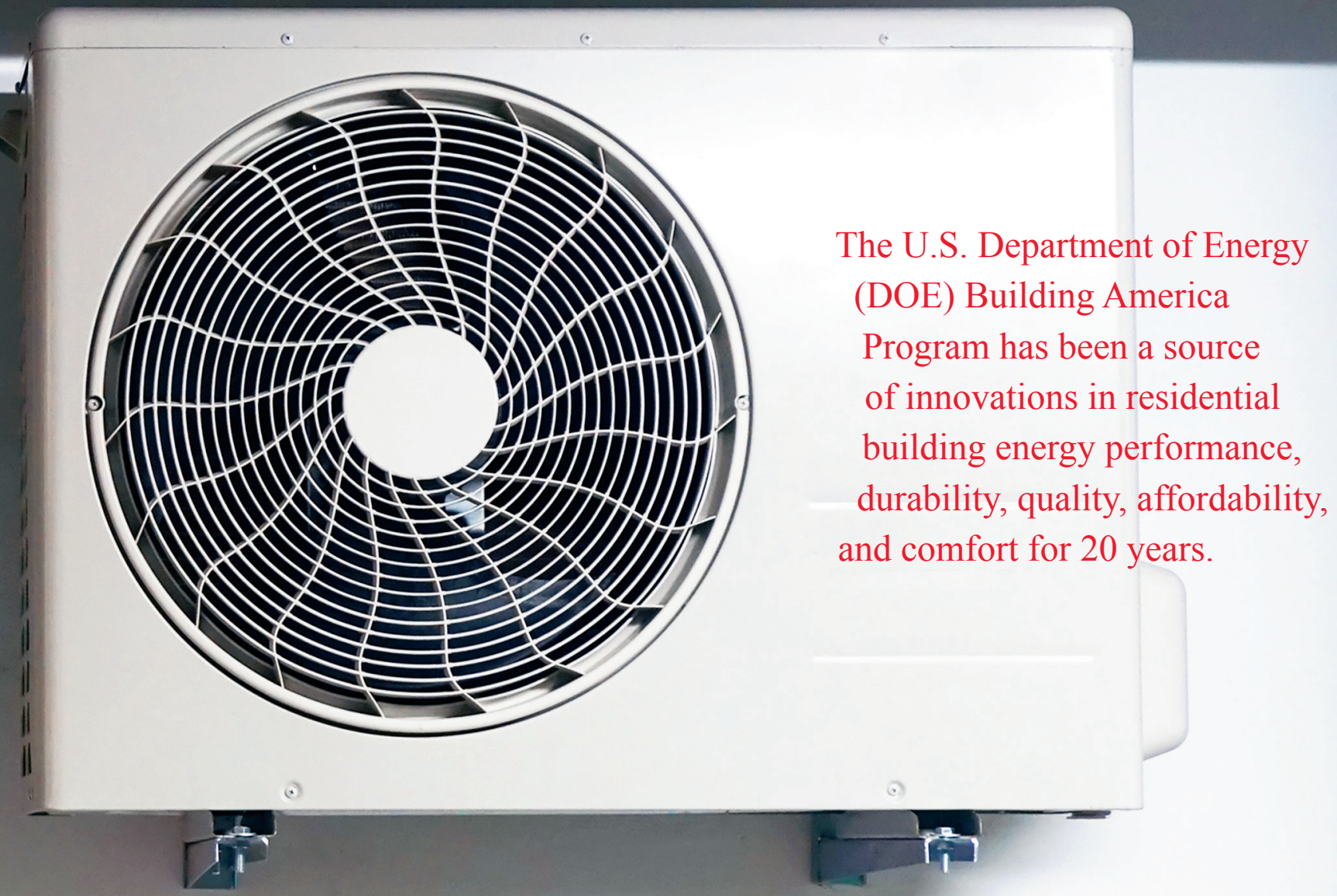

This world-class research program partners with industry to bring cutting-edge innovations and resources to market.

The Building America Program supports the DOE Building Technologies Office Residential Building Integration Program goals to:

1. By 2020 , develop and demonstrate costeffective technologies and practices that can reduce the energy use intensity (EUI) of new single-family homes by $60 \%$ and existing singlefamily homes by $40 \%$, relative to the 2010 average home EUI in each climate zone, with a focus on reducing heating, cooling, and water heating loads.

2. By 2025 , reduce the energy used for space conditioning and water heating in single-family homes by $40 \%$ from 2010 levels.

In cooperation with the Building America Program, the University of Central Florida's Florida Solar
Energy Center is one of many Building America teams working to drive innovations that address the challenges identified in the Program's Research-to-Market Plan.

This report, "Field and Laboratory Testing of Approaches to Smart Whole-House Mechanical Ventilation Control," explores how smart ventilation controls balance energy consumption, comfort, and indoor air quality (IAQ) by optimizing mechanical ventilation operation to reduce the heating and/or cooling loads, improve management of indoor moisture, and maintain IAQ equivalence.

As the technical monitor of the Building America research, the National Renewable Energy Laboratory encourages feedback and dialogue on the research findings in this report as well as others. Send any comments and questions to building.america@ee.doe.gov. 


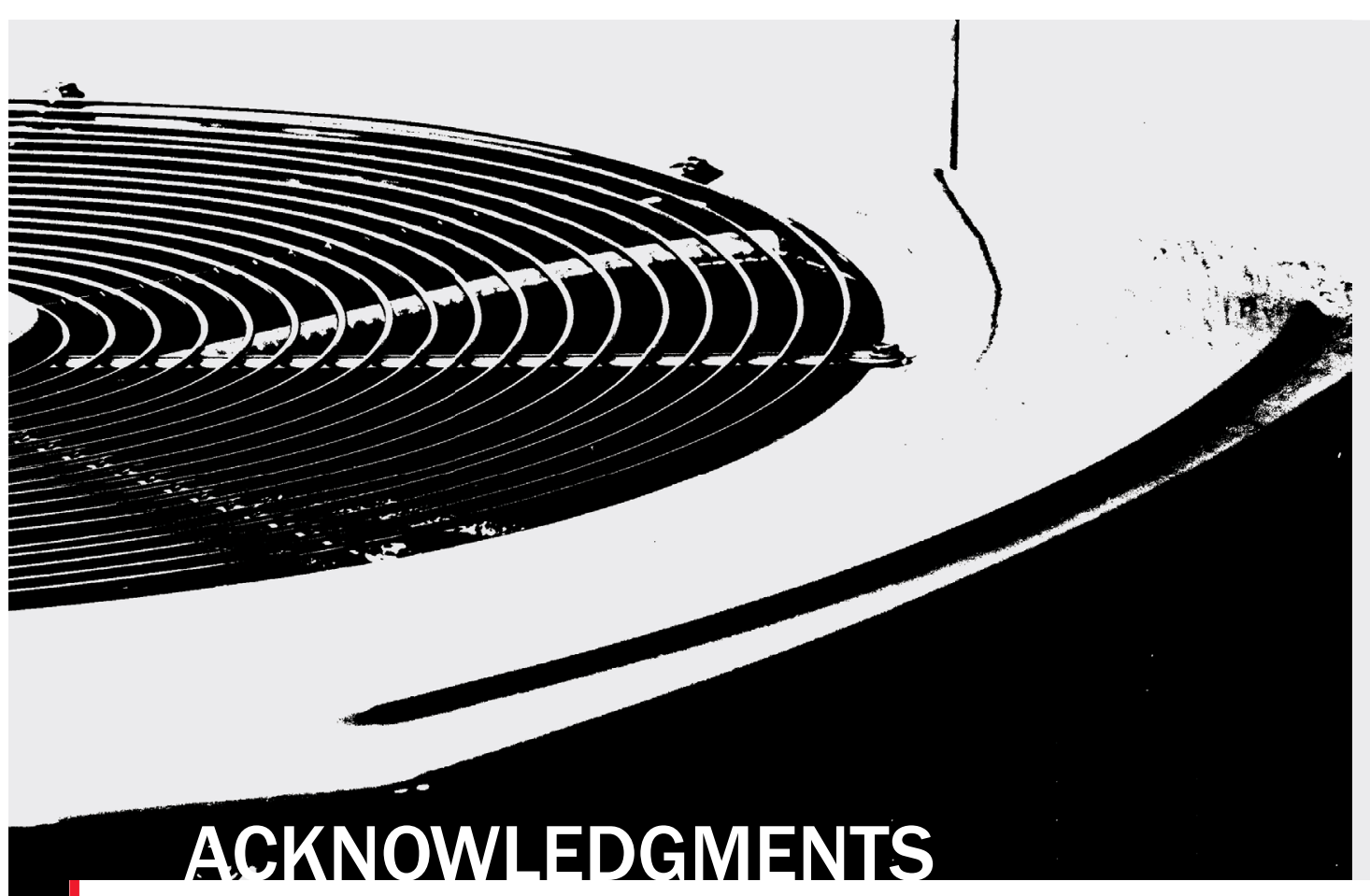

The support and encouragement of U.S. Department of Energy Program Managers Eric Werling, Sam Rashkin, and David Lee, and National Renewable Energy Laboratory Technical Monitor Stacey Rothgeb are gratefully acknowledged. This support does not constitute U.S. Department of Energy endorsement of the views expressed in this report.

The authors would like to thank the following additional individuals and organizations for their assistance and support of this work:

- Chuck Withers and Dave Chasar of the Florida Solar Energy Center (FSEC) for implementing the smart ventilation control in the FSEC test laboratories

- lain Walker and Brennan Less of the Lawrence Berkeley National Laboratory Residential Buildings Group for assisting with indoor air quality simulations

- Paul Francisco, Bill Rose, and Zach Merrin of University of Illinois for their assistance with moisture modeling for the Olympia, Washington, test house

- And the following industry representatives that contributed data and other input relating to commercialization of smart ventilation controls: Don Stevens, Stevens and Associates; Russell Pope, Panasonic; Michael Blasnik, NEST Labs; Jason Wolfson, AirCycler; Gary Nelson, The Energy Conservatory; Rick Karg, Residential Energy Dynamics; Don Feliciano, Honeywell, and Scott Grefsheim, Aprilaire. 


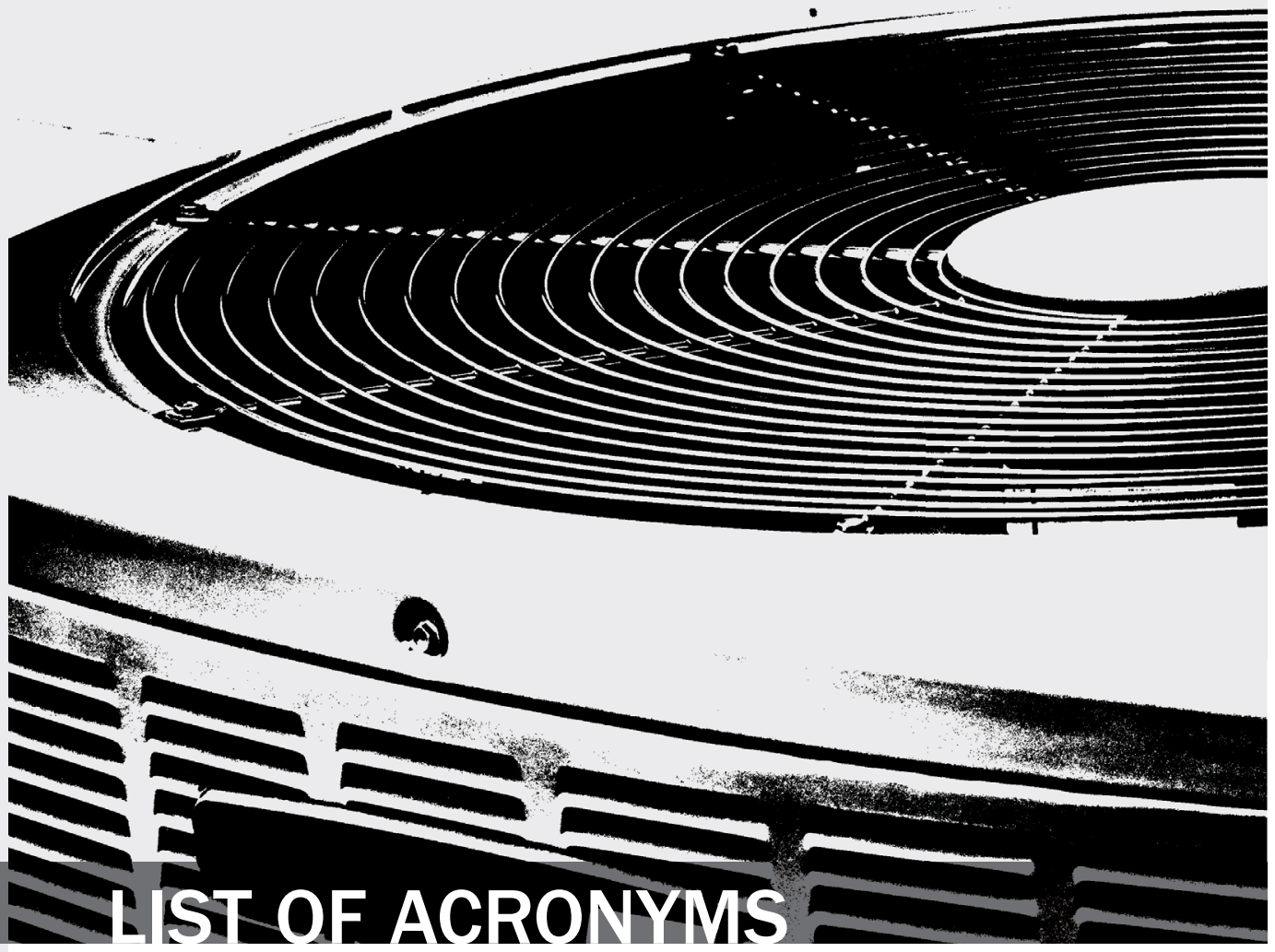

BA-PIRC

Building America Partnership for Improved Residential Construction

cfm cubic feet per minute

$\mathrm{CO}_{2}$

CT carbon dioxide

DHP connected thermostat

FRTF

FSEC ductless heat pump

HVAC

$\mathrm{IAQ}$

IRC

LBNL

Flexible Residential Test Facility

Florida Solar Energy Center

O\&M

heating, ventilating, and air conditioning

OTSVC

ppm

RE

indoor air quality

International Residential Code

Lawrence Berkley National Laboratory

operation and maintenance

occupancy timer-based smart ventilation control

parts per million

relative exposure

$\mathrm{RH}$

relative humidity

RED

Residential Energy Dynamics

RTWSV

real-time weather-based smart ventilation control

STSVC

SVC

TMY3

VOC

seasonal temperature-based smart ventilation control

W smart ventilation controls

typical meteorological year three

volatile organic compounds

absolute moisture of the air 


\section{EXECUTIVE SUMMARY}

\section{Whole-house mechanical ventilation}

is a critical component to a

comprehensive strategy for good indoor air quality (IAQ). comfort, and IAQ by optimizing mechanical ventilation operation to reduce the heating and/or cooling loads, improve management of indoor moisture, and maintain IAQ equivalence according to ASHRAE 62.2. During periods that provide energy, comfort, and/or IAQ advantages, SVC systems ventilate more, whereas they operate less during periods that provide a disadvantage. Mechanical ventilation operation could be controlled in response to singular control variables (e.g., outdoor temperature), or in response to simultaneous consideration of the effect of multiple variables (e.g., occupancy, outdoor temperature, and outdoor moisture). No prior published research on lab or field testing of smart ventilation control systems is available; however, developing "smarter" ventilation systems will enable the residential sector to more reliably design, install, and operate mechanical ventilation systems to achieve best-practice IAQ while minimizing energy and comfort impacts. Three approaches to smart ventilation control were investigated for this report - the first two were investigated in an occupied existing home in the marine climate while the third was investigated in a lab home with simulated occupancy in the hot-humid climate:

\section{Seasonal-Temperature-Based Smart Ventilation Control (STSVC)}

The main principle guiding STSVC for smart ventilation is to shift ventilation from seasonal time periods that have large indooroutdoor temperature differences to periods when these differences are smaller, and their 
energy impacts are expected to be less. In addition, during periods when indoor-outdoor temperature differences are high, stack-driven natural infiltration can also be higher than an

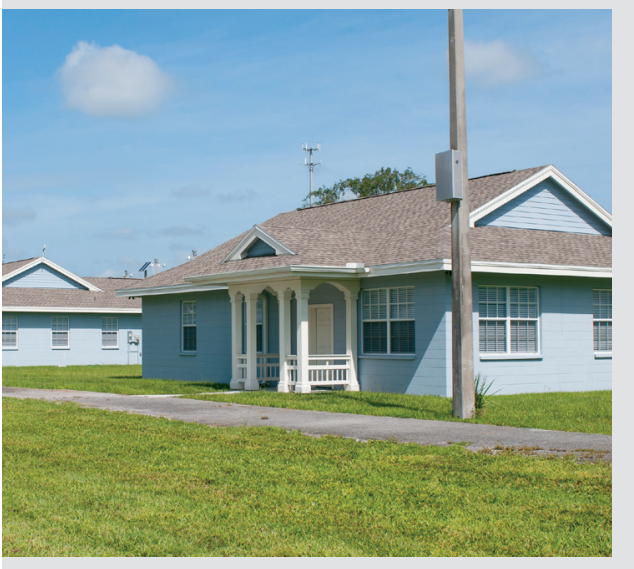
annual average.

A low-cost, prototype STSVC that shut off the mechanical ventilation fan below a pre-determined outdoor temperature $\left(57^{\circ} \mathrm{F}\right)$ was implemented in an occupied existing home in the marine climate zone of Olympia, Washington. Above $57^{\circ} \mathrm{F}$, the fan operated at more than two times the rate determined by ASHRAE 62.2-2016 for continuous ventilation. While this arrangement kept the fan off for much of the winter, natural infiltration during periods of high indoor-to-outdoor temperature difference was modeled as sufficient to prevent unacceptable acute exposure to pollutants as defined by ASHRAE 62.2-2016. Applying the ASHRAE 62.2-2016, Appendix C2.2.2 with hourly timesteps, simulation results show relative exposures (RE) maintained below 1.50, well below the standard's recommended limit of 5 for every hour of the year, and that the scheme achieves an annual average RE of 0.84 , below the standard's recommended limit of 1.0.

Energy simulations indicated potential for 9\% heating and cooling savings for the STSVC approach vs. continuous mechanical ventilation, and analysis of monitored data showed no negative impact on indoor moisture. Analysis of monitored data also showed that while indoor carbon dioxide (CO2) concentration was slightly higher on average with the STSVC approach compared to the continuous ventilation approach, other factors such as occupancy, air mixing, and changes to air exchange via open windows affect indoor $\mathrm{CO} 2$ concentration in similar proportions. Further study regarding other

\section{Seasonal-Temperature-Based Smart Ventilation Control (STSVC):}

\section{Simulated STSVC results show:}

- HVAC energy savings potential of $9 \%$

- Relative exposure to pollutants was in compliance with ASHRAE 62.2-2016.

\section{Monitored results show:}

- Small differences in indoor carbon dioxide and relative humidity levels during all conditions.

A $\$ 20$ controller does an adequate job of cycling fans, as intended. 
contaminants such as volatile organic compounds (VOCs), particularly during long periods where the fan is off, is warranted.

\section{Occupancy Timer-Based Smart Ventilation Control (OTSVC)}

In the same occupied, existing home, a timer system was used as a simplistic approach to modulate the ventilation system according to occupancy. As accurate, low-cost occupancy detection methodologies are not yet available, a fixed occupancy schedule was programmed.

True occupancy-controlled OTSVC systems would vary operation of a mechanical ventilation fan in response to direct measurement of whether the home is occupied or vacant. Resulting energy savings vary based on length of away time, and whether the away time corresponds with a time of day or year when outdoor conditions are such that air exchange poses energy impacts. Occupancy could be sensed directly with sensors, or occupancy could be inferred with signals from home security systems, smart thermostats, etc.

In the Olympia, Washington, occupied residence, an OTSVC system that varied operation of a mechanical ventilation fan in response to a fixed-occupancy schedule was tested. The simple, and lowcost time clock control assumed no occupancy during a typical workday schedule, seven days each week, where the mechanical ventilation fan was not operated. The imperfect control resulted in periods of time when the ventilation system was operating during unoccupied periods, and vice versa. To examine effects of imperfect control, actual occupancy was tracked with sensors and logs. Monitored data and subsequent analysis determined that indoor conditions were wetter during OTSVC with less ventilation air creating less drying potential, but not so wet as to degrade comfort, IAQ, or durability. Monitored $\mathrm{CO}_{2}$ data showed that continuous ventilation maintained lower average concentrations than 
OTSVC, but the differences remained small. Differences in monitored VOC concentrations between the two schemes were not significant. In addition, the differences in VOC and $\mathrm{CO}_{2}$ concentrations between OTSVC and continuous ventilation were similar when OTSVC was evaluated controlling for (eliminating) false occupied/unoccupied readings, indicating that sophisticated occupancy detection may not be required in all cases to achieve desired results. Energy simulations to estimate heating and cooling energy savings from OTSVC show a range of potential savings that can vary by a factor of 10 or more depending on influences such as climate, occupancy schedule, how the schedule corresponds with heating/cooling loads, and the amount of ventilation air reduction provided by the OTSVC strategy.

\section{Real-Time Weather-Based Smart Ventilation Control (RTWSV)}

This system varies mechanical ventilation airflow with an algorithm that interprets measurements of current and 24-hour historical outdoor

\section{Real-Time Weather-Based Smart Ventilation Control (RTWSV):}

Ventilation air discharge into the building is $5^{\circ} \mathrm{F}$ higher than outdoor air temperature measured at weather stations during summer afternoons.

Monitored data show $10 \%$ average monthly cooling energy savings are achieved.

Fan energy use increased with increased capacity needed to achieve these savings and greatly eroded savings.

Simulations suggest this scheme will achieve compliant RE to pollutants according to ASHRAE 62.2-2016. temperature and moisture. The algorithm, developed by the Florida Solar Energy Center (FSEC) as part of this project, optimizes delivery of mechanical ventilation airflow on a daily cycle to minimize sensible and latent load impacts, and simulations were conducted to tune the algorithm with differing flow targets and seasonal adjustment factors to 1) maximize heating and cooling energy savings compared to continuous ventilation, 2) maintain similar indoor relative humidity, and 3) achieve RE with respect 
to ASHRAE 62.2-2016. A ventilation system controlled by the RTWSV algorithm was first simulated and then implemented in a laboratory home and tested side-by-side with an identical home operating with continuous mechanical ventilation. The Phase I simulation results suggest this scheme would produce annual average RE above the target, at 1.08; however, laboratory testing was conducted to ensure theoretical energy savings potential could be realized. Laboratory results of $5.5 \%(1.2 \mathrm{kWh} / \mathrm{d})$ cooling energy savings was obtained, but was found to be limited by two factors: 1 ) the capacity limits of the cooling system caused continuous operation during peak load that could not be curtailed by reduced ventilation flow, and 2) the capacity of the ventilation fan limited the ability of the fan to deliver large enough flows during mild conditions to sufficiently curtail the flow during peak conditions. It is noteworthy that while cooling system and fan capacity limited cooling energy savings, the smart ventilation system did improve indoor comfort by maintaining an indoor temperature $2^{\circ} \mathrm{F}$ cooler than the control building. Another laboratory finding was that the outside ventilation air discharge temperature into the home is fully $5^{\circ} \mathrm{F}$ higher than the outdoor air temperature at height during summer afternoon. In Phase II, the experimental fan capacity was increased to allow for more aggressive algorithm features enabling 1) cooling energy savings during peak load and 2) curtailment of potentially detrimental moisture addition during floating hours that were simulated in Phase I. Simulation results suggest the targeted annual average RE of 1.0 is maintained, while the hourly RE is maintained below the maximum threshold allowed under ASHRAE 62.2-2016. In the laboratory, 10\% monthly average cooling energy savings were measured in Phase II due to the reduction in sensible and latent load created by the advanced system. A fan with a maximum capacity nearly three times greater than the continuous fan was required to achieve these savings, and added fan 
energy needs to be carefully considered so as not to erode potential cooling savings. The negative impact of increased fan power on the savings of the scheme suggests that the use of permanent magnet motors with much lower power would be highly beneficial for both the ability to modulate flow over periods, rather than utilize a fixed fan speed for varying amounts of time, as well as to reduce fan electric power consumption.

Experimental testing of all smart ventilation strategies utilized sensorbased measurements of occupancy and weather parameters collected at the actual test homes, but commercialized systems could leverage both broadband weather data available from internet-connected devices such as smart thermostats, as well as occupied/unoccupied signals from internet connected security systems, thermostats, etc. One lesson learned is that a weather sensor being physically located at a home could have an effect on resulting ventilation system operation, but also may more accurately reflect actual ventilation air conditions than data from an airport weather station. If broadband weather data is used as an element of control, algorithms may need to be tuned to correct for local anomalies.

To further explore challenges and opportunities related to commercialization of smart ventilation controls and systems, the Building America Partnership for Improved Residential Construction team conducted limited research to identify the size of a potential market for smart ventilation controls, and worked with stakeholders to convene an advisory group and solicit input on current and planned smart ventilation activities. Items related to system and component cost, integration, communication, design, commissioning, and credit in code and ratings were identified. Current and future activities of the ASHRAE 62.2 committee, representing the authorizing environment, to enable smart ventilation controls in the marketplace are discussed in the report, including the development of equivalence methodologies and interpretation of constant vs. varying pollutant emission rates. 


\section{Table of Contents}

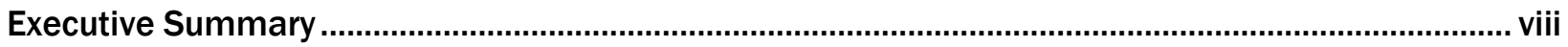

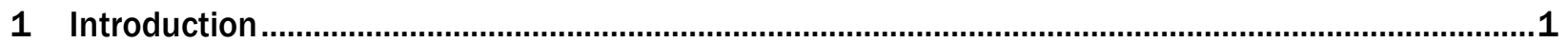

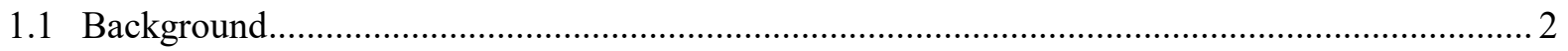

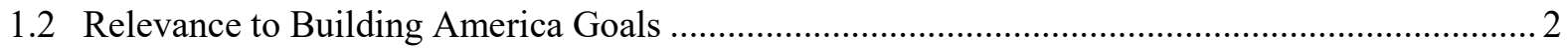

2 Occupied Home Investigation of Smart Ventilation Control in Marine Climate Zone 4C...............4

2.1 Field Test of Seasonal Temperature-Based Smart Ventilation Control.........................................5

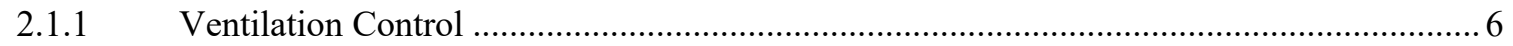

2.1.2 Indoor Air Quality $-\mathrm{CO}_{2}$ and Relative Humidity ...................................................... 9

2.1.3 Ductless Heat Pump Energy Use .............................................................................. 12

2.2 Field Test of Occupancy Timer-Based Smart Ventilation Control ........................................... 13

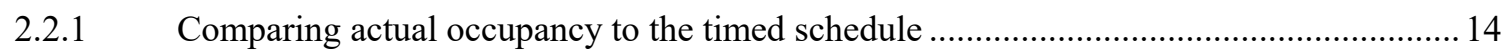

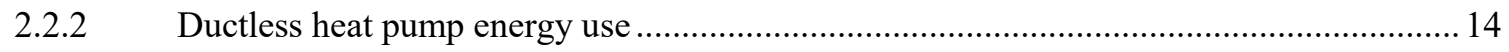

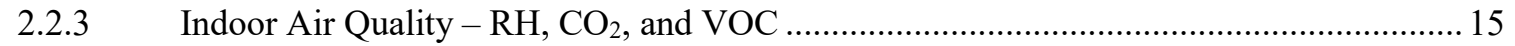

3 Multi-Variable Smart Ventilation Control: Real-Time Weather-Based Smart Ventilation Control Algorithm Development and Laboratory Home Investigation in Climate Zone 2a....................... 17

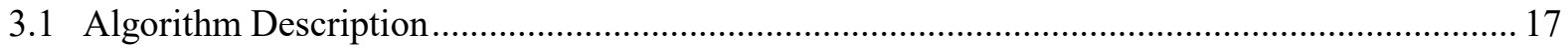

3.2 Phase I Scheme Description and Simulation Results ............................................................. 20

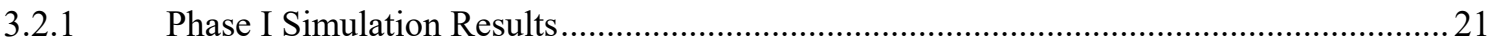

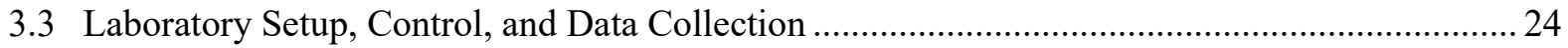

3.4 Early Experimentation to Implement Fan Control .................................................................... 26

3.5 Impact of Outdoor Air Source on Ventilation Air Temperature............................................... 29

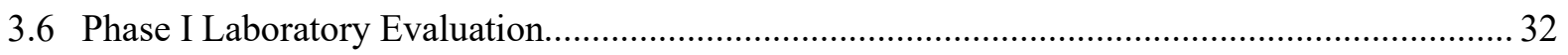

3.6.1 Phase I Results: 2016 Cooling and 2016-17 Floating Periods ....................................... 32

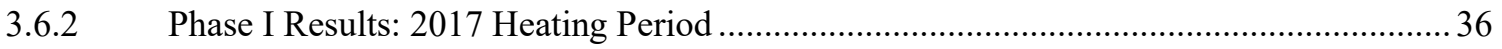

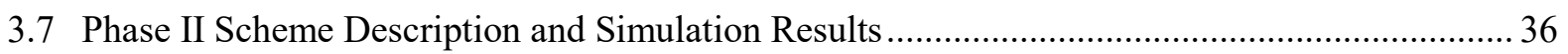

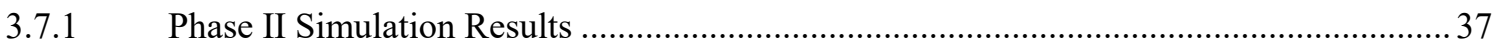

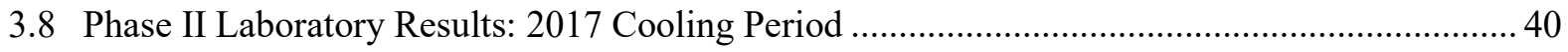

4 Conclusions from Experimental and Simulation-Based Analysis of Smart Ventilation

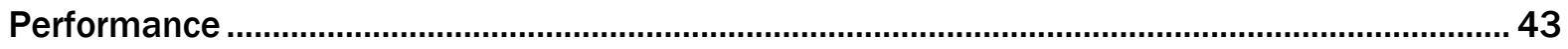

5 Industry Considerations for Commercialization of Smart Ventilation Controls ........................... 45

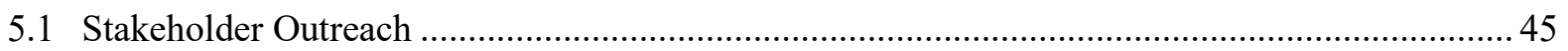

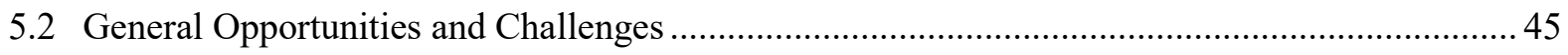

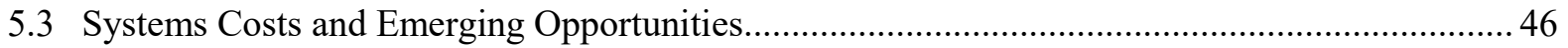

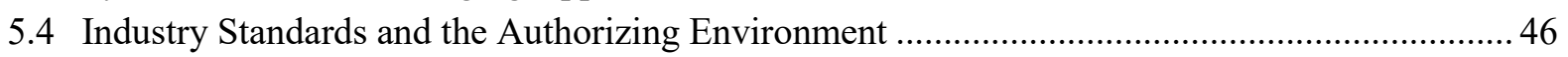

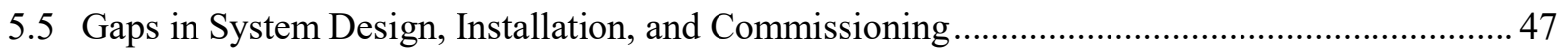

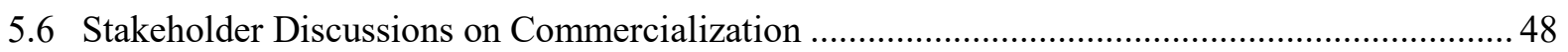

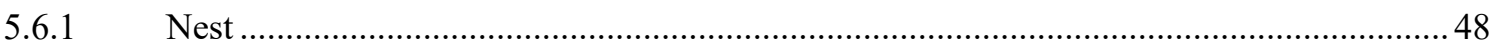

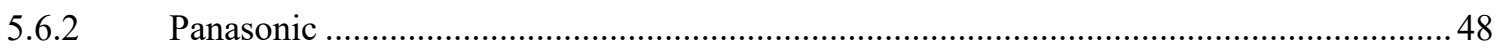

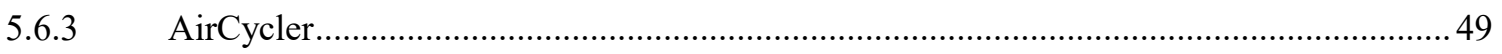




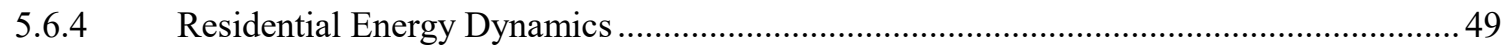

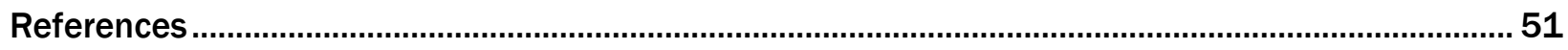




\section{List of Figures}

Figure 2-1. Test home, Olympia, Washington

Figure 2-2. Seasonal temperature-based smart ventilation control simulated total ventilation (infiltration only when there is no fan flow or fan flow + modified infiltration) and daily average RE using Washington area TMY3 data 6

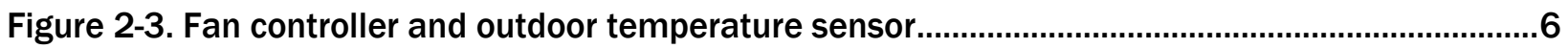

Figure 2-4. Ventilation fan operation at different average hourly outdoor temperatures......................7

Figure 2-5. Hourly average $\mathrm{CO}_{2}$ concentration vs. outdoor temperature for the STSVC test home. Blue symbols indicate hours when the temperature override control was active, with $0 \mathrm{cfm}$ of ventilation delivered below $57^{\circ} \mathrm{F}$ and $90 \mathrm{cfm}$ of ventilation delivered above $57^{\circ} \mathrm{F}$. Red symbols indicate hours with $40 \mathrm{cfm}$ continuous ventilation

Figure 2-6. Hourly indoor RH versus outdoor temperature for the main living area........................... 11

Figure 2-7. Hourly indoor RH versus outdoor temperature for the master bedroom.......................... 11

Figure 2-8. Daily space conditioning energy use vs. outdoor temperature for the STSVC test home. Blue symbols indicate days when the temperature override control was active, with $0 \mathrm{cfm}$ of ventilation delivered below $57^{\circ} \mathrm{F}$ and $90 \mathrm{cfm}$ of ventilation delivered above $57^{\circ} \mathrm{F}$. Red symbols indicate days with $40 \mathrm{cfm}$ continuous ventilation.

Figure 2-9. Whole-house exhaust fan timer deployed for OTSVC field testing....... 13

Figure 2-10. Master bedroom sensed vs. logged occupancy spanning constant flow and OTSVC schemes

Figure 3-1. Illustration of how outdoor absolute moisture (W: green) and root mean sum squared of both temperature and $\mathrm{W}$ deviations (orange) vary over the day in summer in Orlando, Florida 18 19

Figure 3-2. Comparison of the simulated flow rate in $\mathrm{cfm}$ of smart controller (green circles) versus a constant ventilation rate of $76 \mathrm{cfm}$ (horizontal blue line). The two dashed vertical lines show the conditions from May 1-Sept. 30 during the height of the cooling season in Central Florida..... 19

Figure 3-3. Phase I smart ventilation scheme simulated fan flow and RE ....................................... 22

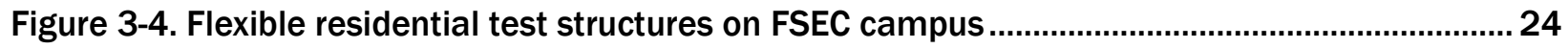

Figure 3-5. Fantech FR140 variable speed fan used to set flow for smart ventilation system ......... 25

Figure 3-6. Indoor temperature $\left({ }^{\circ} \mathrm{F}\right)$ in labs with the baseline system (orange) and advanced system (green)

Figure 3-7. Hourly target ventilation flow (cfm) derived by the algorithm (red), measured delivered ventilation flow to the building (blue), and RE (green)

Figure 3-8. Fifteen-minute ventilation fan run time (minutes) of the advanced system (green, right axis), along with the outdoor temperature (red, left axis) and outdoor dew point (blue, left axis) 
Figure 3-9. Temperature of ventilation intake (green), discharge (orange), and the outdoor temperature (blue) of the smart ventilation building, July 29-Aug. 10, 2016.

Figure 3-10. Average intake (green) and discharge temperatures (orange) of smart ventilation system at the height of summer against outdoor air temperature at roof height (blue), July 29Aug. 10.

Figure 3-11. Example data on Aug 1, 2016 showing how air temperature varies around test buildings at height, vent inlet, and close to ground.

Figure 3-12. Smart ventilation AC power (green) and control building AC power (blue) both fail to keep set point (purple). Control building temperature (red) spikes about $2^{\circ} \mathrm{F}$ higher than smart building (yellow).

Figure 3-13. Average day smart ventilation and control building fan flow and interior RH during December.

Figure 3-14. October average daily profile, displaying smart building AC power (green line), control building AC power (blue line), smart fan flow (green dash), constant control fan flow (blue dash), smart building interior RH (purple dots), control building interior RH (orange dots), and outside air inlet temperature (red line).

Figure 3-15. Smart ventilation heating (orange) versus control building heating (purple). Smart ventilation heating savings observed during a January cold front. 36

Figure 3-16. Phase II smart ventilation scheme simulated fan flow and RE

Figure 3-17. Phase II smart ventilation scheme simulated fan flow and RE for month of August ... 38

Figure 3-18. Average measured HVAC savings for Phase I (August-October) versus Phase II (MayJuly).

Figure 3-19. June average daily profile, displaying smart building AC power (green line), control building AC power (blue line), smart fan flow (light green dash), constant control fan flow (light blue dash), smart building interior RH (purple dots), control building interior RH (orange dots), and outside air inlet temperature (red line). 


\section{List of Tables}

Table 2-1. Temperature \& Occupancy Smart Ventilation Control ........................................................5

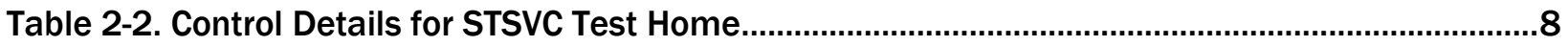

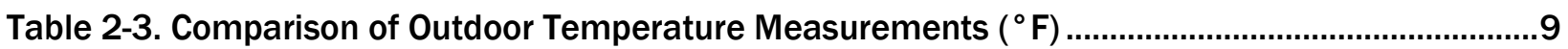

Table 2-4. Main Living Area $\mathrm{CO}_{2}$ Levels at Outdoor Temperatures below $55^{\circ} \mathrm{F}$ and above $60^{\circ} \mathrm{F}$ for Continuous and Temperature-Based Fan Control....................................................................... 10

Table 2-5. Modeled Energy Savings for Temperature Override Control at the STSVC Test Home ..... 12

Table 2-6. Weekly Flip Flop Dates for OTSVC (2016-2017)......................................................... 13

Table 2-7. Statistical Results for Differences in $\mathrm{CO}_{2}$ and VOC Concentrations in Main Living Area Between Continuous Ventilation and Two Types of OTSVC ....................................................... 16

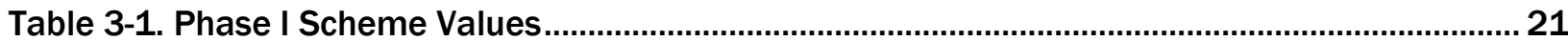

Table 3-2. Hourly Average Phase I Simulated Seasonal Sensible and Latent Loads, and Fan Energy

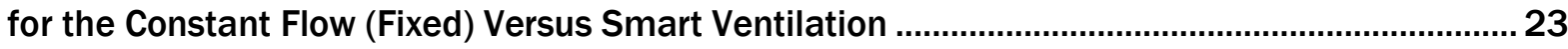

Table 3-3. Estimated Space Conditioning Energy Use and Savings for Fixed and Smart Ventilation

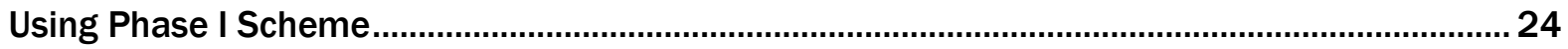

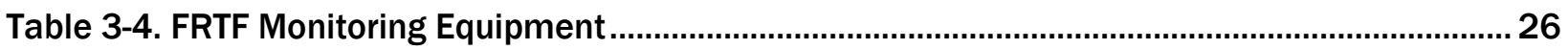

Table 3-5. Phase I Scheme Average Monthly Measured Cooling Energy Use and Savings ................ 33

Table 3-6. Phase I Scheme Average Monthly Measured Fan Flow, RE, and Interior and Exterior

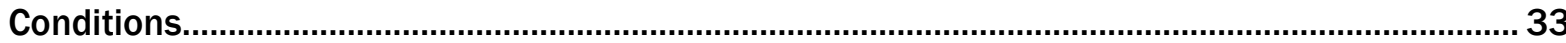

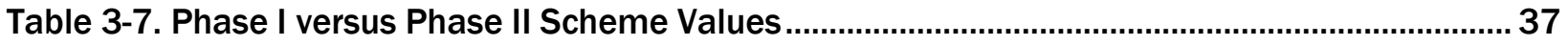

Table 3-8. Hourly Average Phase II Simulated Seasonal Sensible and Latent Loads, and Fan Energy for the Constant Flow (Fixed) Versus Smart Ventilation ................................................................. 39

Table 3-9. Estimated Space Conditioning Energy Use and Savings for Phase II Scheme................... 39

Table 3-10. Phase II Scheme Average Monthly Measured Smart Ventilation AC Savings ................. 40

Table 3-11. Phase II Scheme Average Monthly Measured Fan Flow, RE, and Interior and Exterior Conditions. 


\section{Introduction}

Residential buildings account for $22 \%$ of total U.S. energy consumption, with the majority attributed to heating, ventilating, and air-conditioning (HVAC) systems. Residential energy efficient construction has focused on tighter envelopes to save energy; and this creates limited potential for air exchange (Parker 2014, Viera 2013, Offerman 2009, Sherman and Matson 2002). The purpose of mechanical ventilation is to provide outdoor air to ensure healthy indoor air quality (IAQ) by diluting or removing internally generated contaminants, and to control odor.

IAQ is a complex result of occupant activities, human responses, source emissions, removal/dilution mechanisms, and outdoor conditions. Because people typically spend a significant amount of their time indoors, residential building science principles and ASHRAE Standard 62.2 (ASHRAE 2016), which defines best practice for mechanical ventilation recognize that energy conservation must not negatively impact occupant exposure to IAQ pollutants, such as volatile organic compounds, aldehydes, and particulates.

However, many builders and contractors perceive best practice for mechanical ventilation as a risk, and its voluntary and code mandated adoption varies amongst regions (Martin 2014). Ventilation systems are not effectively integrated with space conditioning equipment, often resulting in the perception that mechanical ventilation is an optional feature, and risks from added costs and energy use to manage associated loads are perceived. In humid climates, this includes the need for supplemental dehumidification. In cold climates, sensible heat recovery is needed. One potential solution is to measure or forecast risk factors, such as extreme outdoor temperature and/or absolute moisture, and optimize ventilation delivery accordingly such that moisture and energy risks are minimized. Development of "smarter" ventilation systems will enable the residential sector to more reliably design, install, and operate mechanical ventilation systems designed to achieve best practice IAQ while minimizing energy and comfort impacts.

The ASHRAE Standard 62.2 assumes that there will be a constant ventilation rate from a purpose-provided mechanical ventilation system, for every hour of the day, with guidance for the equivalent operation of intermittent ventilation system operation. Ventilation fan flows are typically determined based on an annual average natural infiltration rate, and ventilation fans are usually operated for 24-hours per day at the same rate regardless of occupancy, the actual natural infiltration rate for a given hour, or outdoor environmental conditions.

Smart ventilation controls (SVC) balance energy consumption, comfort, and IAQ by optimizing mechanical ventilation operation to reduce the heating and/or cooling loads, improve management of indoor moisture, and maintain IAQ equivalence (Sherman, Walker, and Logue 2012) according to ASHRAE 62.2. SVC systems ventilate more during periods that provide energy, comfort, and/or IAQ advantages and less during periods that provide a disadvantage. Mechanical ventilation operation could be controlled in response to singular control variables, such as outdoor temperature, or in response to simultaneous consideration of the effect of multiple variables, such as occupancy, outdoor temperature, and outdoor moisture.

Three approaches to smart ventilation control were investigated for this report - the first two were investigated in an occupied existing home in the marine climate while the third was investigated in a lab home with simulated occupancy in the hot humid climate:

Seasonal Temperature-Based Smart Ventilation Control (STSVC): The main principle guiding STSVC for smart ventilation is to shift ventilation from seasonal time periods that have large indoor-outdoor temperature differences to periods when these differences are smaller and their energy impacts are expected to be less. In addition, during periods when indoor-outdoor temperature differences are high, stack-driven natural infiltration can also be higher than an annual average. Ignoring varying weather-driven natural infiltration can lead to excess ventilation and unnecessary energy expense, while overestimating the contribution of infiltration can lead to poor IAQ and contaminant exposure. 
Occupancy Timer-Based Smart Ventilation Control (OTSVC): The OTSVC system varied operation of a mechanical ventilation fan in response to a fixed schedule roughly corresponding to whether the home is occupied or vacant. With any occupancy controlled system, resulting energy savings vary based on length of away time, and whether the away time corresponds with a time of day or year when outdoor conditions are such that air exchange poses energy impacts. In a true occupancy controlled system, occupancy could be sensed directly with sensors, or occupancy could be inferred with signals from home security systems, smart thermostats, etc.

Real-Time Weather-Based Smart Ventilation Control (RTWSV): This system varies mechanical ventilation airflow with an algorithm that interprets measurements of current and 24-hour historical outdoor temperature and moisture. The algorithm optimizes delivery of mechanical ventilation airflow on a daily cycle to minimize sensible and latent load impacts, and was tuned via simulation to provide equivalent annual average relative exposure to ASHRAE 62.2. The control could use local measurements of weather parameters with sensors, or could use broadband weather data available from internet connected devices such as smart thermostats.

\subsection{Background}

Previous studies by Lawrence Berkeley National Laboratory (LBNL) have incorporated smart ventilation strategies that included the effects of other fans operating in the home as well as passive ventilation systems (Sherman and Walker 2011; Turner and Walker 2012). These studies included development of a ventilation model to include control algorithms and IAQ calculations suitable for evaluating performance of variable ventilation rate systems (Sherman and Walker 2011). LBNL used these simulations to develop a smart ventilation algorithm based on a minimum temperature threshold (Less, Walker, and Tang 2014). Another study (Walker, Sherman, and Less 2014) proposes a variety of additional control options for smart ventilation systems including occupancy and outdoor moisture. Recently, LBNL simulation techniques have been used to investigate the effect of smart ventilation control on indoor relative humidity (RH) (Less and Walker 2016). No prior published research on lab or field testing of smart ventilation control systems is available.

LBNL work on ventilation equivalence was adopted by ASHRAE 62.2-2016 in the form of Appendix C, which provides a procedure to calculate pollutant exposure resulting from varying ventilation rates, relative to a continuous rate, and termed "relative exposure" (RE). The user has a choice of time period over which to average the exposure, for which a time varying ventilation system targets an average value of 1.0 to provide exposure to pollutants equivalent to a continuously operating mechanical ventilation system. A stipulation has been adopted that to remain equivalent to continuous ventilation, at no time can a time varying ventilation system produce an RE that exceeds five times the baseline. ASHRAE 62.2-2016 calls for exposure to be evaluated for all occupied periods, and the equivalence procedure is based on there being a constant indoor emission rate of pollutants during both occupied and unoccupied hours.

\subsection{Relevance to Building America Goals}

In pursuit of goals including reducing the energy use intensity of new homes by at least $60 \%$ and existing homes by at least $40 \%$, relative to the 2010 average for homes in each major U.S. climate, Building America has identified limitations in available ventilation systems toward providing the control necessary to minimize the impact of mechanical ventilation on energy use and comfort. Elements of the Building America Research to Market Plan (Building America Program 2015) include efforts to validate/demonstrate smart ventilation controls, and to work with manufactures to commercialize those controls. To contribute to those efforts, research described in this report explores related questions including:

- What are the potential energy savings from different SVC approaches?

- How do prototype SVC controls function in actual field conditions?

- What is the impact of SVC approaches on indoor environmental parameters including carbon dioxide $\left(\mathrm{CO}_{2)}, \mathrm{RH}\right.$, and volatile organic compounds (VOCs)? 
- What is the exposure generated by SVC approaches relative to ASHRAE 62.2-2016 continuous ventilation?

- What considerations should manufacturers prioritize as they commercialize prototype controls (i.e. cost, commissioning, interoperability, etc.)? 


\section{Occupied Home Investigation of Smart Ventilation Control in Marine Climate Zone 4C}

STSVC and OTSVC were implemented and tested in an occupied existing home. The test home (Figure 2-1) is a two-story, 1,640 square foot historical house located in Olympia, Washington. It underwent a deep energy retrofit in 2010 that significantly upgraded the building envelope (R-38/R-49 ceiling, R15/R26 wall, R-30 floor insulation). Air leakage after the retrofit was measured at just over 5.0 air changes per hour at $50 \mathrm{~Pa}$. Space conditioning is provided by a 1 -ton single head ENERGY STAR ${ }^{\circledR}$ (heating season performance factor $=12$, seasonal energy efficiency ratio 25) ductless heat pump (DHP) with the indoor unit located on the first floor. Whole-house ventilation is provided by the bathroom exhaust fan on the first floor. This is the fan controlled for the smart ventilation field tests. ASHRAE 62.2-2016 recommends minimum continuous fan forced ventilation of $40 \mathrm{cfm}$ for the home, based on an annual average infiltration rate of $40 \mathrm{cfm}$, resulting in an average total continuous ventilation requirement of $80 \mathrm{cfm} .{ }^{1}$
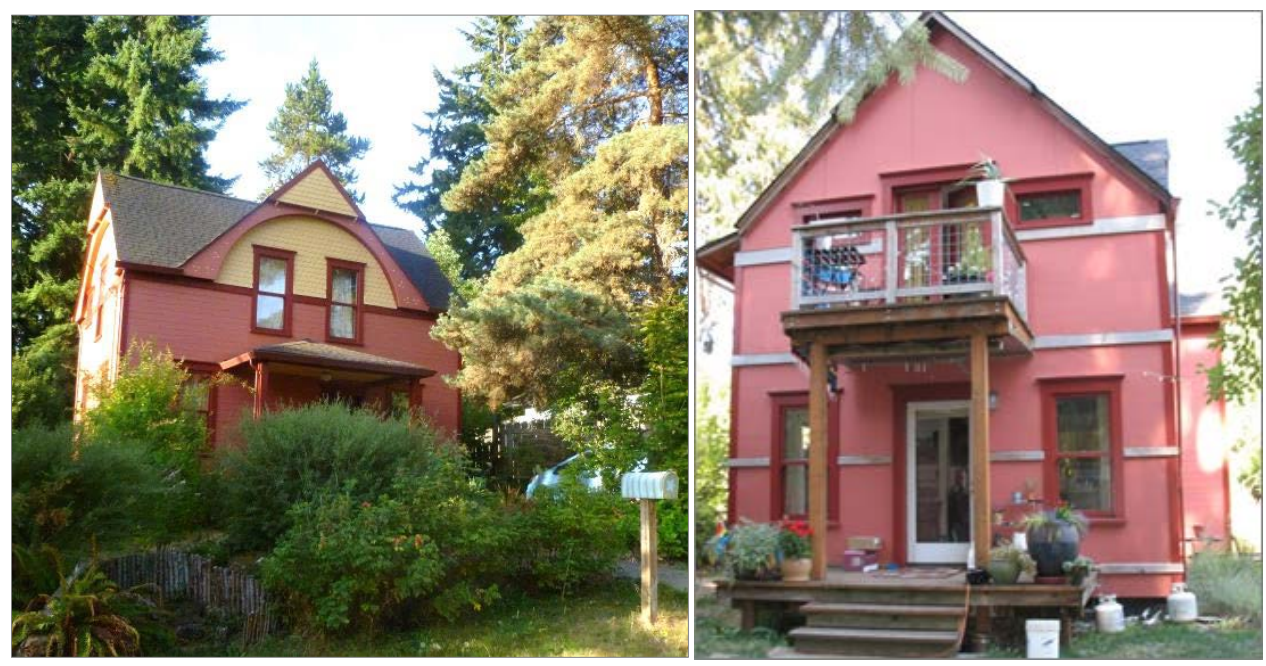

Figure 2-1. Test home, Olympia, Washington

The data recorded for the field tests included:

- Indoor temperature, $\mathrm{RH}$, and $\mathrm{CO}_{2}$ levels in the main living area on the first floor and in the three upstairs bedrooms

- Door closure status for the first-floor bathroom door and the three upstairs bedrooms

- Outdoor temperature (north side of home, left photo in Figure 2-1)

- Ventilation fan operation-on time

- Whole-house and DHP energy use

- Refrigerant line temperature for the DHP (as an indicator of DHP operation mode)

- Occupancy sensor on the first floor and bedrooms

\footnotetext{
${ }^{1}$ Although this was a retrofitted home, because of the intensive nature of the home changes we did not use the ASHRAE 62.2 Appendix A: Existing Buildings compliance path that adjusts whole-house ventilation rates if local kitchen and bath exhaust are not ASHRAE 62.2 compliant.
} 
- Occupancy log maintained and updated weekly to inform occupancy

- Total volatile organic compounds on each floor

- Front and back door state loggers (also indicators of occupancy, but not used in current analysis).

Data intervals were event dependent at 15-minute intervals then compiled at 1-hour intervals and merged into a data file for analysis. The fan operation data were compiled at one-minute intervals to examine fan operation in more detail. The monitoring equipment specifications and description are provided in Table 2-1.

Table 2-1. Temperature \& Occupancy Smart Ventilation Control

\begin{tabular}{|c|c|c|}
\hline Measurement & Equipment & Accuracy \\
\hline Data acquisition & $\begin{array}{c}\text { ONSET }^{\circledR} \text { HOBO - U30, } 15 \\
\text { Wattnode WNB-3Y-208-Pulse Input } \\
\text { Adapters CT input 0.5 VAC, \# VAC max }\end{array}$ & $\begin{array}{l}512 \mathrm{~K} \text { bytes, } 15 \mathrm{~min} \\
\text { logging intervals } \\
+/-5 \mathrm{~s} / \text { week @ } 77^{\circ} \mathrm{F}\end{array}$ \\
\hline Temperature and $\mathrm{RH}$ indoors & ONSET HOBO - U12-013 & $\begin{array}{c}\text { temp. }+/-0.63^{\circ} \mathrm{F} \\
\mathrm{RH}+/-3.5 \%\end{array}$ \\
\hline Temperature and $\mathrm{RH}$ outdoors & ONSET HOBO - U-10-003 & $\begin{array}{c}\text { temp. }+/-0.95^{\circ} \mathrm{F} \\
\mathrm{RH}+/-5.0 \% \\
+/-0.36^{\circ} \mathrm{F}\end{array}$ \\
\hline Temperature DHP vapor line & ONSET HOBO - U30 12 Bit temp. Sensor & $+/-0.36^{\circ} \mathrm{F}$ \\
\hline Energy - total \& DHW loads & ONSET HOBO - U30 and CT $100 \& 50 \mathrm{~A}$ & $+/-10 \%-130 \%$ \\
\hline Carbon dioxide & Veris Industries \#CWLSXX & 30 ppm +/- $2 \%$ \\
\hline Total volatile organic compounds & $\begin{array}{c}\text { Power Wise inSense Multi-Sensor Rev. } \\
2.0\end{array}$ & E-monitor \\
\hline Occupancy data loggers \& sensors & ONSET HOBO - UX90-006 & $39.4 \mathrm{ft}$ max range \\
\hline Window and door state loggers & ONSET HOBO - UX90-001 & $+/-1$-min per month \\
\hline Fan run time loggers & $\begin{array}{l}\text { ONSET HOBO - UX90-001 w/ Veris } \\
\text { Industries Hawkeye } 300 \text { CT }\end{array}$ & Low 0.15 A CT \\
\hline
\end{tabular}

Note: Total volatile organic compounds sensors and HOBO occupancy sensors were not installed until OTSVC testing began.

\subsection{Field Test of Seasonal Temperature-Based Smart Ventilation Control}

Modeling by LBNL utilizing typical meteorological year three (TMY3) data showed that to achieve annual average RE equivalent to a continuous fan flow of $40 \mathrm{cfm}$, the fan can be turned off below an outdoor temperature of $57^{\circ} \mathrm{F}$, if the fan was operated at $90 \mathrm{cfm}$, its maximum capacity, when outdoor temperatures are above $57^{\circ} \mathrm{F}$. A temperature of $57^{\circ} \mathrm{F}$ was chosen based on simulations suggesting the annual average RE target could be achieved given this fan capacity. With this approach, during hours when the fan is off, natural ventilation is sufficient to minimize short-term fluctuations in indoor RE such that the lack of fan run time should not present health concerns. Simulated results of the daily average RE and total ventilation flow for the scheme are plotted in Figure 2-2. Results show REs maintained below 1.50, well below the ASHRAE 62.22016 recommended limit of 5 for every hour of the year, and that the scheme achieves an annual average RE of 0.84 , below the ASHRAE 62.2-2016 recommended limit of 1.0. 


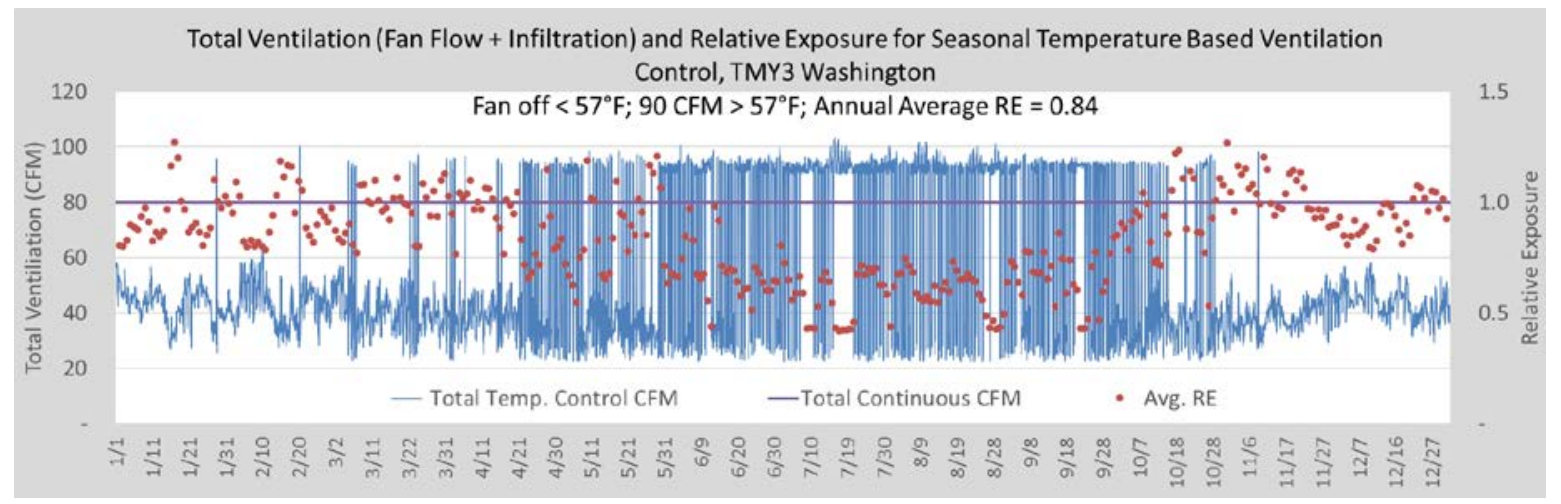

Figure 2-2. Seasonal temperature-based smart ventilation control simulated total ventilation (infiltration only when there is no fan flow or fan flow + modified infiltration) and daily average RE using Washington area TMY3 data

A prototype STSVC system was implemented in the test home and tested during winter of 2016. No change out of the existing ventilation fan was required because it had excess capacity to run at $90 \mathrm{cfm}$. An outside thermostat/relay control was installed to control the fan and set to lock out below $57^{\circ} \mathrm{F}$. This is a simple outdoor thermostat connected to a line-voltage relay located on the shaded side of the home. The STSVC prototype control used in the test home was purchased for less than $\$ 20$ and required less than an hour of electrical work to install. As seen in Figure 2-3, the outdoor temperature sensor was located on the west side of the house behind the outdoor unit for the DHP, which provides shading from direct sunlight.

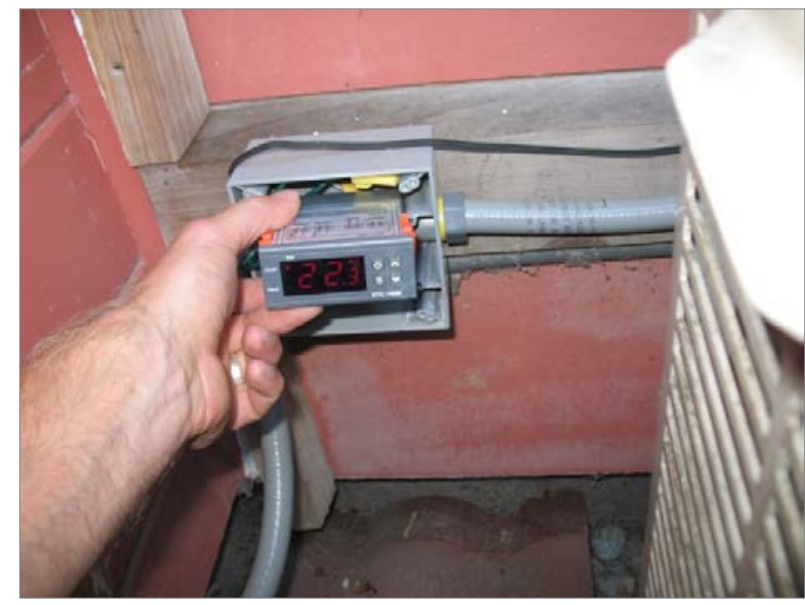

Figure 2-3. Fan controller and outdoor temperature sensor

To estimate the difference in performance and energy use, weekly flip-flop tests were conducted, during which the ventilation system control alternated between $40 \mathrm{cfm}$ continuous use and the prototype STSVC, which ventilates at either $90 \mathrm{cfm}$ or no fan flow based on outdoor temperature.

\subsubsection{Ventilation Control}

Testing of the ventilation fan control modes began on April 27, 2015. One of the questions answered by the field testing was that the relatively low-cost fan control operated as intended. Three issues were considered: fan cycling, whether the temperature control was working properly, and differences in outdoor temperature measurements.

Fan cycling - There is a 1-minute delay in the fan controller and a $0.5^{\circ} \mathrm{F}$ deadband between when the fan turns on and off to avoid rapid cycling of the fan. A review of 1-minute fan-on time data indicates there were a little over 40 instances of rapid fan cycle flip-flop-on-off-on or off-on-off in consecutive 1-minute periods- 
during the 1,466 hours of temperature-based fan control. While these instances were fairly isolated, they do indicate some fan cycling did occur. This could occur more frequently during spring and fall periods when temperatures are more often around $57^{\circ} \mathrm{F}$. This suggests further research and discussions with fan manufacturers to evaluate a slightly longer delay period on the controller may be appropriate ( 2 or 3 minutes).

Temperature Control - The thermostat controlling the fan is located on the west side of the house behind the outdoor unit of the DHP. This location provides shading from direct sun and some air movement when the heat pump is operating. The temperature of the fan controller was not monitored, so it is not possible to directly compare the fan control temperature and fan run-time. Outdoor temperature was measured at two locations on the porch on the north side of the house: one below and one above the porch deck. Hourly average temperatures were recorded. This does not allow for a precise comparison of fan control since temperature can be above and below the $57^{\circ} \mathrm{F}$ fan control set point during an hour. However, comparing the average hourly outdoor temperature with fan run-time during the hour gives an indication whether the temperature control was functioning properly.

Figure 2-4 indicates the fan temperature control worked properly. The fan was always off when the average hourly outdoor temperature was less than $55^{\circ} \mathrm{F}$. The fan was always on when the average hourly outdoor temperature on the porch was greater than $60^{\circ} \mathrm{F}$ with a handful of exceptions. These exceptions occur on summer mornings when the temperature was rising rapidly, so that temperatures during a portion of the hour were below the fan set point. ${ }^{2}$ For hourly average temperatures between $55^{\circ} \mathrm{F}$ and $60^{\circ} \mathrm{F}$, there is a mix of operation as expected since the outdoor temperature during an hour could be above or below the fan control set point, but the fan is increasingly on as the outdoor temperature rises.

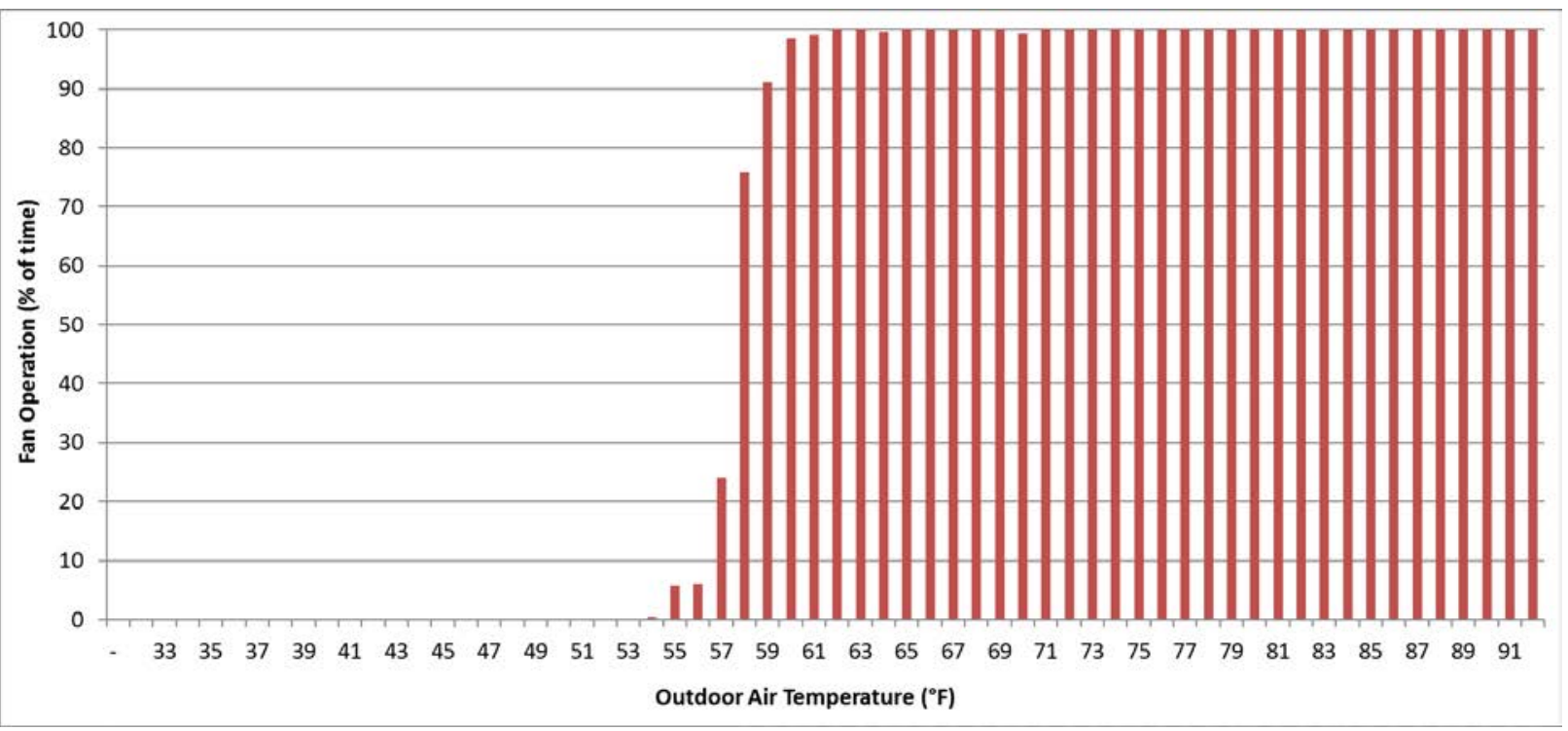

Figure 2-4. Ventilation fan operation at different average hourly outdoor temperatures

Table 2-2 shows the periods for the temperature-based and continuous control modes along with the fan speed and the percent on and off time. Note that for periods 2 and 9 the fan speed was reduced, but the control was not re-set from temperature-based control to continuous control. Thus, there are more temperature-based control periods and for two of these the fan speed was $40 \mathrm{cfm}$ rather than $90 \mathrm{cfm}$.

\footnotetext{
${ }^{2}$ There is also some evidence that the outdoor temperature sensor on the porch on the north side of the house is being influenced by sun light on the porch early in the morning. Temperature would rise until 8 a.m. or so and then slightly drop or stay stable before rising during the mid-day.
} 
Table 2-2. Control Details for STSVC Test Home

\begin{tabular}{|c|c|c|c|c|c|c}
\hline Period ID & Control & Start Date & End Date & On-Speed & \% time on & \% time off \\
\hline 0 & Pre-Period & April 14 & April 27 & 50 & 67 & 33 \\
\hline 1 & Temp.-Based & April 27 & May 4 & 90 & 45 & 55 \\
$2^{a}$ & Temp.-Based & May 4 & May 13 & 40 & 35 & 65 \\
3 & Continuous & May 13 & May 18 & 40 & 100 & 0 \\
4 & Temp.-Based & May 18 & May 25 & 90 & 53 & 47 \\
5 & Continuous & May 25 & June 15 & 40 & 100 & 0 \\
6 & Temp.-Based & June 15 & July 7 & 90 & 94 & 6 \\
\hline 7 & Continuous & July 7 & July 13 & 40 & 100 & 0 \\
8 & Temp.-Based & July 13 & July 21 & 90 & 98 & 2 \\
$9 a$ & Temp.-Based & July 21 & July 27 & 40 & 92 & 8 \\
\hline 10 & Temp.-Based & July 27 & Aug. 3 & 90 & 95 & 5 \\
\hline 11 & Continuous & Aug. 3 & Aug. 12 & 40 & 100 & 0 \\
12 & Temp.-Based & Aug. 12 & Aug. 17 & 90 & 96 & 4 \\
13 & Continuous & Aug. 17 & Aug. 26 & 40 & 100 & 0 \\
\hline 14 & Temp.-Based & Aug. 26 & Sept. 11 & 90 & 80 & 20 \\
\hline 15 & Continuous & Sept. 11 & Oct. 5 & 40 & 100 & 0 \\
16 & Temp.-Based & Oct. 5 & Oct. 28 & 90 & 44 & 56 \\
17 & Continuous & Oct. 28 & Nov. 12 & 40 & 100 & 0 \\
\hline 18 & Temp.-Based & Nov. 12 & Nov. 21 & 90 & 1 & 99 \\
\hline 19 & Continuous & Nov. 21 & Dec. 9 & 40 & 100 & 0 \\
\hline 20 & Temp.-Based & Dec. 9 & Dec. 18 & 90 & 0 & 100 \\
\hline
\end{tabular}

${ }^{a}$ Contains periods of incorrect fan flow during temperature-based operation.

The data in Table 2-2 show that in temperature-based control mode the fan was off a little more than half the time in May. However, as outdoor temperatures increased in June and July, the fan operated over $90 \%$ of the time, and continued to do so until outdoor temperature began to cool off again in September.

Outdoor Temperature Differences - To compare the sensitivity of the location of the temperature sensor, the two outdoor temperature measurements on the porch were compared. These sensors were near each other, one below the porch and one above the porch on the north side of the home (left photo in Figure 2-1). Temperatures are very similar (Table 2-3), with the sensor below the porch having an average and median temperature $0.8^{\circ} \mathrm{F}$ cooler than the sensor above the porch. This comparison suggests either of these temperature sensors would provide very similar fan control. For future field testing, it would be valuable to record the fan control temperature values so they can be compared to other sources. 
Table 2-3. Comparison of Outdoor Temperature Measurements $\left({ }^{\circ} \mathrm{F}\right)$

\begin{tabular}{l|c|c}
\hline & Below Porch & Above Porch \\
\hline Median & 55.08 & 55.88 \\
Average & 56.08 & 56.86 \\
Std. Dev. & 9.70 & 9.80 \\
Max. & 91.12 & 91.43 \\
Min. & 29.66 & 29.99 \\
Count & 2,951 & 2,951 \\
\hline
\end{tabular}

\subsubsection{Indoor Air Quality - $\mathrm{CO}_{2}$ and Relative Humidity}

A second question addressed by the field testing is whether the fan control had any impact on IAQ. Indoor $\mathrm{CO}_{2}$ and $\mathrm{RH}$ were measured to check if there were differences between continuous fan operation and temperaturebased fan operation. Average hourly $\mathrm{CO}_{2}$ in the main living area is plotted against outdoor air temperature in Figure 2-5.

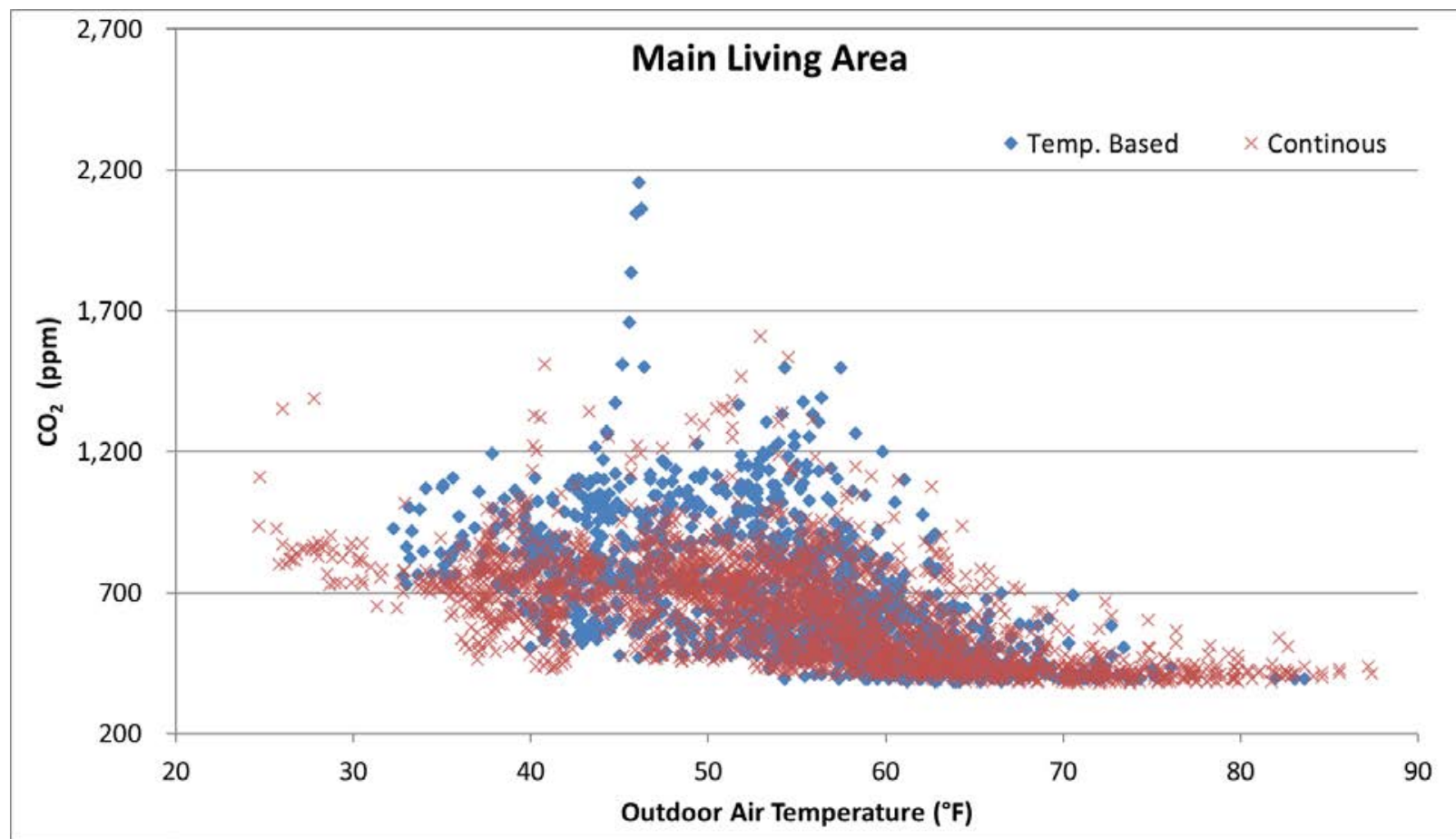

Figure 2-5. Hourly average $\mathrm{CO}_{2}$ concentration vs. outdoor temperature for the STSVC test home. Blue symbols indicate hours when the temperature override control was active, with $0 \mathrm{cfm}$ of ventilation delivered below $57^{\circ} \mathrm{F}$ and $90 \mathrm{cfm}$ of ventilation delivered above $57^{\circ} \mathrm{F}$. Red symbols indicate hours with $40 \mathrm{cfm}$ continuous ventilation

For the evaluation of $\mathrm{CO}_{2}$, only periods when the house was fully occupied (three occupants) and the fan control mode was operating as intended are included. Still, unknowns remain that generate uncertainty in the results, such as if guests were in the home or if kitchen or bath exhaust fans were operating. $\mathrm{CO}_{2}$ levels in the main living area and master bedroom are considered at temperatures below $55^{\circ} \mathrm{F}$ and above $60^{\circ} \mathrm{F}$ to identify 
differences between the control modes. The main living area is on the first floor, the master bedroom is on the second floor, and the ventilation fan being controlled is in the first-floor bathroom.

As seen in Table 2-4, average $\mathrm{CO}_{2}$ concentration at outdoor temperatures below $55^{\circ} \mathrm{F}$ are around $600 \mathrm{ppm}$ and above $60^{\circ} \mathrm{F}$ around $450 \mathrm{ppm}$. The very low indoor $\mathrm{CO}_{2}$ levels (near ambient levels) are when the outdoor temperature is above $60^{\circ} \mathrm{F}$. The residents indicated that windows were closed throughout the heating season but were often open at night in the summer months. Therefore, the following analysis screens out JuneSeptember. The highest $\mathrm{CO}_{2}$ levels in the Washington home occurred when all windows were closed. Levels of $\mathrm{CO}_{2}$ tended to be higher with STSVC, particularly at lower temperatures. A two-sample t-test shows that the difference in $\mathrm{CO}_{2}$ levels is statistically significant, with the STSVC being statistically higher (average 748 $\mathrm{ppm}$ ) than the continuous ventilation (average $666 \mathrm{ppm}$ ) at the $95 \%$ confidence level $\left(\mathrm{p}<0.0001\right.$ ). Above $57^{\circ} \mathrm{F}$ $\left(14^{\circ} \mathrm{C}\right)$, the $\mathrm{CO}_{2}$ levels in STSVC mode should be lower because of higher ventilation from fan operation at 90 $\mathrm{cfm}$ instead of $40 \mathrm{cfm}$. However, this is not the case. A two-sample t-test shows that $\mathrm{CO}_{2}$ in STSVC mode in the main living area when outdoor temperature is above $57^{\circ} \mathrm{F}\left(14^{\circ} \mathrm{C}\right)$ averaged $567 \mathrm{ppm}$ compared to $527 \mathrm{ppm}$ with continuous ventilation, and that this difference is statistically significant at the $95 \%$ confidence level $(\mathrm{p}=$ 0.0024). This is possibly due to differences in occupancy, air mixing, and possibly some window opening. The small differences in $\mathrm{CO}_{2}$ levels during all conditions for the two modes of operation suggest that other influences on $\mathrm{CO}_{2}$ were greater than the control mode. Further study regarding other contaminants, particularly when the ventilation system is off in STSVC mode, seems warranted.

Table 2-4. Main Living Area $\mathrm{CO}_{2}$ Levels at Outdoor Temperatures below $55^{\circ} \mathrm{F}$ and above $60^{\circ} \mathrm{F}$ for Continuous and Temperature-Based Fan Control

\begin{tabular}{l|c|c|c|c}
\hline & \multicolumn{4}{|c}{ Carbon Dioxide Concentration (ppm) } \\
\hline & Continuous Vent <55 & TSVC <55 & Continuous Vent >60 & TSVC >60 \\
\hline Median & 614 & 579 & 429 & 432 \\
Average & 617 & 600 & 456 & 458 \\
Std. Dev. & 117 & 118 & 84 & 75 \\
Max. & 889 & 894 & 969 & 823 \\
Min. & 417 & 396 & 380 & 394 \\
Hours & 143 & 100 & 333 & 103 \\
\hline
\end{tabular}

Indoor RH was also measured as an indicator of IAQ. Indoor RH levels in the main living area (Figure 2-6) and master bedroom (Figure 2-7) are primarily between $40 \%$ and $60 \%$, with the temperature-based RH levels trending a little higher than the continuous RH levels, especially when the outdoor temperatures are colder. This suggests that indoor RH is staying at comfortable levels in the house. There is little difference in the indoor RH for the continuous and temperature-based control modes. The likelihood that windows were opened at higher outdoor temperatures would tend to minimize any differences. 


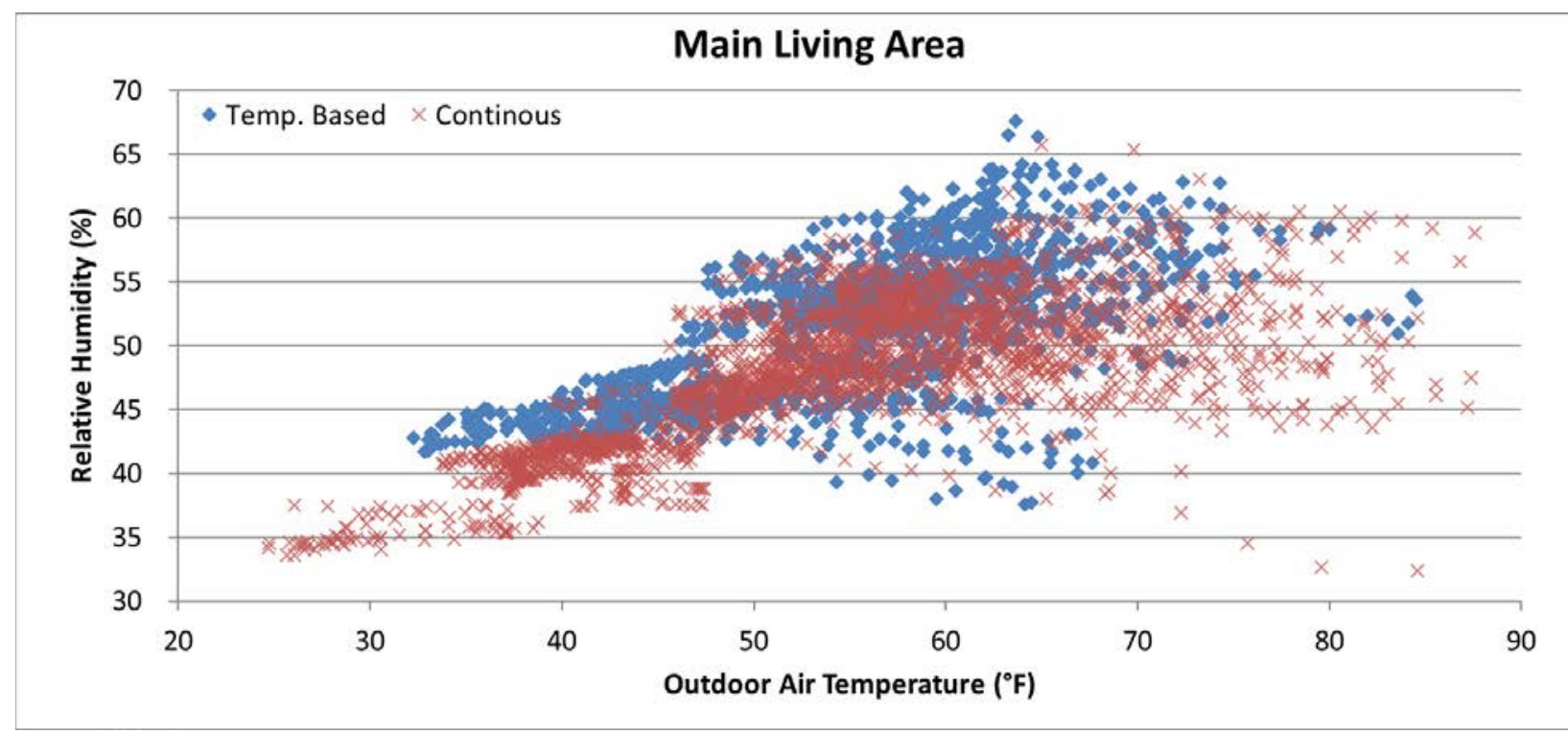

Figure 2-6. Hourly indoor RH versus outdoor temperature for the main living area

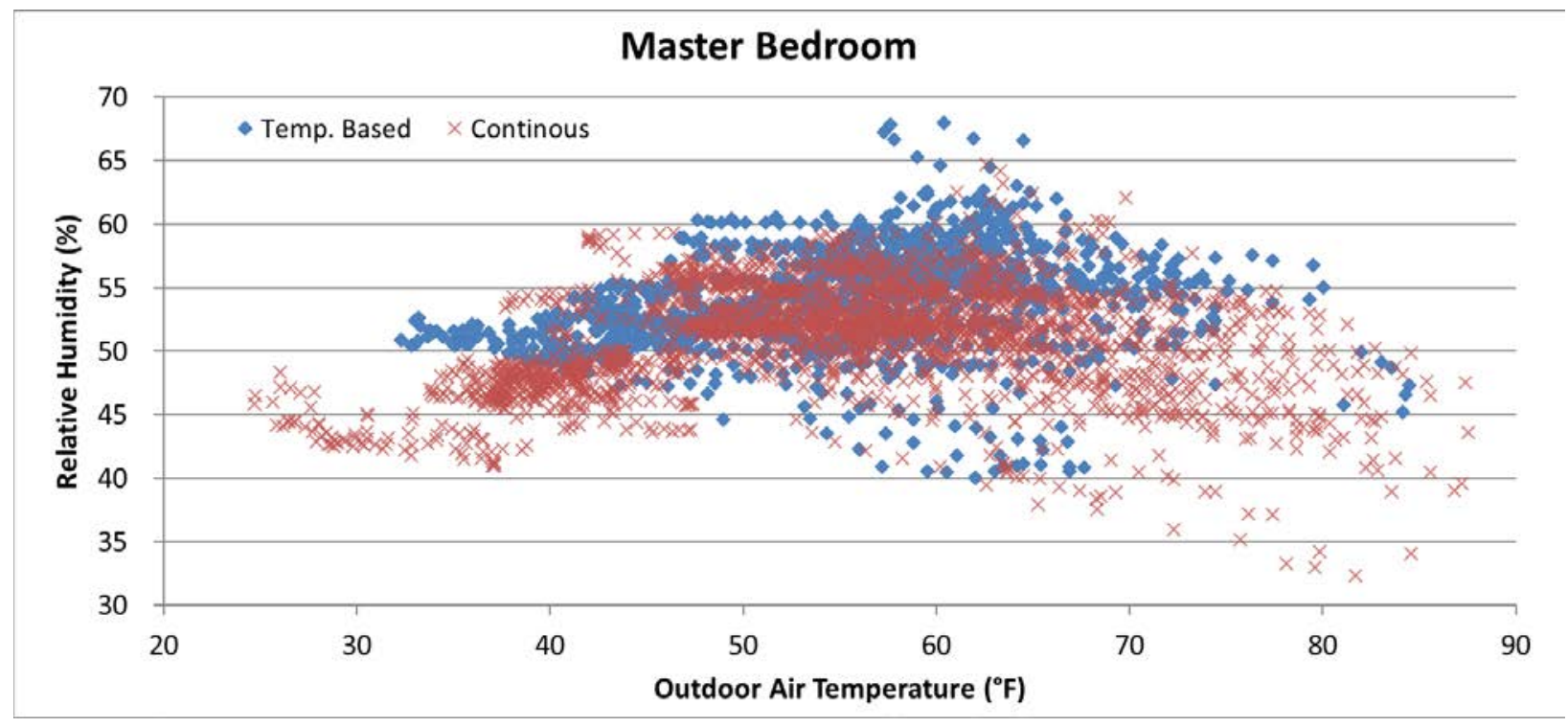

Figure 2-7. Hourly indoor RH versus outdoor temperature for the master bedroom

Analysis of indoor moisture is not straightforward for a variety of reasons, including that RH is temperaturedependent, outdoor air can be a significant source, and there can be significant moisture storage in building materials and furnishings. The first two of these issues can be addressed by using the "moisture balance" technique (Francisco and Rose 2010). This technique compares the indoor vapor pressure (which is temperature-independent) to the vapor pressure outdoors over a range of outdoor temperatures. The method involves preforming a linear regression on the data between $68^{\circ} \mathrm{F}$ and $32^{\circ} \mathrm{F}$ and forcing the regression through zero at $68^{\circ} \mathrm{F}$. The value at the $32^{\circ} \mathrm{F}$ intercept is the vapor pressure excess value used to characterize the home. The analysis found that with the temperature-based control, the vapor pressure excess was $616 \mathrm{~Pa}$; for continuous ventilation, the vapor pressure excess was $472 \mathrm{~Pa}$. The direction of this change is as expected since less dry, outdoor air is introduced during STSVC. Qualitatively, while the STSVC results in wetter indoor conditions, the difference from continuous ventilation is not enough to affect comfort or durability. 


\subsubsection{Ductless Heat Pump Energy Use}

A third question addressed by the field testing is whether the fan control had any impact on the energy use of the DHP. Figure 2-8 shows that there is significant scatter and suggests that these results may not be statistically significant. Blue symbols indicate days when the temperature override control was active, with 0 $\mathrm{cfm}$ of ventilation delivered below $57^{\circ} \mathrm{F}$ and $90 \mathrm{cfm}$ of ventilation delivered above $57^{\circ} \mathrm{F}$. Red symbols indicate days with $40 \mathrm{cfm}$ continuous ventilation. It is difficult given the small STSVC "signal" energy savings to "noise" to determine statistical significance from these data. Therefore, EnergyGauge USA Simulation Software was employed to estimate STSVC energy savings.

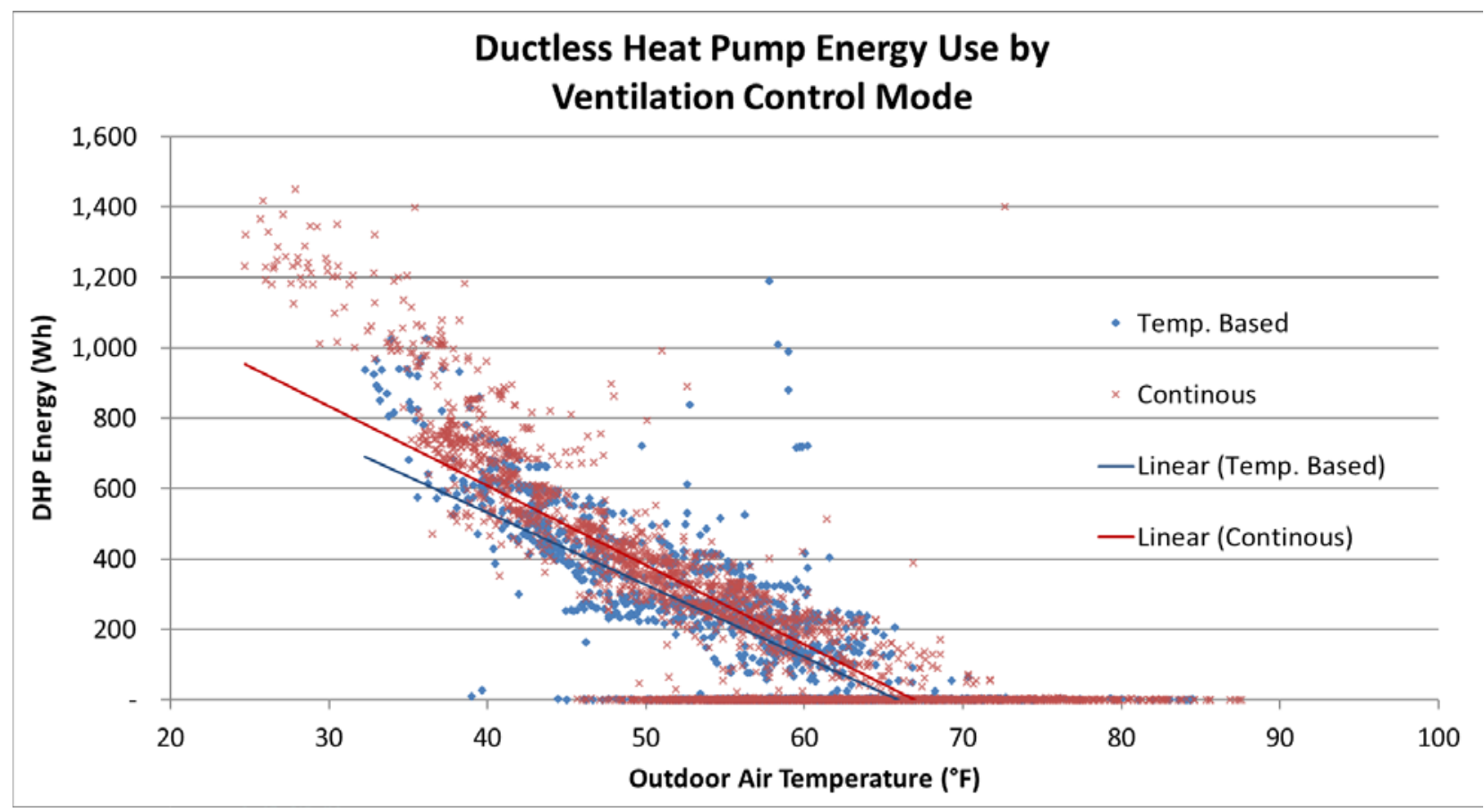

Figure 2-8. Daily space conditioning energy use vs. outdoor temperature for the STSVC test home. Blue symbols indicate days when the temperature override control was active, with $0 \mathrm{cfm}$ of ventilation delivered below $57^{\circ} \mathrm{F}$ and $90 \mathrm{cfm}$ of ventilation delivered above $57^{\circ} \mathrm{F}$. Red symbols indicate days with $40 \mathrm{cfm}$ continuous ventilation.

Energy simulation of the temperature override control utilizing EnergyGauge USA indicates potential for 9\% annual space conditioning energy savings; annual energy savings are 10\% when vent fan energy is considered. Details are shown in Table 2-5.

Table 2-5. Modeled Energy Savings for Temperature Override Control at the STSVC Test Home

\begin{tabular}{c|c|c|c|c|c|c|c}
\hline Case & Cooling & $\begin{array}{c}\text { Cooling } \\
\text { Fan }\end{array}$ & $\begin{array}{c}\text { Vent Fan } \\
\text { Cool }\end{array}$ & Heating & $\begin{array}{c}\text { Heating } \\
\text { Fan }\end{array}$ & $\begin{array}{c}\text { Vent Fan } \\
\text { Heat }\end{array}$ & Total \\
\hline $\begin{array}{c}\text { Continuous Vent Energy } \\
\text { Use (kWh/yr) }\end{array}$ & 229 & 82 & 23 & 1,700 & 273 & 26 & 2,333 \\
$\begin{array}{c}\text { STSVC Energy Use } \\
\text { (kWh/yr) }\end{array}$ & 216 & 77 & 22 & 1,566 & 217 & 5 & 2,103 \\
$\begin{array}{c}\text { Energy Savings } \\
\text { (kWh/yr) }\end{array}$ & 13 & 5 & 1 & 134 & 56 & 21 & 230 \\
$\begin{array}{c}\text { Cost Savings (\$/yr) } \\
\text { Savings (\%) }\end{array}$ & 1.3 & 0.5 & 0.1 & 13.4 & 5.6 & 2.1 & 23 \\
\hline
\end{tabular}




\subsection{Field Test of Occupancy Timer-Based Smart Ventilation Control}

The same test home used for the STSVC experiment was switched over to an OTSVC, and eight bi-weekly flip flop tests (but a week was lost to atypical holiday behavior, for 15 total weeks) were conducted during the period from November 2016 to March 2017 as shown in Table 2-6.

Table 2-6. Weekly Flip Flop Dates for OTSVC (2016-2017)

\begin{tabular}{c|c|c|c|c|c}
\hline Period ID & Vent Control & Start Date & End Date & $\begin{array}{c}\text { Outdoor Temp. } \\
\left({ }^{\circ} \mathrm{F}\right)\end{array}$ & Outdoor RH \\
\hline 1 & OTSVC & Nov. 13 & Nov. 19 & 50.5 & 81.3 \\
2 & Continuous & Nov. 20 & Nov. 26 & 47.0 & 88.9 \\
3 & OTSVC & Nov. 27 & Dec. 3 & 45.2 & 83.9 \\
4 & Continuous & Dec. 4 & Dec. 10 & 37.0 & 75.6 \\
5 & OTSVC & Dec. 11 & Dec. 17 & 36.0 & 75.7 \\
6 & Continuous & Dec. 18 & Dec. 22 & 38.7 & 77.0 \\
7 & Continuous & Jan. 12 & Jan. 7 & 36.4 & 86.4 \\
8 & OTSVC & Jan. 8 & Jan. 14 & 40.9 & 88.6 \\
9 & Continuous & Jan. 15 & Jan. 21 & 45.6 & 89.7 \\
10 & OTSVC & Jan. 22 & Jan. 28 & 48.4 & 86.1 \\
\hline 11 & Continuous & Jan. 29 & Feb. 4 & 42.5 & 84.0 \\
\hline 12 & OTSVC & Feb. 5 & Feb. 11 & 45.9 & 83.9 \\
13 & Continuous & Feb. 12 & Feb. 18 & 49.6 & 86.4 \\
\hline 14 & OTSVC & Feb. 19 & Feb. 25 & 44.5 & 79.0 \\
15 & Continuous & Feb. 26 & March 4 & 47.8 & 82.5 \\
\hline
\end{tabular}

Figure 2-9 shows the timer that was employed to control the whole-house exhaust fan during the OTSVC field testing. The OTSVC timer prototype control used in the test home was a simple 24/7/365 line voltage timer set by the occupants.

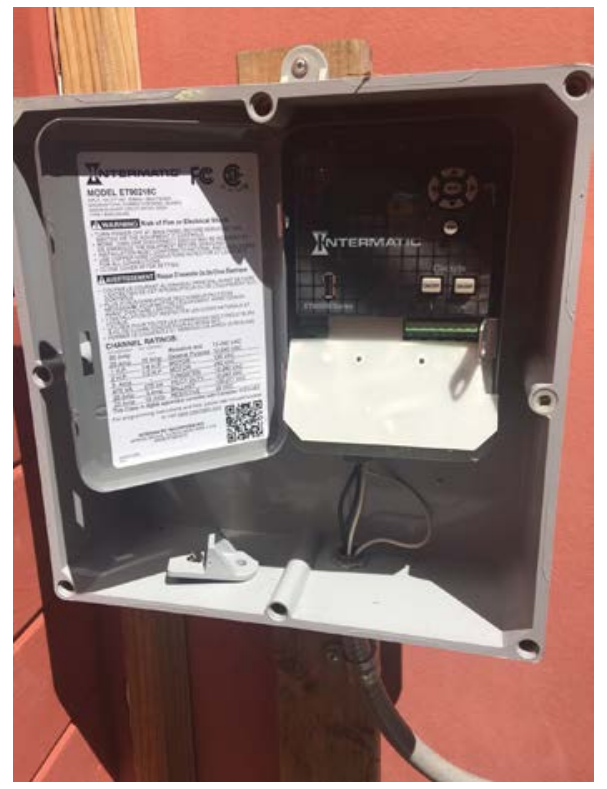

Figure 2-9. Whole-house exhaust fan timer deployed for OTSVC field testing 
The timer employed allowed for automatic flip flop during the experiments; however, a lower cost simple line voltage timer could have been selected. An OTSVC simple timer with weekend and weekday settings and a 365 clock can be purchased for under $\$ 50$ and required less than an hour of electrical work to install. The timer was configured to operate the ventilation fan from 5 p.m. to 9 a.m. seven days a week at $40 \mathrm{cfm}$, and off during other hours. It was understood that this operation would not enable the home to maintain equivalent RE with ASHRAE 62.2-2016 (the simulation predicted an annual RE of 1.70 for this scheme), and would have required a flow rate of roughly $90 \mathrm{cfm}$ during occupied hours to do so. However, the impact of a simple form of occupancy control on indoor air quality and indoor moisture was of interest.

\subsubsection{Comparing actual occupancy to the timed schedule}

The programmed occupancy schedule approximated the actual occupancy schedule of the occupants, but certainly resulted in some ventilation during unoccupied periods, and vice versa. The actual schedule often involved two occupants arriving home at 3 p.m. not 5 p.m., and therefore the ventilation system was not operating for roughly 2 hours per day when the OTSVC home was occupied. An ideal OTSVC control would sense when occupants are home and override the timer setting, to ensure that the home is ventilated when occupied.

A great disparity was found between the nighttime sensed and logged occupancy. During the night, the occupancy sensor often reported false negatives, presumably due to lack of movement while residents were sleeping. Figure 2-10 is an example of this in the master bedroom, comparing about a week of sensed occupancy (red) to logged occupancy (green). Sensed and logged occupancy alignment is identified where red and green overlap. Ventilation hours are noted in light blue. The left half of the plot is during constant flow and the right half during the OTSVC scheme. Because of the discrepancy between sensed and logged occupancy, the logged occupancy data were used during the night. Occupancy logs were only recorded at night; therefore, sensed occupancy data were used during the day. Nighttime logs and daytime-sensed occupancy data were resolved on an hourly basis, tallying hours with any sort of occupancy and hours with no occupancy at all.

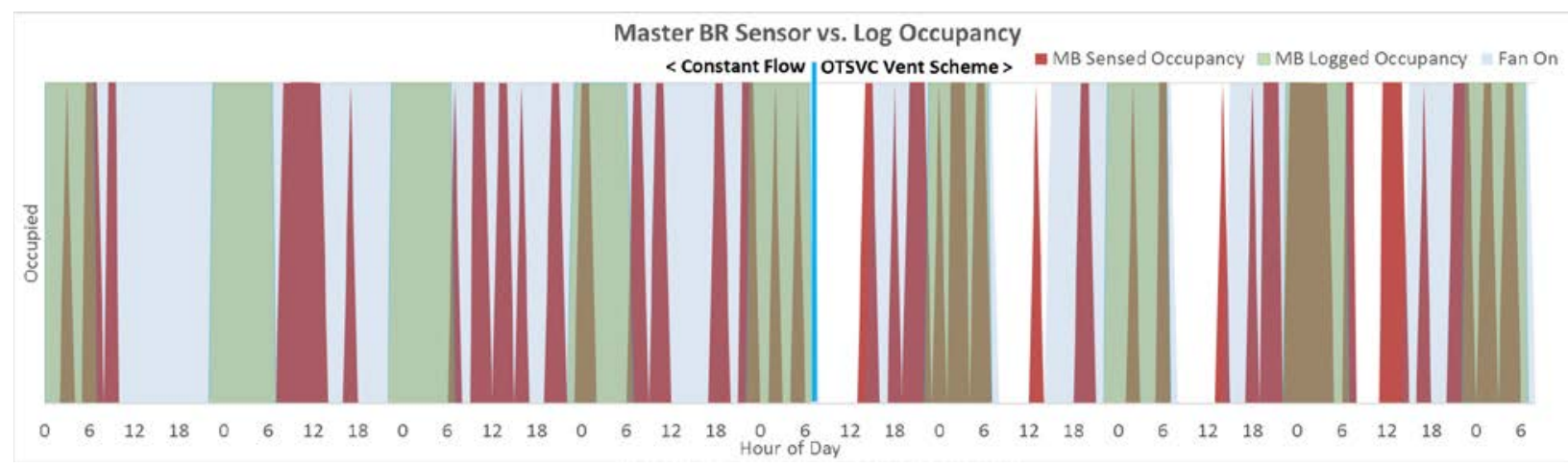

Figure 2-10. Master bedroom sensed vs. logged occupancy spanning constant flow and OTSVC schemes

\subsubsection{Ductless heat pump energy use}

Considering the difficulty in discerning differences in DHP energy use experienced during STSVC and OTSVC, and because the energy savings regression "signal" was expected to be even smaller than in the case of STSVC and difficult to see from the energy use variability "noise," analysis of monitored DHP energy use during OTSVC experiments was not conducted. In addition, as previously mentioned, the strategy employed was not deemed to be in compliance with ASHRAE 62.2-2016 from a RE perspective, and therefore energy savings is not representative. Instead, data analysis focused on indoor environmental parameters (discussed in the next section) and energy simulations for compliant strategies were conducted utilizing EnergyGauge USA to estimate energy savings. 
Energy simulations were configured to utilize a realistic and representative occupancy schedule compiled with away data from over 100,000 Nest Learning Thermostats, each with one year's worth of data. Nest Labs provided the results, which yielded a median value of 1,226 unoccupied hours per year. The median home had 10-12 days that were full day away, with balance of hours being part time away. Part time away was found to peak at 9 a.m. -2 p.m. for weekdays and 11 a.m. -3 p.m. weekends. The simulations were configured to maintain the same thermostat set points during occupied and unoccupied periods, and not utilize a setup/setback in conjunction with the occupancy controlled ventilation system. The effect of utilizing a thermostat setup/setback would likely affect savings, and would vary by climate according to how heating/cooling loads coincide with occupancy.

An energy model of the test home was configured to utilize this occupancy schedule, and heating and cooling energy use differences among continuous mechanical ventilation flow of $40 \mathrm{cfm}$ and varying OTSVC flows was simulated. The flow during occupied periods was $40 \mathrm{cfm}$ regardless of the number of occupants. For the OTSVC case, the fan was reduced to $10 \mathrm{cfm}$ when unoccupied, rather than shut off entirely. This reduction in flow corresponds with informal discussions taking place within the ASHRAE 62.2 committee surrounding changing fundamental assumption about constant pollutant emission rates while residences are occupied and unoccupied. Additional information on this discussion is provided in the commercialization section of this report.

For the unbalanced exhaust ventilation system operating at the test home, heating and cooling energy savings from the modeled OTSVC are minimal, at only $28 \mathrm{kWh}$ per year, or $1 \%$. These modest savings are in part due to an efficient heating system, and a schedule that calls for away time to occur during the day, when heating loads are less than they are overnight in the heating dominated climate. Another factor affecting savings is the unbalanced nature of the ventilation system, which minimizes the difference in total ventilation flow between the occupied and unoccupied case, due to interactive effects with natural infiltration. When the simulations are run using a balanced ventilation system (with no heat recovery), the amount of total air exchange increases for each case and the difference in air exchange between the two cases increases. This has a substantial effect on results, with the balanced case generating heating and cooling energy savings 10 times greater than the unbalanced case at $289 \mathrm{kWh} / \mathrm{y}$.

\subsubsection{Indoor Air Quality - $\mathrm{RH}, \mathrm{CO}_{2}$, and VOC}

Indoor humidity levels were measured in the main living area and master bedroom, and guest bedroom. All $\mathrm{RH}$ levels were typically between $40 \%$ and $60 \%$ except for a small number of hours below $40 \%$. This suggests that RH is staying at comfortable levels in the house. There is little difference in the RH for the continuous and OTSVC modes during the ten bi-weekly flip flop tests periods. The moisture balanced technique described in the STSVC section was utilized to analyze data obtained during the OTSVC experimentation. The method compares the indoor vapor pressure (which is temperature-independent) to the vapor pressure outdoors over a range of outdoor temperatures. The method involves preforming a linear regression on the data between $68^{\circ} \mathrm{F}$ and $32^{\circ} \mathrm{F}$ and forcing the regression through zero at $68^{\circ} \mathrm{F}$. The value at the $32^{\circ} \mathrm{F}$ intercept is the vapor pressure excess value used to characterize the home.

The regression analysis found that with the OTSVC, the average vapor pressure excess was $501 \mathrm{~Pa}$; for continuous ventilation, the average vapor pressure excess was $426 \mathrm{~Pa}$. This means that, with occupancy-based ventilation, the house was wetter by an average of about $75 \mathrm{~Pa}$. Qualitatively, the direction of this change is as expected. The fact that the home was wetter during OTSVC does not imply that the house was too wet during that mode. In this home, these values in either mode do not represent a situation where IAQ and or/durability issues could arise from mold etc.

Statistical analysis was conducted on $\mathrm{CO}_{2}$ and $\mathrm{VOC}$ data from the downstairs zone using standard T-tests to determine differences in concentrations among the continuous and OTSVC ventilation schemes. The analysis was conducted on two different bases: 1) simple timer control — comparing all data obtained during continuous ventilation periods and OTSVC periods, including hours with imperfect occupancy control, i.e., ventilation 
operating during unoccupied periods and no ventilation operating during occupied periods and 2) occupancy sensor control - utilizing the data from the occupancy sensors to screen data for perfect occupancy control, i.e., using only occupied periods when the ventilation is operating or unoccupied periods when no ventilation is operating. For this case, downstairs was deemed occupied if occupancy was sensed by occupancy sensors in either the kitchen or the entryway over a given hour. Results using all data "timer control" and those screened for perfect control "occupancy sensor control" are presented in Table 2-7. The t-statistics indicates significant correlations at the $95 \%$ level relating ventilation scheme to $\mathrm{CO}_{2}$ concentration for both cases, where OTSVC correlates with higher average concentrations. Differences in concentrations of VOCs between schemes were not significant for either case. While this experiment only provides limited data, the results from this single home indicate the possibility that there may not be a large difference in resulting RE between perfect occupancy detection and a time-clock approach.

Table 2-7. Statistical Results for Differences in $\mathrm{CO}_{2}$ and VOC Concentrations in Main Living Area Between Continuous Ventilation and Two Types of OTSVC

\begin{tabular}{|c|c|c|c|c|c|c|c|c|c|c|}
\hline \multirow[b]{3}{*}{$\begin{array}{c}\text { OTSVC } \\
\text { Scheme }\end{array}$} & \multicolumn{5}{|c|}{$\mathrm{CO}_{2}$} & \multicolumn{5}{|c|}{ VOC } \\
\hline & \multicolumn{2}{|c|}{ Concentration (PPM) } & \multirow[b]{2}{*}{$\begin{array}{c}\mathrm{t}- \\
\text { value }\end{array}$} & \multirow[b]{2}{*}{$\begin{array}{c}p- \\
\text { value }\end{array}$} & \multirow[b]{2}{*}{$\mathrm{n}$} & \multicolumn{2}{|c|}{ Concentration (PPM) } & \multirow[b]{2}{*}{ t-value } & \multirow[b]{2}{*}{$\begin{array}{c}\mathrm{p}- \\
\text { value }\end{array}$} & \multirow[b]{2}{*}{$\mathrm{n}$} \\
\hline & $\begin{array}{c}\text { Continuous } \\
\text { Vent }\end{array}$ & OTSVC & & & & $\begin{array}{c}\text { Continuous } \\
\text { Vent }\end{array}$ & OTSVC & & & \\
\hline Timer Control & 659 & 759 & (13.7) & - & 2,645 & 838 & 855 & (1.3) & 0.202 & 2,509 \\
\hline $\begin{array}{l}\text { Occupancy } \\
\text { Sensor } \\
\text { Control }\end{array}$ & 682 & 769 & -8.9 & 0 & 1,451 & 849 & 875 & -1.4 & 0.2 & 1,387 \\
\hline
\end{tabular}




\section{Multi-Variable Smart Ventilation Control: Real-Time Weather-Based Smart Ventilation Control Algorithm Development and Laboratory Home Investigation in Climate Zone 2a}

A smart ventilation algorithm was developed by FSEC as part of this project, which takes advantage of the time varying ventilation procedure allowable by ASHRAE Standard 62.2-2016 Appendix C. As stated in the Introduction Section of this report, rather than a constant ventilation rate, the procedure allows varying ventilation rates that achieve acceptable acute and chronic RE for the indoor occupant. Given that the ventilation rate may vary, the algorithm takes advantage of the fact that the temperature outdoors and the absolute moisture of the air (absolute humidity [W]) varies over a seasonal and sometimes daily cycle relative to the desired indoor conditions. The algorithm can be tuned to achieve RE on an annual basis while minimizing hourly sensible and latent loads by modulating fan flow.

In all locations, optimizing ventilation against outdoor temperature deviation from preferred indoor temperatures is desirable. However, in Central Florida as well as other humid locations, outdoor moisture levels are a legitimate concern for ventilation since ambient air dewpoints are frequently above $70^{\circ} \mathrm{F}$, which represents heavily moisture-laden air that may result in uncomfortable indoor conditions during much of the time unless appropriately controlled. Also, although not well known, outdoor air moisture levels often vary with time of day. In humid Florida for instance, outdoor W is typically highest in the morning hours when ground dew is being driven off by solar radiation. The evaluation of the smart ventilation algorithm includes two phases with varied schemes related to optimizing energy savings and comfort. There may be other constraints to ventilation that could be optimized by a multi-parameter optimization approach. For instance, utilities are very concerned with minimizing HVAC loads during system generation peaks that often come in late afternoon in summer and early morning hours in winter.

\subsection{Algorithm Description}

Mathematically, the calculation examines the preceding 24-hour period and compares the recursively weighted hours with the current hour and seeks to minimize the sum of the square deviations from multiple targets: difference between indoor and outdoor temperature and difference between indoor and outdoor W. Other parameters can be added as needed, such as whether the current hour is a utility peak period, along with appropriate weights $(\mathrm{X})$ for each to help optimize flows.

$$
R S S=\sqrt{\left(\Delta T * X_{T}\right)^{2}+\left(\Delta W * X_{W}\right)^{2}}
$$

Where:

$\Delta \mathrm{T}\left({ }^{\circ} \mathrm{F}\right)=($ indoor temperature $)-($ outdoor temperature $)$

$\mathrm{X}_{\mathrm{T}}=$ delta temperature weight

$\Delta \mathrm{W}\left(\mathrm{g} / \mathrm{m}^{3}\right)=($ indoor moisture $)-($ outdoor moisture $)$

$\mathrm{X}_{\mathrm{W}}=$ delta moisture weight

The time weighted RSS (Average $\left(\mathrm{RSS}_{1}: \mathrm{RSS}_{23}\right) / \mathrm{RSS}_{24}$ ) becomes a multiplier to adjust total ventilation flow (mechanical + natural), which is proportional to RE.

In Figure 3-1 we show how outdoor W varies over the 24-hour cycle in Orlando, Florida, as evident from evaluating TMY3 data for the Central Florida summer from May 1-Sept. 30. Note that W (green) is high in the 
early morning with the dew burn off. The mean root sum square (orange) is the average root of the sum of squares of $\Delta \mathrm{T}$ and $\Delta \mathrm{W}$. With moisture given twice the weight of temperature, the estimation shows that on average any time between 6 a.m. and 4 p.m. (standard time) in Orlando is a poor time to be ventilating, both with respect to temperature and moisture; the best time is 7 p.m. to 2 a.m.

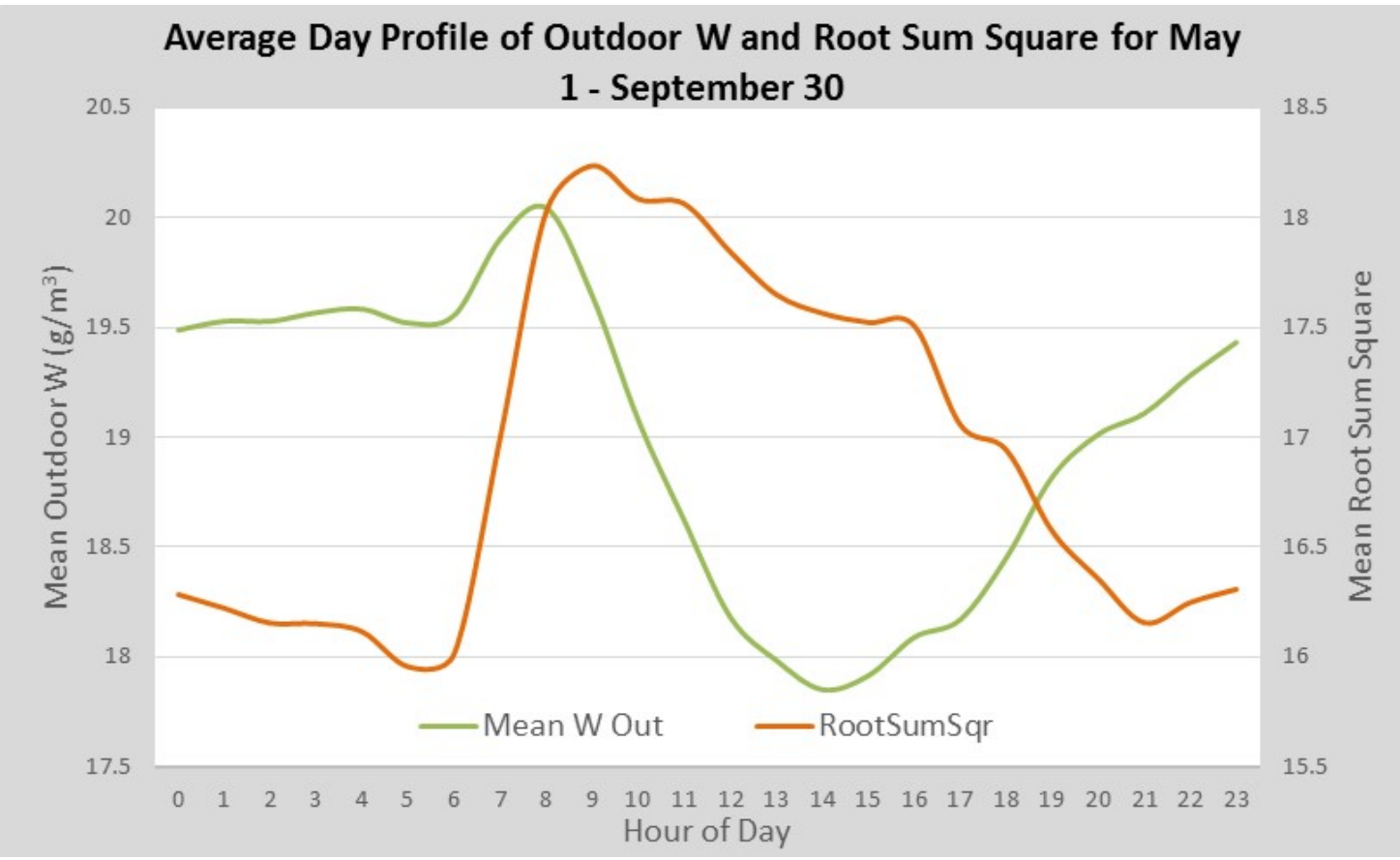

Figure 3-1. Illustration of how outdoor absolute moisture (W: green) and root mean sum squared of both temperature and W deviations (orange) vary over the day in summer in Orlando, Florida

However, the best time to ventilate will vary with each day depending on how weather conditions change. The dynamic FSEC algorithm seeks to takes advantage of this dynamically changing weather. Obviously, indicated ventilation rates would differ dramatically in different places and with varying weights (likely less weight to delta-W would be appropriate in non-humid climates). For example, we conducted similar calculations for Phoenix and the model greatly prefers ventilating at night rather than during the day - no surprise given the high daytime temperatures there in summer. Even without the weight changed for W, the model wants to ventilate more when it is more humid outside as the outdoors is generally too dry. However, the Phoenix example also shows another interesting facet: ventilating more at night in the shoulder months will likely reduce cooling needs.

Figure 3-2 shows the impact of dynamically calculating an optimum ventilation rate for each hour of the year using TMY3 weather data for central Florida, while targeting an annual average RE of 1 . For this example, the RSS algorithm inputs included weights of 1 for both delta-T and delta-W, and an hourly fan flow target of 76 $\mathrm{cfm}$ (the continuous fan flow requirement of ASHRAE 62.2-2016 for this example), by which the RSS is multiplied. (Complete algorithm inputs are described in the next section.) The figure shows how the hourly flow varies over the year, driven by outdoor temperature and moisture, with lower flows in the summer and greater flows at milder times of the year. 


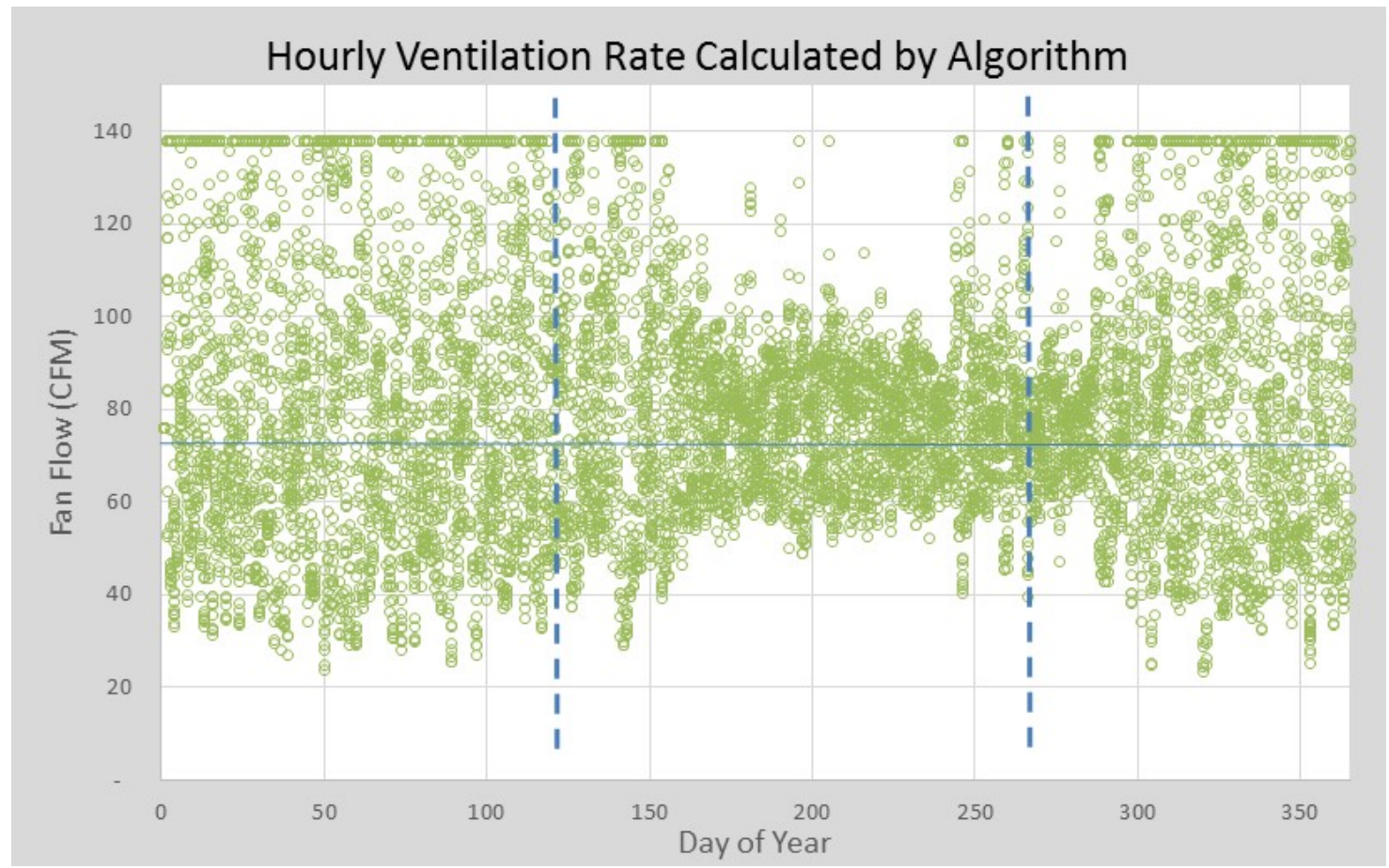

Figure 3-2. Comparison of the simulated flow rate in cfm of smart controller (green circles) versus a constant ventilation rate of $76 \mathrm{cfm}$ (horizontal blue line). The two dashed vertical lines show the conditions from May 1-Sept. $30 \mathrm{during}$ the height of the cooling season in Central Florida.

We were further able to experiment with both backward and backward/forward differencing schemes in performing the control. The backward/forward differencing scheme assessed 24 hours of weather data in both directions and was evaluated by imagining that the future weather forecasts, (perhaps made available via broadband weather forecast) in terms of coming temperatures and dew points, were perfect. To evaluate the differences between backward and backward/forward differencing, a comparison between the two was conducted using TMY3 weather data. This is done by looking 24 hours backward into the TMY3 weather file and using that to compute the current hour ventilation rate, as compared to using last 24 hours and the future 24 hours in the TMY3 weather file. This exercise was also conducted with backward and forward time periods up to one week. Surprisingly, they show similar performance-likely due to the slow change in weather patterns and that an algorithm that looks back 24 hours continuously quickly catches up with changes to current weather. Similar results were found for Phoenix and Chicago as well, leading to the conclusion that the seasonal shape of the typical or average daily weather pattern is likely more predictive of potential variable ventilation savings than are short term periods of hot or cold conditions. Therefore, to enhance potential for savings, seasonal adjustment factors were determined iteratively to ensure the RE target is achieved. The adjustment factors considered include changes to the target ventilation flow and flow overrides based on outdoor temperature and moisture, which are described below.

Total ventilation flow (mechanical + natural) was initially utilized as the target, because it is inversely proportional to RE. But ultimately mechanical ventilation fan flow was used as the target. In a climate such as Central Florida, relatively weak driving forces provide only limited natural infiltration in the tight experimental buildings. Also, use of fan flow prevented maximum total ventilation from being limited when approaching flow capacity limits of the fan. By capping the algorithm's output at maximum fan flow rather than maximum total flow, this enabled any natural infiltration occurring at that time to be counted, with consideration given to interactive effects with the proposed unbalanced experimental ventilation system (discussed in detail in a later section). Parametric simulations allow for fine tuning of the adjustment factors to achieve a predicted annual average RE of 1 (based on TMY3) data, even with use of the fan flow target. 


\section{Hourly Fan Flow $=\left(\right.$ Target Fan Flow $*\left(\right.$ Average $\left.\left(\mathrm{RSS}_{1}: \mathrm{RSS}_{23}\right) / \mathrm{RSS}_{24}\right)$}

Where flow targets can vary as follows:

- Target fan flow:

○ Cooling period target if hourly outdoor temperature $>$ given threshold

○ Heating period target if hourly outdoor temperature $<$ given threshold

- Floating period target if hourly outdoor temperature is in between cooling and heating thresholds

- Target fan flow optional adjustment:

If outdoor moisture $>$ given threshold

With the following overrides:

- If hourly fan flow $>$ maximum fan flow capacity, hourly fan flow = maximum fan flow capacity

- If outdoor temperature $>$ some given maximum, hourly fan flow $=0$

FSEC developed a simulation tool and conducted experiments in side-by-side laboratory homes in 2016-2017 to investigate heating and cooling energy savings and resulting indoor conditions with optimized algorithms utilizing differing combinations of these seasonal adjustment factors.

\subsection{Phase I Scheme Description and Simulation Results}

The simulation tool was used to test integrative schemes of the smart ventilation algorithm, including adjustments to period flow targets and temperature parameters for the evaluation of RE, fan flow, total flow, potential sensible and latent ventilation load savings. Parametric simulations were conducted to determine an optimum scheme, to later be implemented in the laboratory. The Phase I scheme input values included a cooling period fan flow target of $55 \mathrm{cfm}$, heating period fan flow target of $75 \mathrm{cfm}$, and floating period fan flow target of $138 \mathrm{cfm}$ (the maximum capacity achieved with the Phase I fan). The logic for the chosen flow targets for Phase I were cooling energy savings focused: the maximum flow target during the floating season was set, assigned the ASHRAE 62.2.-2016 continuous fan flow value for Florida's limited heating season target, and dropped the cooling season target below the heating season target by $20 \mathrm{cfm}$. The delta-T term in the algorithm was weighted at 2 , while the delta-W term in the algorithm was weighted at 1 . Simulation runs showed delta-T to be much more impactful on energy savings. A complete list of the Phase I scheme parameters, including the outdoor temperature ranges defining the varying flow periods, are listed in Table 3-1. 
Table 3-1. Phase I Scheme Values

\begin{tabular}{c|c|c}
\hline $\begin{array}{c}\text { Period (defined } \\
\text { by hourly outdoor } \\
\text { Temp.) }\end{array}$ & Parameter & $\begin{array}{c}\text { Phase I Scheme } \\
\text { Values }\end{array}$ \\
\hline Cooling & Outdoor temp. range for cooling period target & $>71.5^{\circ} \mathrm{F}$ \\
\cline { 2 - 3 } & Cooling period target fan flow & $55 \mathrm{cfm}$ \\
\cline { 2 - 3 } & Outdoor temp. range for fan override $(0 \mathrm{cfm})$ & $\mathrm{n} / \mathrm{a}$ \\
\hline \multirow{2}{*}{ Heating } & Outdoor temp. range for heating period target & $<60^{\circ} \mathrm{F}$ \\
\cline { 2 - 3 } & Heating period target fan flow & $75 \mathrm{cfm}$ \\
\hline \multirow{2}{*}{ Floating } & Outdoor temp. range for floating period target & $<=71.5^{\circ} \mathrm{F} ;>=60^{\circ} \mathrm{F}$ \\
\cline { 2 - 3 } & Floating period target fan flow & $138 \mathrm{cfm}$ (fan limit) \\
\cline { 2 - 3 } & Outdoor W range to adjust floating period target & $\mathrm{n} / \mathrm{a}$ \\
\cline { 2 - 3 } & Floating period target adjusted for W & $64.4^{\circ} \mathrm{F}$ \\
\cline { 2 - 3 } & Indoor temp. & 2 \\
\cline { 2 - 3 } & Delta-temp. weight $\left(\mathrm{X}_{\mathrm{T}}\right)$ & $12 \mathrm{~g} / \mathrm{m}^{3}$ \\
& $\begin{array}{c}\text { Indoor moisture }(\mathrm{W}) \\
\text { Delta-moisture weight }\left(\mathrm{W}_{\mathrm{W}}\right)\end{array}$ \\
\hline
\end{tabular}

The indoor temperature target is set intentionally below a typical thermostat set point temperature as simulations showed such a low value required to generate algorithm response that would result in cooling energy savings. The indoor $\mathrm{W}$ target of $12 \mathrm{~g} / \mathrm{m}^{3}$ corresponds to an $\mathrm{RH}$ of $55 \%$ at $75^{\circ} \mathrm{F}$.

\subsubsection{Phase I Simulation Results}

Simulation results for the smart ventilation scheme chosen for Phase I, assuming TMY3 Orlando weather data, resulted in an average annual fan flow of $79 \mathrm{cfm}$, slightly higher than the ASHRAE 62.2-2016 Standard continuous fan flow requirement of $75 \mathrm{cfm}$. Hourly fan flow ranged from $17 \mathrm{cfm}$ to the upper-limit of what the laboratory fan could deliver, $138 \mathrm{cfm}$. Total annual average ventilation rate was $80 \mathrm{cfm}$, determined hourly by adding the modified natural infiltration to the fan component. ${ }^{3}$ Annual RE averaged 1.08, reaching a maximum of 2.09 for a single hour, well below the 5.00 threshold provided by the ASHRAE standard. While the average annual exposure is slightly higher than the desired 1.00, a compromise was struck to hedge against a design that might generate excessive internal moisture. The simulation results are displayed graphically in Figure 3-3. Hourly fan flow of the smart ventilation system is plotted in light blue with average daily RE in red. The black line represents the ASHRAE Standard 62.2-2016 constant fan flow recommended for the laboratory buildings at $75 \mathrm{cfm}$ and the associated RE of 1.00 .

\footnotetext{
${ }^{3}$ ASHRAE Standard 62.2-2016 Appendix C, formulas C7 \& C8 for unbalanced mechanical ventilation (ASHRAE 2016).
} 


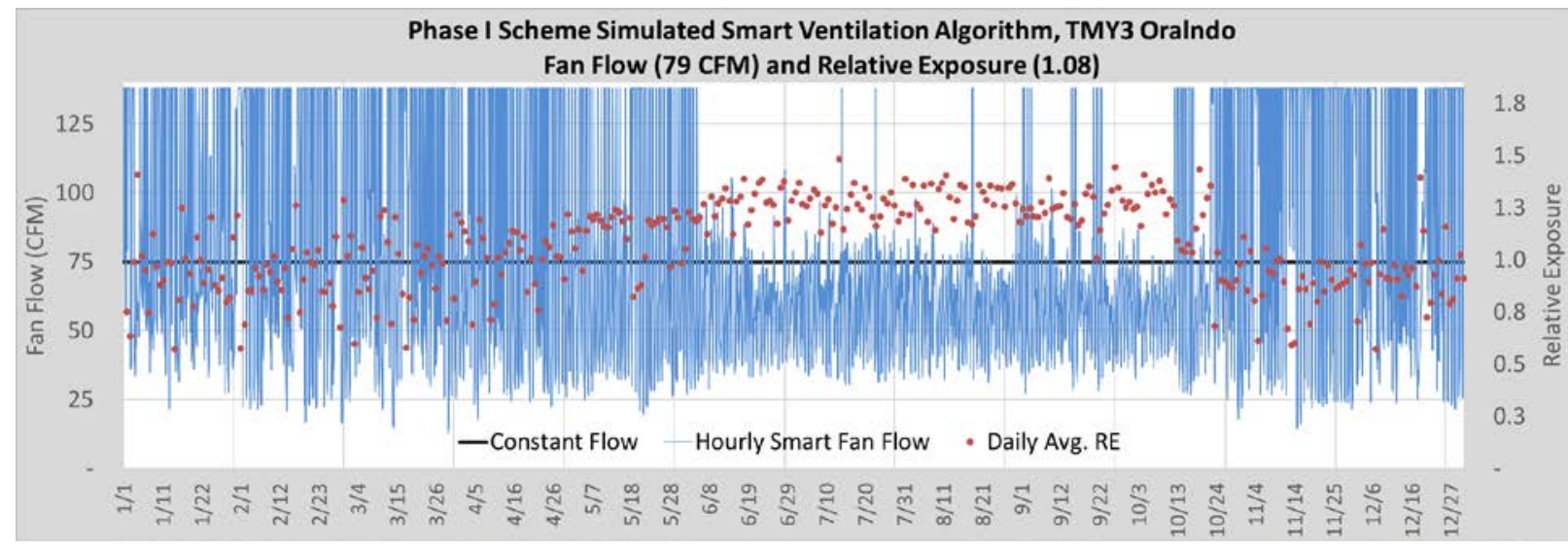

Figure 3-3. Phase I smart ventilation scheme simulated fan flow and RE

The plot demonstrates essentially two dominant seasons (based on the seasonal targets applied): cooling and floating. The smart ventilation scheme has a dynamic response, especially from mid-October through May when the fan is frequently flowing at its maximum when exterior conditions are ideal, often at night. During this floating period, average daily RE hovers near or just below 1.00. The aggressive floating period ventilation rate accommodates the restricted cooling period ventilation, balancing out the annual average RE, with the ultimate goal of generating space conditioning energy savings, especially during the cooling season in Florida's challenging summer climate.

Simulated seasonal differences in sensible and latent ventilation load between the constant, or fixed fan and this smart ventilation scheme are presented in Table 3-2. The table segments results into four seasons, or periods:

1. Summer: The period between May 1 and October 31, 2017, which is comprised almost exclusively of cooling and floating hours.

2. Non-Summer Cooling: The hours outside of the summer period when the outdoor air temperature exceeds $71.5^{\circ} \mathrm{F}$.

3. Non-Summer Floating: The hours outside the summer period when the outdoor air temperature falls below the set parameter for cooling and is at least $50^{\circ} \mathrm{F}$.

4. Heating: The hours when the outdoor air temperature falls below $50^{\circ} \mathrm{F}$.

Compared to a fixed fan, the simulation suggests that on an hourly average, the smart ventilation scheme delivers $0.20 \mathrm{kBtu}$ less heat (reducing cooling load) and $0.31 \mathrm{lb}$ less moisture to the building in summer, and $0.10 \mathrm{kBtu}$ less heat (reducing cooling load) and $0.16 \mathrm{lb}$ less moisture to the building during the remaining cooling hours. On average, more heat is also being removed during the non-summer floating hours as well, which is beneficial in the hot humid climate and could act to further reduce cooling hours later in the day by pre-cooling the building. However, during these hours more moisture is being introduced on average by the smart ventilation system $(0.12 \mathrm{lb} / \mathrm{h})$ than with the constant fan $(-0.06 \mathrm{lb} / \mathrm{h})$. Although these numbers are small, on average, the smart scheme had a negative impact on indoor moisture, which is something the Phase II scheme attempts to address. Negative numbers in the table represent heat or moisture leaving the building, positive numbers represent heat entering the building. During heating hours, the smart ventilation scheme removes $0.55 \mathrm{kBtu} / \mathrm{h}$ less heat (reducing heating load) and removes $0.46 \mathrm{lb} / \mathrm{h}$ less moisture. 
Table 3-2. Hourly Average Phase I Simulated Seasonal Sensible and Latent Loads, and Fan Energy for the Constant Flow (Fixed) Versus Smart Ventilation

\begin{tabular}{c|c|c|c|c|c|c|c|c|c|c|c}
\hline \multirow{2}{*}{$\begin{array}{c}\text { Season/ } \\
\text { Period }\end{array}$} & \multicolumn{3}{|c|}{ Sensible (kBtu/h) } & \multicolumn{3}{c|}{ Latent (Ib/h) } & \multicolumn{3}{c|}{$\begin{array}{c}\text { Fan Power } \\
\text { (Average Watts) }\end{array}$} & \multicolumn{3}{c}{ Average } \\
\cline { 2 - 11 } & Fixed & Smart & $\Delta$ & Fixed & Smart & $\Delta$ & Fixed & Smart & $\Delta$ & $\begin{array}{c}\text { Flow } \\
\text { (cfm) }\end{array}$ & RE \\
\hline $\begin{array}{c}\text { Summer } \\
\text { Non-Summer } \\
\text { Cooling }\end{array}$ \\
$\begin{array}{c}\text { Non-Summer } \\
\text { Floatingb }\end{array}$ & 0.25 & 0.05 & 0.20 & 1.88 & 1.57 & 0.31 & 40 & 28 & 11.62 & 65 & 1.22 \\
\hline $\begin{array}{c}\text { Heatingc } \\
\text { Annual }\end{array}$ & $(0.92)$ & $(1.33)$ & 0.41 & $(0.06)$ & 0.12 & $(0.18)$ & 40 & 50 & $(10.11)$ & 116 & 0.76 \\
\hline
\end{tabular}

a The period between May 1 and Oct. 31 .

${ }^{\mathrm{b}}$ The hours outside of the summer period when the outdoor air temperature falls within set parameters Cooling $>71.5^{\circ} \mathrm{F}$; Floating $\leq 71.5^{\circ} \mathrm{F}, \geq 50^{\circ} \mathrm{F}$.

${ }^{\circ}$ The hours when the outdoor air temperature falls below $50^{\circ} \mathrm{F}$.

The changes in loads were converted to energy savings in kWh and are shown in Table 3-3. These results assume a cooling and heating system with efficiency of seasonal energy efficiency ratio 13/COP 1 (as was present in the laboratory buildings during experimentation), $75 \%$ sensible heat ratio, and a $20 \%$ distribution loss. We implicitly assume that half of the differences in latent loads show up as increased load on the airconditioning system and the other half ends up as the observed changes to interior RH that were observed experimentally. This approximation is verified by the increase in condensate seen in the experiments as well as the modest changes in interior moisture level. The effect of latent loads on air conditioner electricity ends up similar in magnitude to the sensible changes seen. The change in sensible load during floating hours can be ignored, as this period is defined as hours when the outdoor temperature suggests the building should not be heating or cooling.

Fan energy is also converted into kWh and summed annually in the Table 3-3. The smart ventilation scheme saves fan energy during the cooling when flows are lower, but uses more fan energy during the heating and especially the floating hours when flow is more aggressive. The table shows potential for $7 \%$ annual energy savings, and over the 183-day period defined as summer in Central Florida (May 1-Oct. 31), the Phase I system is estimated to save $1.2 \mathrm{kWh} /$ day versus the constant speed ventilation system. 
Table 3-3. Estimated Space Conditioning Energy Use and Savings for Fixed and Smart Ventilation Using Phase I Scheme

\begin{tabular}{|c|c|c|c|c|c|c|c|c|c|c|c|}
\hline \multirow{2}{*}{$\begin{array}{l}\text { Season/ } \\
\text { Period }\end{array}$} & \multicolumn{3}{|c|}{ Sensible (kWh) } & \multicolumn{3}{|c|}{ Latent (kWh) } & \multicolumn{3}{|c|}{ Fan (kWh) } & \multicolumn{2}{|c|}{ Total Savings } \\
\hline & Fixed & Smart & Savings & Fixed & Smart & Savings & Fixed & Smart & Savings & (kWh) & $\%$ \\
\hline Summera & 140 & 30 & 110 & 397 & 331 & 65 & 175 & 124 & 51 & 226 & 32 \\
\hline $\begin{array}{c}\text { Non-Summer } \\
\text { Coolingb }\end{array}$ & 20 & 6 & 15 & 21 & 13 & 8 & 44 & 76 & (31) & (8) & -10 \\
\hline $\begin{array}{l}\text { Non-Summer } \\
\text { Floating }\end{array}$ & & & & & & & 117 & 219 & (102) & (102) & -87 \\
\hline Heatingc & 232 & 170 & 62 & & & & 12 & 104 & (91) & (29) & -12 \\
\hline Annual & 392 & 206 & 186 & 418 & 344 & 74 & 349 & 522 & (173) & 87 & 7 \\
\hline
\end{tabular}

a The period between May 1 and Oct. 31 .

b The hours outside of the summer period when the outdoor air temperature falls within set parameters - Cooling $>71.5^{\circ} \mathrm{F}$; Floating $\leq 71.5^{\circ} \mathrm{F}, \geq 50^{\circ} \mathrm{F}$.

c The hours when the outdoor air temperature falls below $50^{\circ} \mathrm{F}$.

\subsection{Laboratory Setup, Control, and Data Collection}

Experimental work was conducted in FSEC's Flexible Residential Test Facility (FRTF), which features two full-scale, geometrically identical side-by-side residential energy research facilities as shown in Figure 3-4. General characteristics of the 1,536- $\mathrm{ft}^{2}$ single-story buildings (volume $=13,050 \mathrm{ft}^{3}$ ) including details of the general instrumentation package and schedule and methods for simulating occupancy by generating indoor sensible and latent loads are provided elsewhere (Parker 2014). One building acted as a control and utilized a fixed ventilation rate. The other building varied the ventilation rate with a variable speed fan, which was operated with a smart controller created as part of this task utilizing a programmable datalogger.

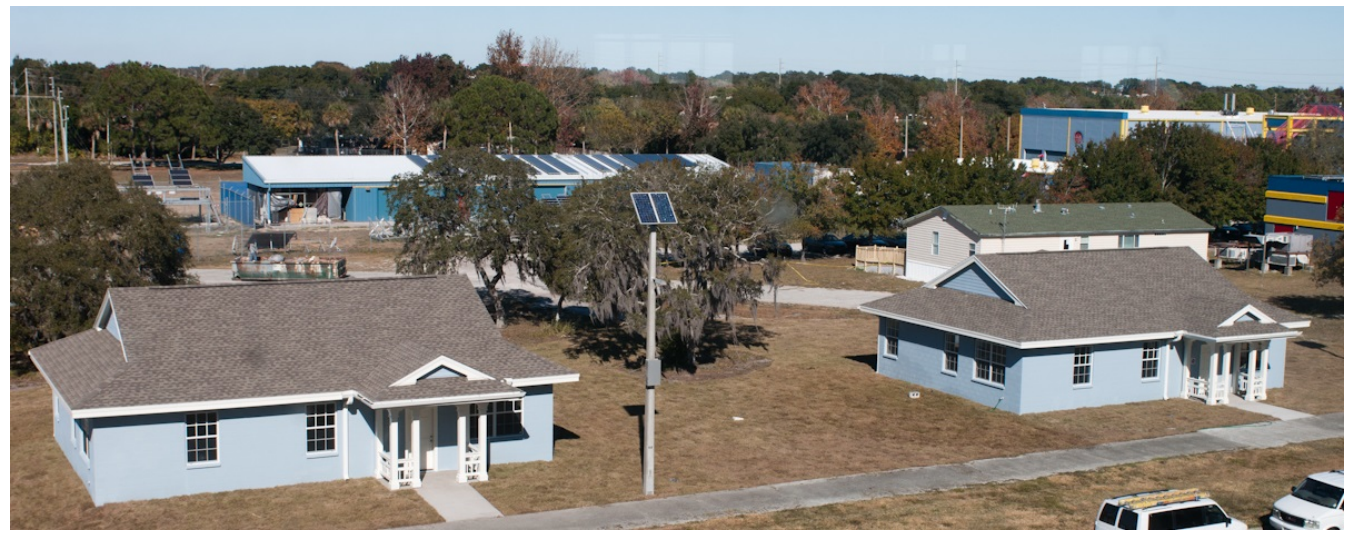

Figure 3-4. Flexible residential test structures on FSEC campus

Air leakage across the buildings' envelopes is controllable; however, for these experiments both buildings were set to their "tight" condition, resulting in approximately 2.2 air changes per hour at $50 \mathrm{~Pa}$, characterized with both blower door and pulse tracer gas injection prior to beginning experiments. Under the "tight" condition, ASHRAE 62.2-2016 requires $75 \mathrm{cfm}$ of whole-house mechanical ventilation fan flow, which was provided to the control building continuously, on a supply basis, directly into the zone via an inline fan. The 75 $\mathrm{cfm}$ is determined as the fan component of total continuous ventilation required by ASHRAE 62.2-2016, including natural infiltration modified by use of superposition to dictate interactive effects of the desired unbalanced ventilation system, as described in the standard's Appendix C. 
Components of the Phase I ventilation system in each home include a Fantech FR 140 centrifugal inline fan, illustrated in Figure 3-5, for which the maximum produced flow at full output was measured at $138 \mathrm{cfm}$ once installed. The fan is ducted with Continental Fan 6" IRIS damper and sections of 6" round metal and flex ducts insulated to R6. Outside air is drawn through a 12" x 12" filter back grill into an eight-foot section of 6" flex duct, which in turn is connected to a 10-foot section of 6" round metal duct with the IRIS damper at the center and inline fan at the end of the 10-foot metal duct. Air from the fan is then supplied to the living space through a six-foot section of flex duct. The IRIS damper was mounted between two five-foot sections of straight metal duct to increase measurement accuracy. Continental Fans provides standard flow equations for each IRIS damper setting that are adequate for general field use. An airflow equation was determined using a TSI wind tunnel and monitored in real-time with IRIS damper differential pressure readings.

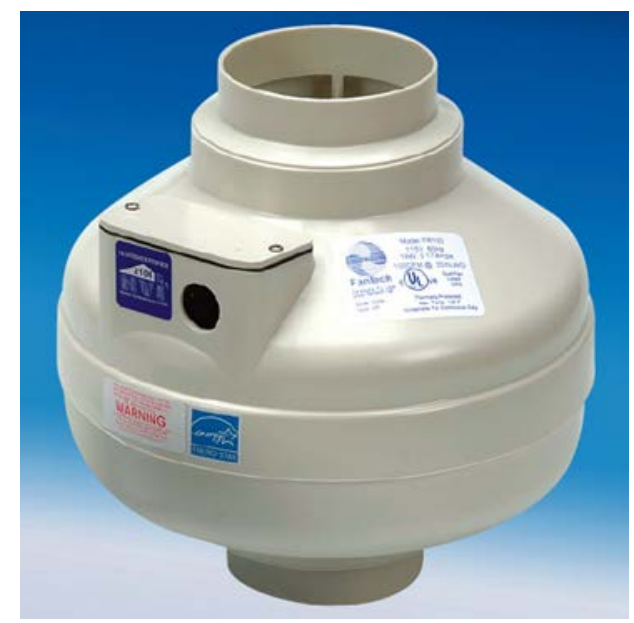

Figure 3-5. Fantech FR140 variable speed fan used to set flow for smart ventilation system

While the simulations were hourly-based, the experiments controlled the fan in 15-minute increments. Variation of airflow rates in the experimental building is achieved by altering the run time of the inline fan with the programmable datalogger as dictated by the smart ventilation algorithm. That is, the fan itself runs at a fix speed while operating, but run time is varied during each 15 -minute period to match the total flow called for. Flow measurements are determined using digital output from the manometer and the average recorded each 15-minutes. Temperature and RH are measured at the entrance and exit of the ventilation duct only while the fan is running and averaged for each 15-minute scan period. Indoor temperature and RH measurements were taken near the thermostat and HVAC energy measurements were recorded. Meteorological parameters were taken on a $10-\mathrm{m}$ tower. Outdoor temperature sensors were aspirated and shielded.

Real-time data acquisition was accomplished with Campbell Scientific CR3000 and CR1000 dataloggers operating at a 10-second scan rate and storing 15-minute data. Instrumentation equipment is shown in Table 34. 
Table 3-4. FRTF Monitoring Equipment

\begin{tabular}{|c|c|c|}
\hline Measurement & Equipment & Accuracy \\
\hline Data acquisition & Campbell Scientific CR3000 and CR1000 & $0.06 \%$ \\
\hline $\begin{array}{c}\text { Temperature and } \mathrm{RH} \text { at center of home } \\
\text { and outdoor airstream }\end{array}$ & $\begin{array}{c}\text { Vaisala HMP60 (Thin-film, dielectric } \\
\text { capacitive) }\end{array}$ & $\begin{array}{c} \pm 0.5^{\circ} \mathrm{C}, \pm 3 \% \\
\mathrm{RH}\end{array}$ \\
\hline Additional room temperatures & Type-T Thermocouple & $\pm 0.5^{\circ} \mathrm{C}$ \\
\hline Energy & $\begin{array}{l}\text { Continental Control Systems Wattnode } \\
\text { energy meters and current transformers }\end{array}$ & $\begin{array}{c} \pm 1 \% \text { of rated } \\
\text { current }\end{array}$ \\
\hline Pressure differential (outside airflow) & $\begin{array}{c}\text { The Energy Conservatory DG2 pressure } \\
\text { gauge with analog output }\end{array}$ & $\pm 1 \%$ \\
\hline Airflow & Continental Fans IRIS-06 damper & $5 \%$ \\
\hline Building envelope air leakage & $\begin{array}{c}\text { Minneapolis Blower Door System with DG- } \\
700 \text { digital gauge }\end{array}$ & $3 \%$ \\
\hline
\end{tabular}

\subsection{Early Experimentation to Implement Fan Control}

Early experiments to initially investigate reductions to heating energy began in January 2016 with a less sophisticated set of algorithm targets and parameters. During this brief period, a target fan flow of $66 \mathrm{cfm}$ was used, prior to implementing interactive effects of the unbalanced system in accordance with ASHRAE 62.22016 Appendix C. As seen in Figure 3-6, temperature control between the buildings is very tight during periods of heating (set point $=73^{\circ} \mathrm{F}$, to give a good heating signal during Florida's mild winter) and floating (indoor temperatures exceeding $80^{\circ} \mathrm{F}$ ). The last few days of the plot are after the labs were switched from heating to cooling $\left(75^{\circ} \mathrm{F}\right.$ set point $)$. 


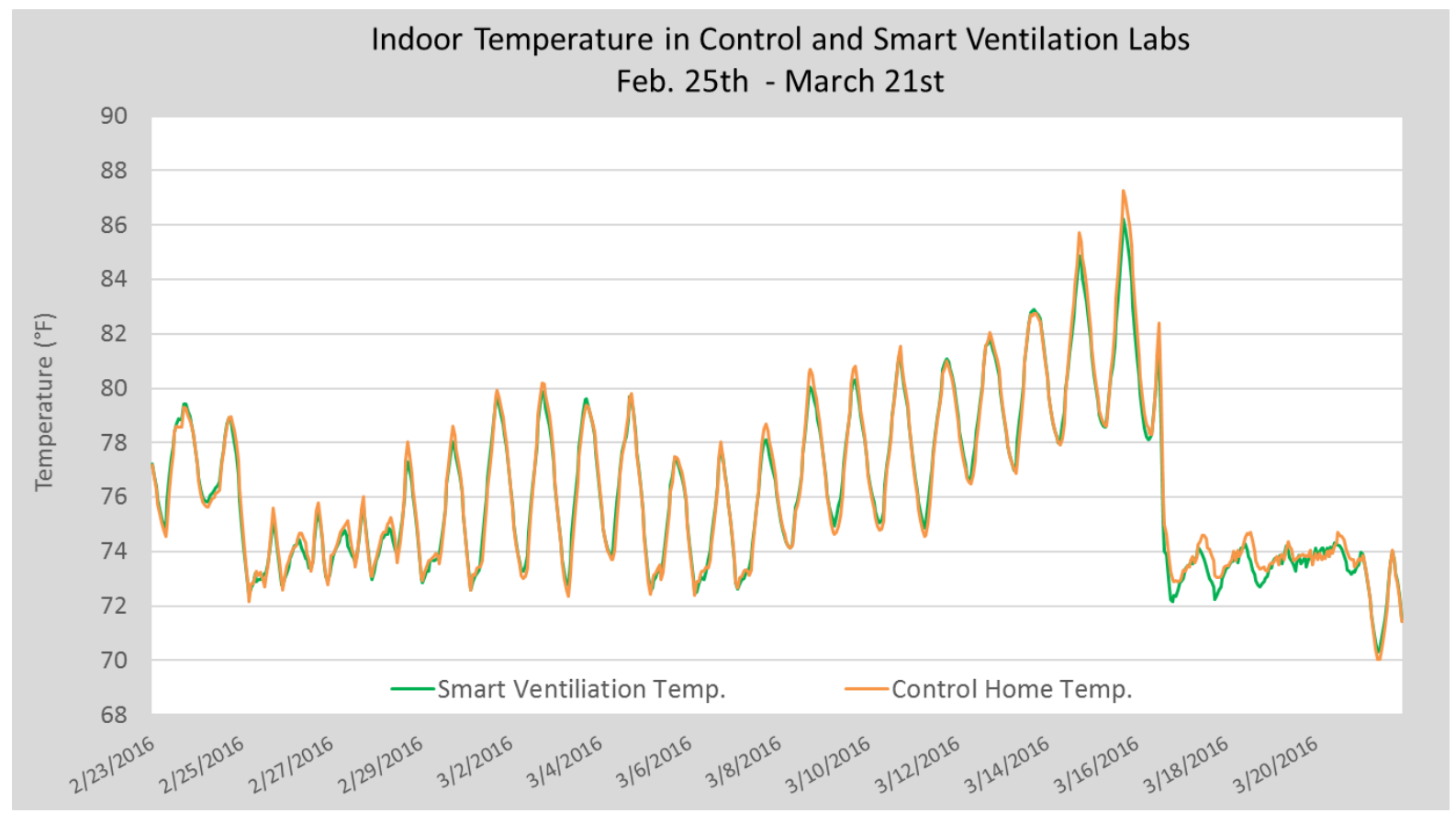

Figure 3-6. Indoor temperature $\left({ }^{\circ} \mathrm{F}\right)$ in labs with the baseline system (orange) and advanced system (green)

Figure 3-7 shows that the fan control is nearly perfectly providing the ventilation that the algorithm desires most of the time except when the algorithm calls for flow in excess of the fan's capacity. Shown in the plot is the target flow calculated by the algorithm along with the equivalent continuous flow delivered to the building. Again, the laboratory fan operates with a fixed flow of $138 \mathrm{cfm}$. The variation in measured flow is an average of the run time captured in 15-minute intervals. The only discrepancies are when the outdoor temperatures are mild, the algorithm wishes the fan to deliver a lot more ventilation than it is physically capable of, with a maximum flowrate of $138 \mathrm{cfm}$. These spikes in the algorithm's desired flow are particularly large (exceeding the plots axis maximum several times and over $1,000 \mathrm{cfm}$ at one point) when ideal outdoor conditions follow a trend of unfavorable conditions. 


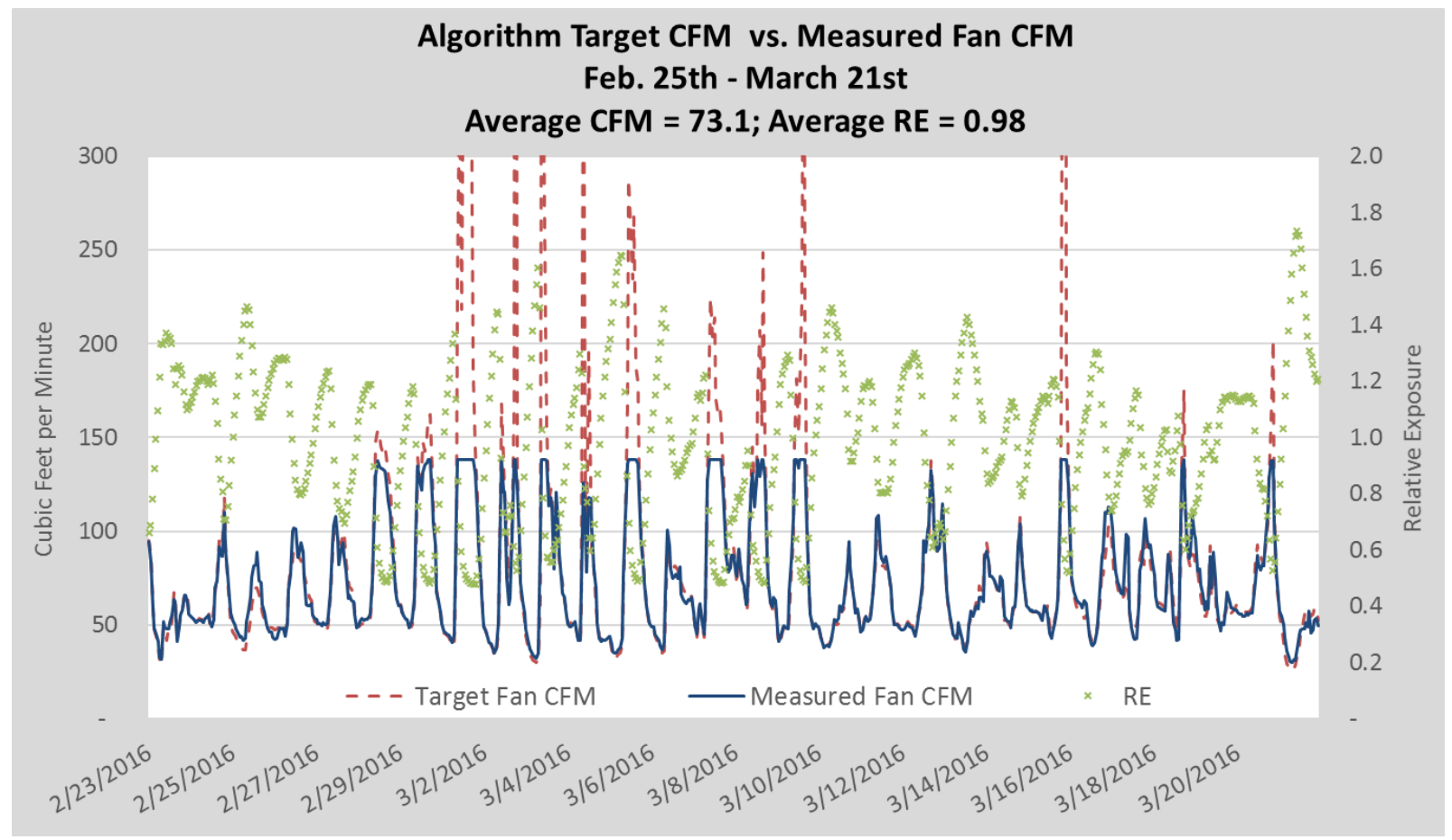

Figure 3-7. Hourly target ventilation flow (cfm) derived by the algorithm (red), measured delivered ventilation flow to the building (blue), and RE (green)

Figure 3-7 also shows the movement in RE, which averaged 0.98 during this period, slightly better than the target annual RE of 1.00. The average flow delivered during this period was $73.1 \mathrm{cfm}$, a bit higher than the continuous flow target of $66 \mathrm{cfm}$.

Figure 3-8 shows the fan run time (minutes, right axis) along with the two fundamental driving forces: outdoor temperature and outdoor dew point. The smart ventilation scheme generates high flows when the temperatures are close to $75^{\circ} \mathrm{F}^{4}$ with dew points in the $50 \mathrm{~s}$ to $60 \mathrm{~s}$ (March 1 and 8), but reduces flows greatly when the dew points are around $60^{\circ} \mathrm{F}$ to $70^{\circ} \mathrm{F}$ (March 13-15). This would seem to indicate that relaxing the target interior RH on which the moisture target is based from $50 \%$ to $55 \%$ would have beneficial effects on the ability of the temperature-driven part of the algorithm to deliver savings. Another approach would be to set the RH weight lower (perhaps 0.5 ) or vary the weight by the direction of the delta and see how much more savings can be produced. Each of these approaches was evaluated in later simulations to develop a Phase II ventilation scheme.

\footnotetext{
${ }^{4}$ During this short experimental run, the target indoor temperature was set at $75^{\circ} \mathrm{F}$ before it was subsequently lowered for the Phase I experimental scheme discussed later.
} 


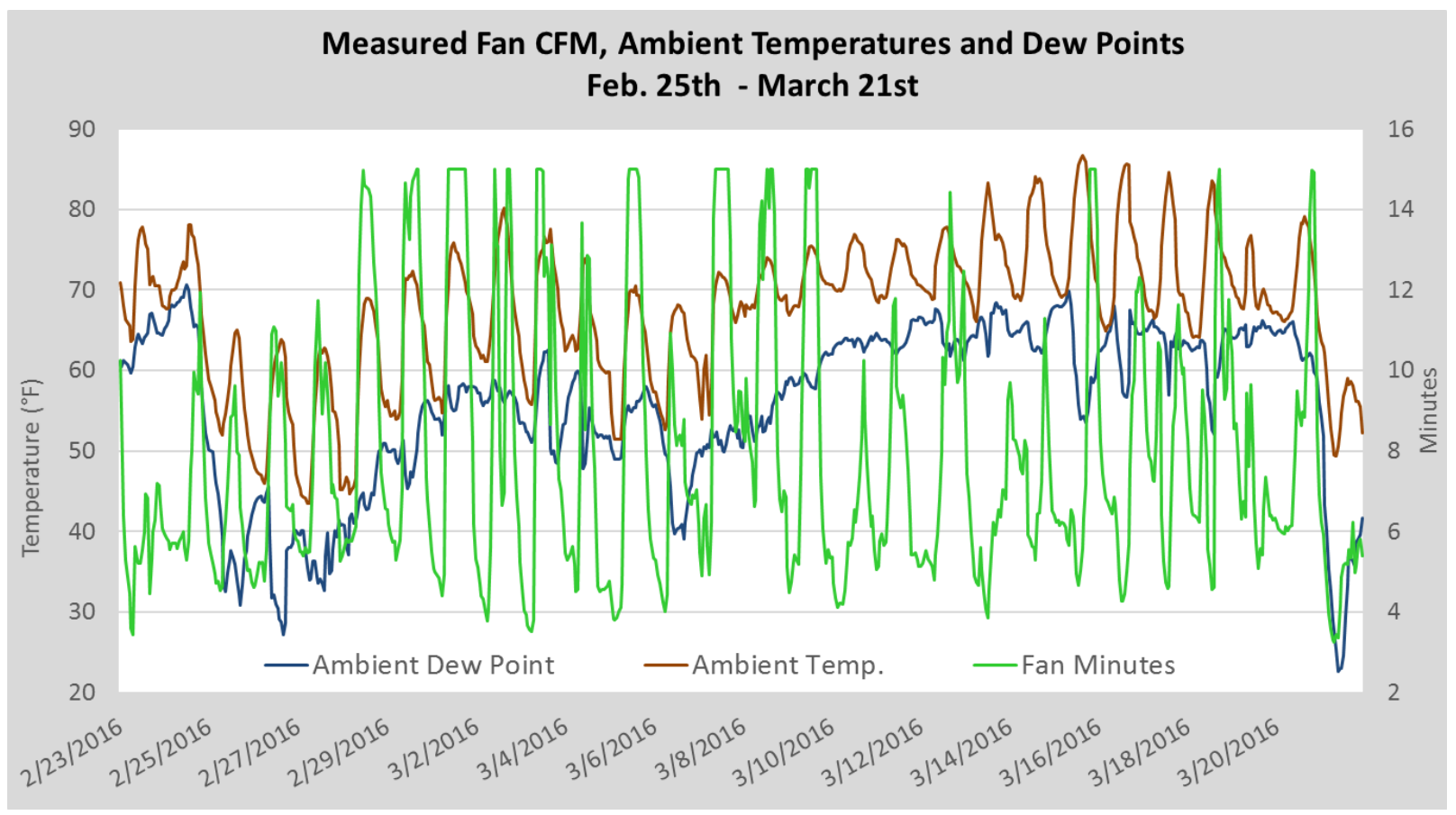

Figure 3-8. Fifteen-minute ventilation fan run time (minutes) of the advanced system (green, right axis), along with the outdoor temperature (red, left axis) and outdoor dew point (blue, left axis)

\subsection{Impact of Outdoor Air Source on Ventilation Air Temperature}

One surprise finding from the early fan control experimentation was that the temperature of air being introduced to the center of the test home by either the smart or constant flow supply ventilation system was considerably warmer than the outdoor air temperature measured at height $(15 \mathrm{ft})$. We knew that the supply ventilation fan heat would raise the temperature of the air to the interior space, and be a partial contributor to this effect. For instance, with 40 Watts of fan power producing $66 \mathrm{cfm}$, the added fan heat can be expected to raise the discharge ventilation air temperature by $1.9^{\circ} \mathrm{F}$ over the intake temperature. Unfortunately, the temperature rise of the discharge air was considerably greater than $2^{\circ} \mathrm{F}$; the cause of this is described below. Figure 3-9 shows data for a two-week period during the height of summer. The temperatures of the intake and discharge are only those when the ventilation system is operating so there is no bias of non-run time conditions. 


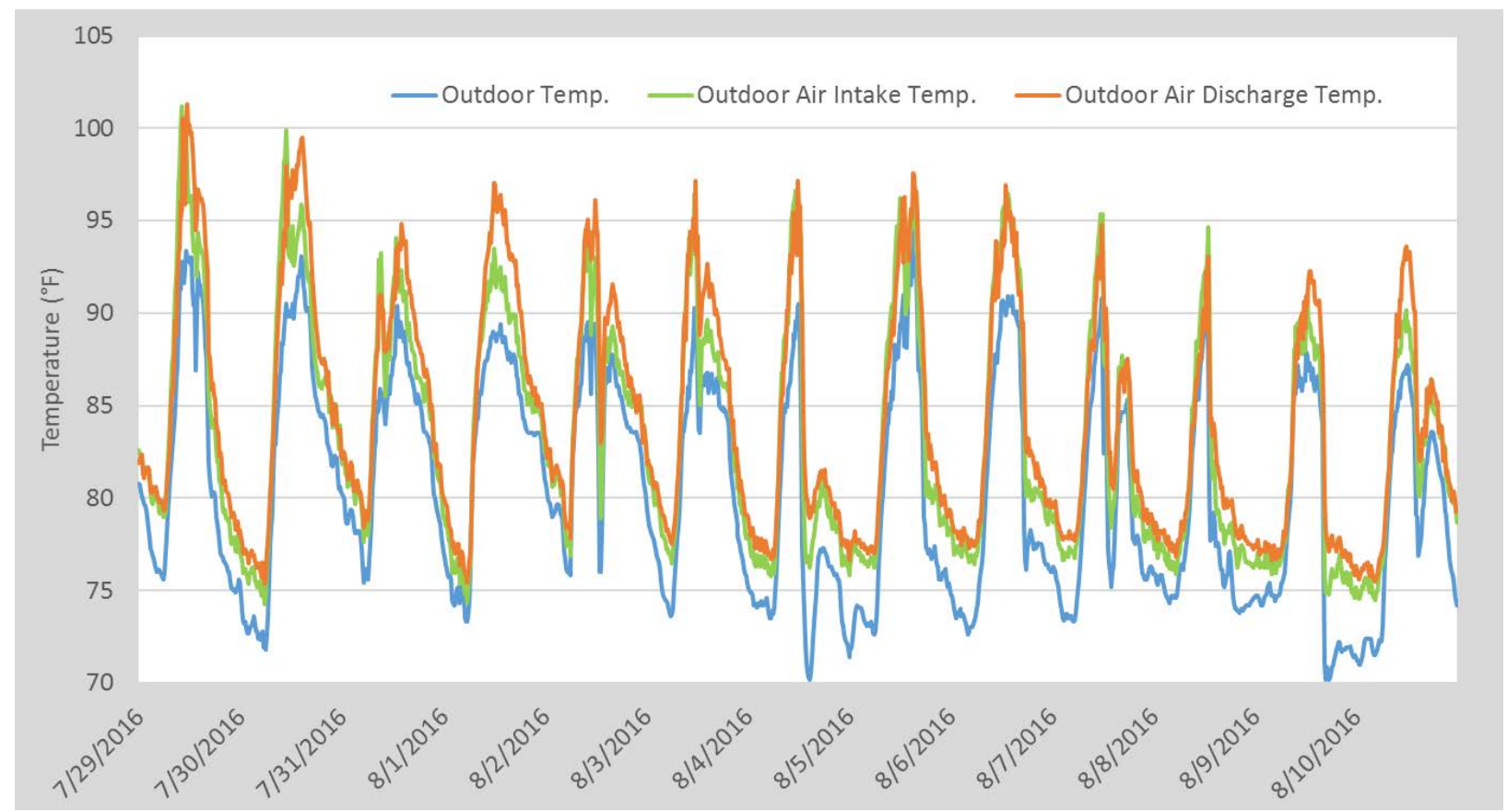

Figure 3-9. Temperature of ventilation intake (green), discharge (orange), and the outdoor temperature (blue) of the smart ventilation building, July 29-Aug. 10, 2016

Averages over the period show the increase of the intake vs. ambient temperature is greatest during the afternoon hours, which likely comes from both gains to the 6" insulated duct system, located in the vented attic, as well as heating of the east wall by sunlight. Figure 3-10 reveals that the discharge temperature is fully $5^{\circ} \mathrm{F}$ higher than the outdoor air temperature at height during summer afternoon, and the outdoor temperature and outdoor air intake were $4^{\circ} \mathrm{F}$ higher than the outdoor temperature taken at roof height. The averages over the period: ambient $80.4^{\circ} \mathrm{F}$; ventilation intake $83.4^{\circ} \mathrm{F}$; ventilation discharge $84.3^{\circ} \mathrm{F}$. 


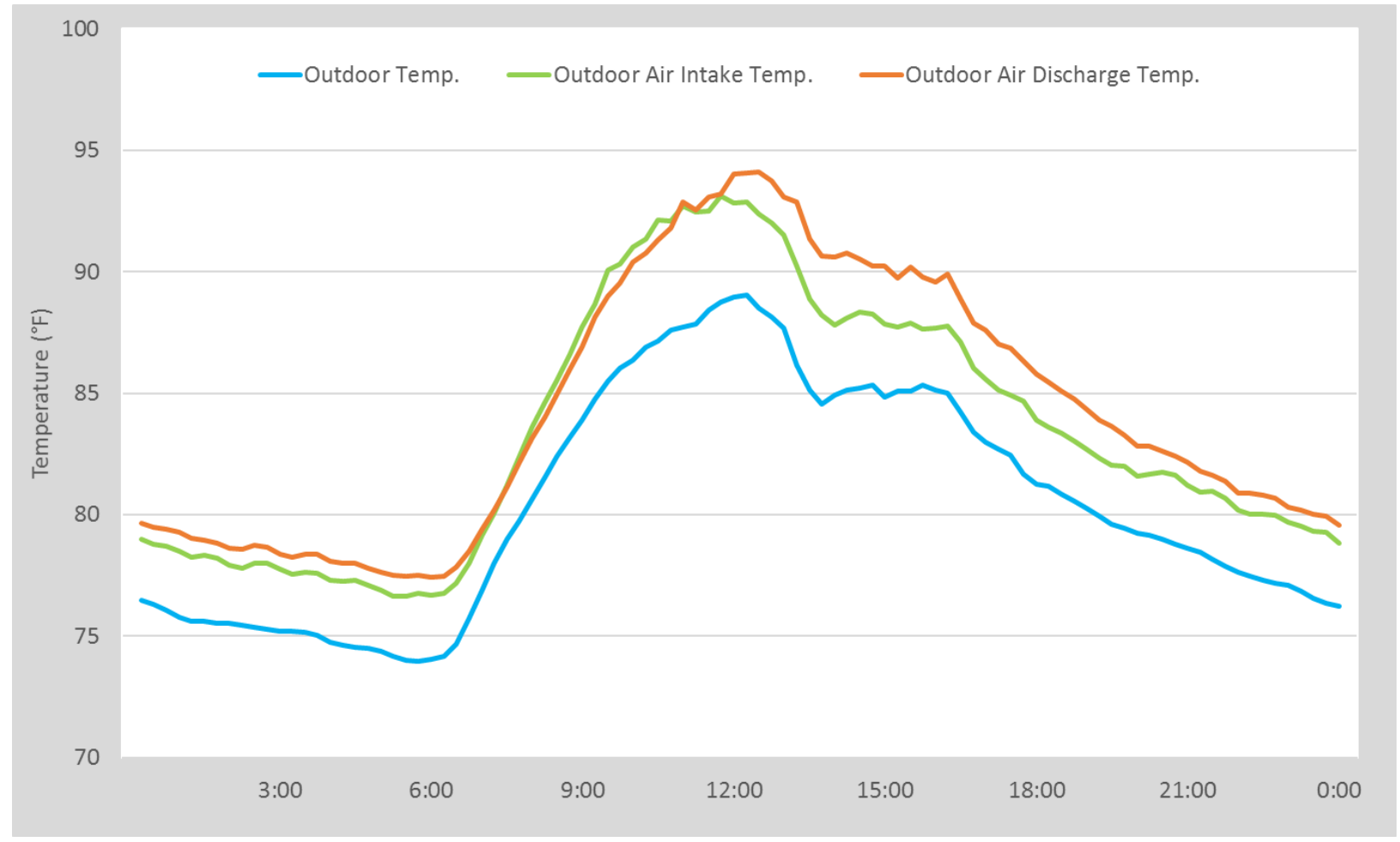

Figure 3-10. Average intake (green) and discharge temperatures (orange) of smart ventilation system at the height of summer against outdoor air temperature at roof height (blue), July 29-Aug. 10

To compensate for this impact during development of the Phase I scheme, the target indoor temperature was set $5^{\circ} \mathrm{F}$ cooler than would be otherwise selected, which we also conclude will be necessary for implemented smart ventilation strategies in cooling dominated climates. This will be particularly true when temperatures acquired from internet sources are used in place of local measurements, which can be expected to be biased low. Figure 3-11 shows how temperatures closer to the ground and near ventilation air intakes can be higher relative to temperatures at higher elevations where weather station data are typically collected. 


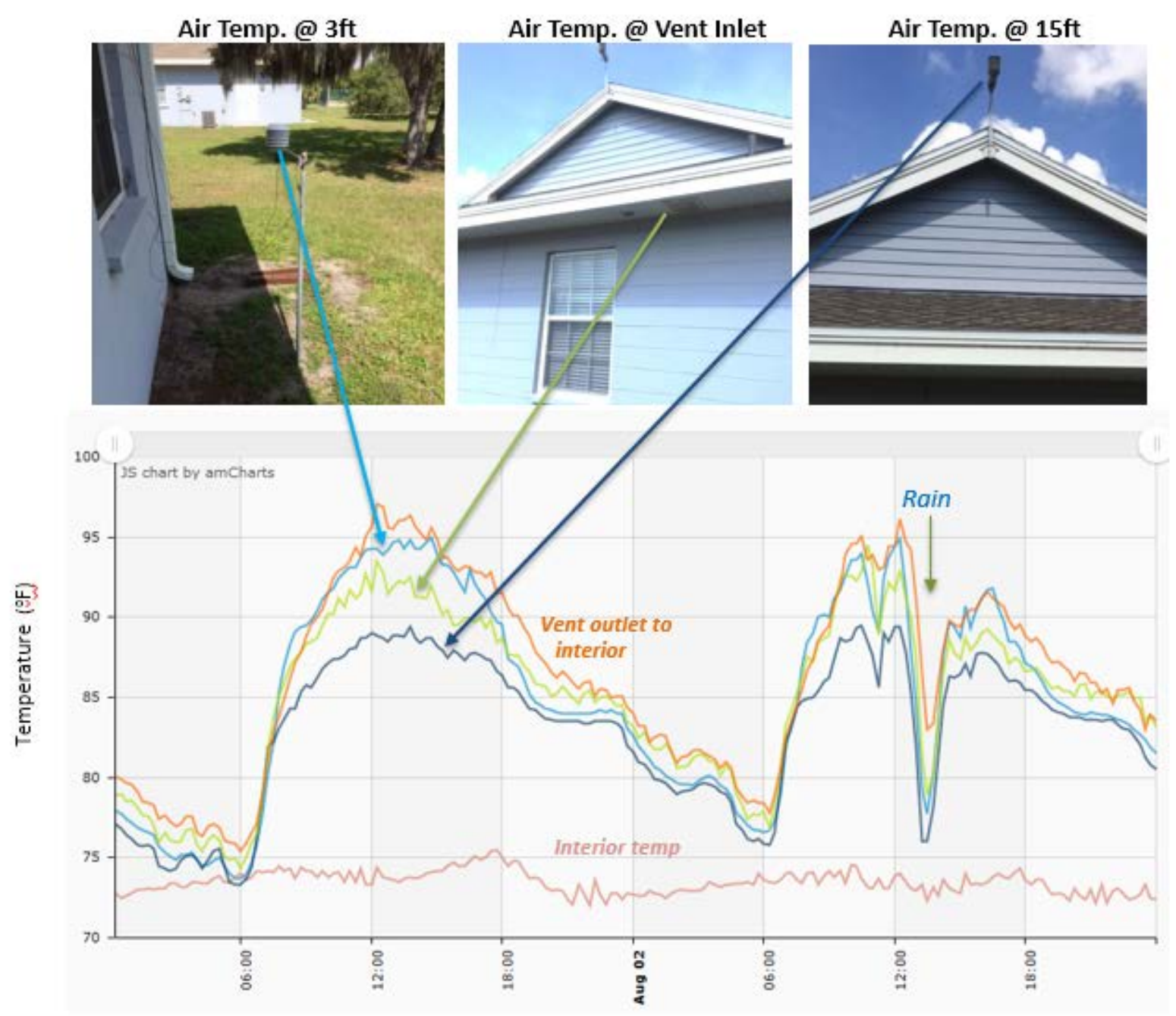

Aug. 1-2, 2016

Figure 3-11. Example data on Aug 1, 2016 showing how air temperature varies around test buildings at height, vent inlet, and close to ground

\subsection{Phase I Laboratory Evaluation}

The Phase I scheme determined through simulation evaluation and described in Section 3.2 was implemented into the FRTF building with the smart controller, while the control building ran a constant ventilation rate of $75 \mathrm{cfm}$, to evaluate ventilation-specific cooling load and energy savings. This scheme was run from August 2016 through March 2017. With the mild winter experienced, this evaluation segment is nearly exclusively cooling and floating periods, with the thermostat in both buildings set to $74^{\circ} \mathrm{F}$.

\subsubsection{Phase I Results: 2016 Cooling and 2016-17 Floating Periods}

Measured monthly energy savings for the cooling and floating periods are provided in Table 3-5, and average RE, fan flow, and interior and exterior conditions are shown in Table 3-6. Results have been projected into 30day bins, as a full month of data were rarely available for a variety of reasons, including disparities between the two buildings in internal gains, AC failure, complete power failure during Hurricane Matthew, and a few days requiring heating. 
Table 3-5. Phase I Scheme Average Monthly Measured Cooling Energy Use and Savings

\begin{tabular}{c|c|c|c|c|c|c|c|c|c|c}
\hline Month & \multicolumn{3}{|c|}{ Cooling Energy $(\mathrm{kWh})$} & \multicolumn{3}{c|}{ Fan Energy $(\mathrm{kWh})$} & \multicolumn{4}{c}{ Total $(\mathrm{kWh})$} \\
\hline $\begin{array}{c}\text { ( } \mathrm{n}=\text { days of } \\
\text { good data) }\end{array}$ & Fixed & Smart & Savings & Fixed & Smart & Savings & Fixed & Smart & Savings & $\begin{array}{c}\% \\
\text { Savings }\end{array}$ \\
\hline Aug. $(\mathrm{n}=21)$ & 1,312 & 1,295 & 16 & 29 & 18 & 11 & 1,340 & 1,313 & 27 & $2 \%$ \\
Sep. $(\mathrm{n}=15)$ & 1,011 & 1,013 & $(2)$ & 29 & 18 & 10 & 1,039 & 1,031 & 8 & $1 \%$ \\
Oct. $(\mathrm{n}=25)$ & 671 & 624 & 47 & 29 & 21 & 8 & 700 & 645 & 55 & $8 \%$ \\
Nov. $(\mathrm{n}=9)$ & 295 & 246 & 49 & 29 & 25 & 3 & 324 & 271 & 53 & $16 \%$ \\
Dec. $(\mathrm{n}=31)$ & 286 & 234 & 52 & 29 & 27 & 2 & 314 & 261 & 53 & $17 \%$ \\
Jan. $(\mathrm{n}=15)$ & 300 & 248 & 53 & 29 & 25 & 3 & 329 & 273 & 56 & $17 \%$ \\
Average & 646 & 610 & 36 & 29 & 22 & 6 & 674 & 632 & 42 & $6.2 \%$ \\
\hline
\end{tabular}

Table 3-6. Phase I Scheme Average Monthly Measured Fan Flow, RE, and Interior and Exterior Conditions

\begin{tabular}{c|c|c|c|c|c|c|c|c}
\hline $\begin{array}{c}\text { Month }(\mathrm{n}= \\
\text { days of good } \\
\text { data) }\end{array}$ & $\begin{array}{c}\text { Smart } \\
\text { Flow } \\
(\mathrm{cfm})\end{array}$ & $\begin{array}{c}\text { Smart } \\
\mathrm{RE}\end{array}$ & $\begin{array}{c}\text { Outdoor } \\
\text { OA Inlet } \\
\text { Temp. } \\
\left({ }^{\circ} \mathrm{F}\right)\end{array}$ & $\begin{array}{c}\text { Control } \\
\text { Indoor } \\
\text { Temp. }\left({ }^{\circ} \mathrm{F}\right)\end{array}$ & $\begin{array}{c}\text { Smart } \\
\text { Vent } \\
\text { Indoor } \\
\text { Temp. } \\
\left({ }^{\circ} \mathrm{F}\right)\end{array}$ & $\begin{array}{c}\text { Outdoor Air } \\
\text { Inlet Dew } \\
\text { Point }\end{array}$ & $\begin{array}{c}\text { Control } \\
\text { Indoor } \\
\mathrm{RH}\end{array}$ & $\begin{array}{c}\text { Smart } \\
\text { Vent } \\
\text { Indoor } \\
\mathrm{RH}\end{array}$ \\
\hline Aug. $(\mathrm{n}=21)$ & 57 & 1.33 & 84.4 & 73.6 & 73.6 & 75.5 & 52.1 & 51.2 \\
\hline Sep. $(\mathrm{n}=15)$ & 59 & 1.31 & 81.5 & 73.6 & 73.9 & 73.5 & 53.1 & 53.9 \\
\hline Oct. $(\mathrm{n}=25)$ & 66 & 1.25 & 76.8 & 74.2 & 74.1 & 65.8 & 50.5 & 50.6 \\
\hline Nov. $(\mathrm{n}=9)$ & 82 & 1.08 & 70.3 & 74.0 & 74.1 & 60.0 & 50.9 & 53.3 \\
\hline Dec. $(\mathrm{n}=31)$ & 87 & 1.03 & 69.6 & 73.9 & 73.9 & 61.0 & 54.0 & 56.2 \\
\hline Jan. $(\mathrm{n}=15)$ & 82 & 1.06 & 65.3 & 74.3 & 73.9 & 54.0 & 48.3 & 52.8 \\
\hline
\end{tabular}

The smart ventilation algorithm delivered $36 \mathrm{kWh} /$ month or $1.2 \mathrm{kWh} /$ day and $5.5 \%$ cooling energy savings for this 180 -day period. Results are improved slightly, to $6.2 \%$ when fan energy is considered. Average monthly savings ranged from $1 \%$ to $17 \%$. The average monthly fan flow for the smart ventilated building gradually rose from $57 \mathrm{cfm}$ in August to $87 \mathrm{cfm}$ in December, as higher flow targets were programmed to help reduce the average annual RE, which ranged from 1.33 to 1.03 during these months. The smallest cooling savings were experienced during the hottest months when air delivered by the smart ventilation system was less than that of the control. During these months, the air conditioner ran nearly constantly and sometimes failed to keep the interior set points at $74^{\circ} \mathrm{F}$. The plot in Figure 3-12 shows the AC running constantly much of the day, and at times failing to bring the interior temperature down to the set point. In August, the smart building with reduced ventilation is better able to maintain desired interior conditions (yellow) than the control (red). The control building temperature spikes about $2^{\circ} \mathrm{F}$ higher than smart building. However, cooling energy in both buildings is continuous for extended periods, hence there are essentially no energy use savings experienced during this month. 


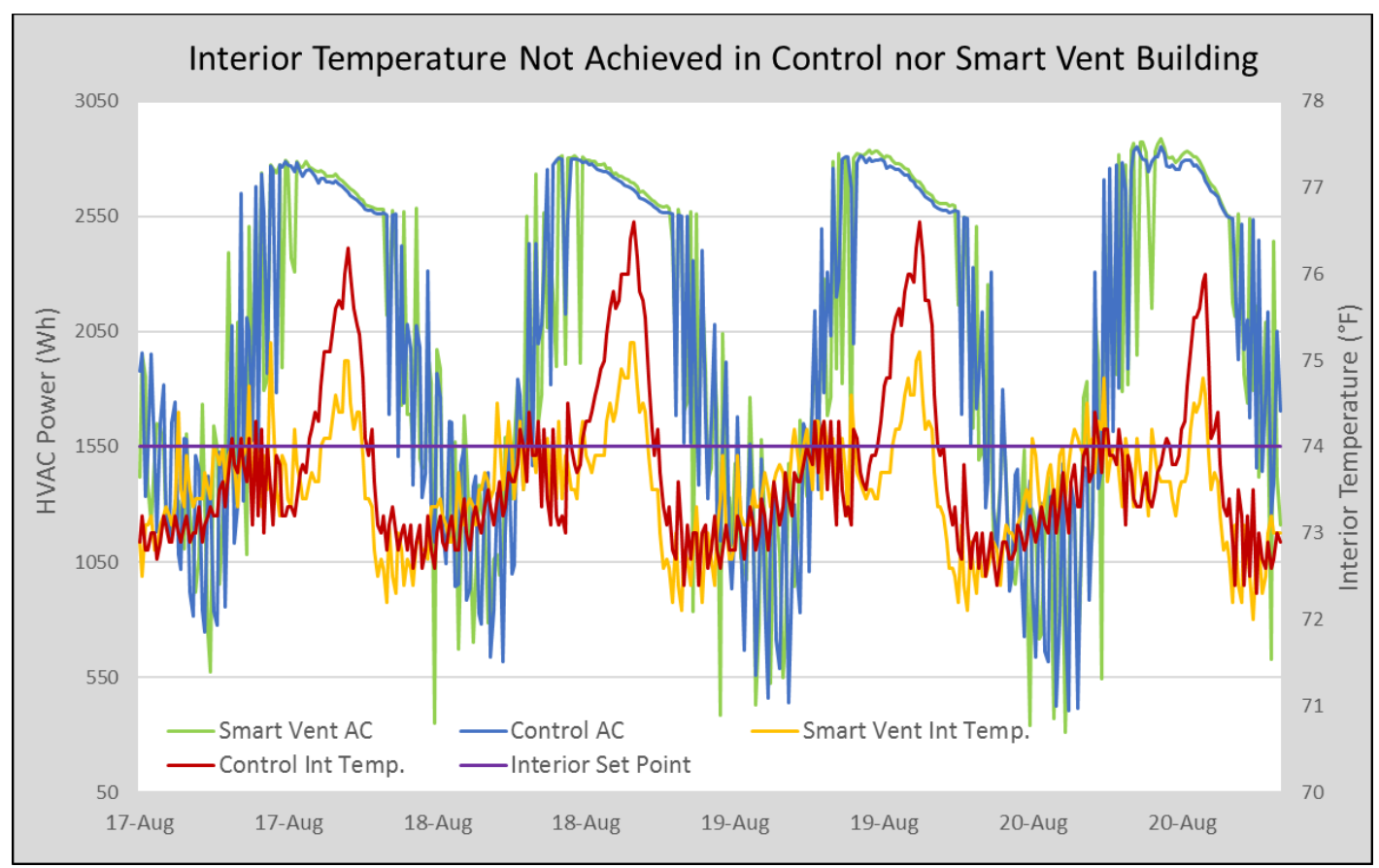

Figure 3-12. Smart ventilation AC power (green) and control building AC power (blue) both fail to keep set point (purple). Control building temperature (red) spikes about $2^{\circ} \mathrm{F}$ higher than smart building (yellow).

Average indoor temperature in the control and smart ventilation buildings were closely aligned overall, although with daily variation as noted in Figure 3-12. The smart ventilation building experienced higher indoor $\mathrm{RH}$ during the floating period when the outside airflow is at its greatest. December experiences the highest average interior RH for both buildings, $54.0 \%$ in the control and $56.2 \%$ in the smart. The smart building's indoor RH regularly rose between $60 \%$ and $64 \%$ during morning hours, as plotted in Figure 3-13. The hours of elevated indoor RH follow the hours during which the smart ventilation building flow exceeds that of the control building. The smart building's elevated indoor RH is in response to greater ventilation rather than a buildup of internally-generated moisture that is not adequately ventilated during low-flow hours.

October is highlighted as an average month for the smart ventilation scheme with ventilation energy savings at $7 \%$ and $47 \mathrm{kWh}$. Figure 3-14 is the average daily profile for October, displaying air conditioning power, fan flow, and RH for both buildings, along with outside air inlet temperature. 


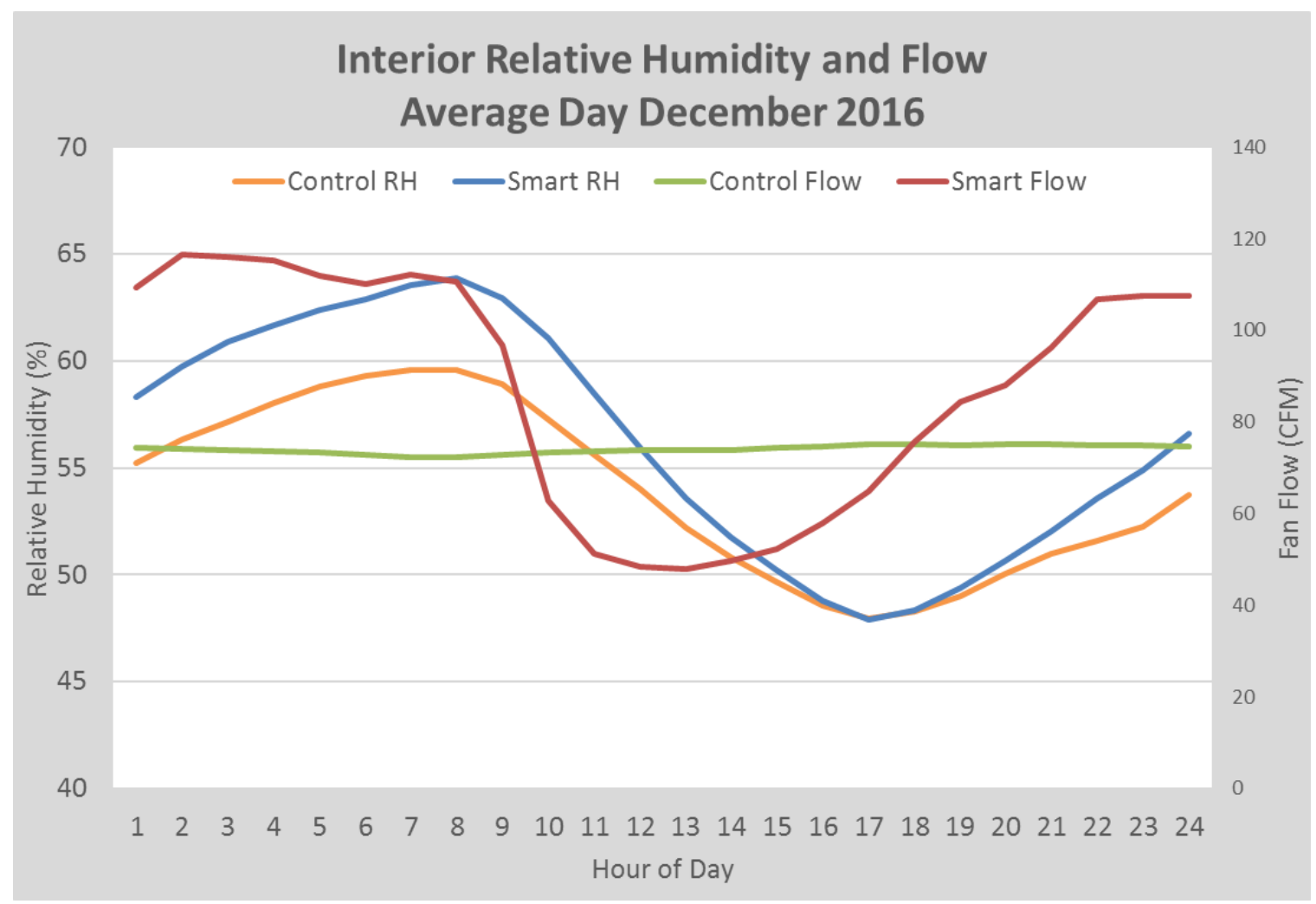

Figure 3-13. Average day smart ventilation and control building fan flow and interior RH during December

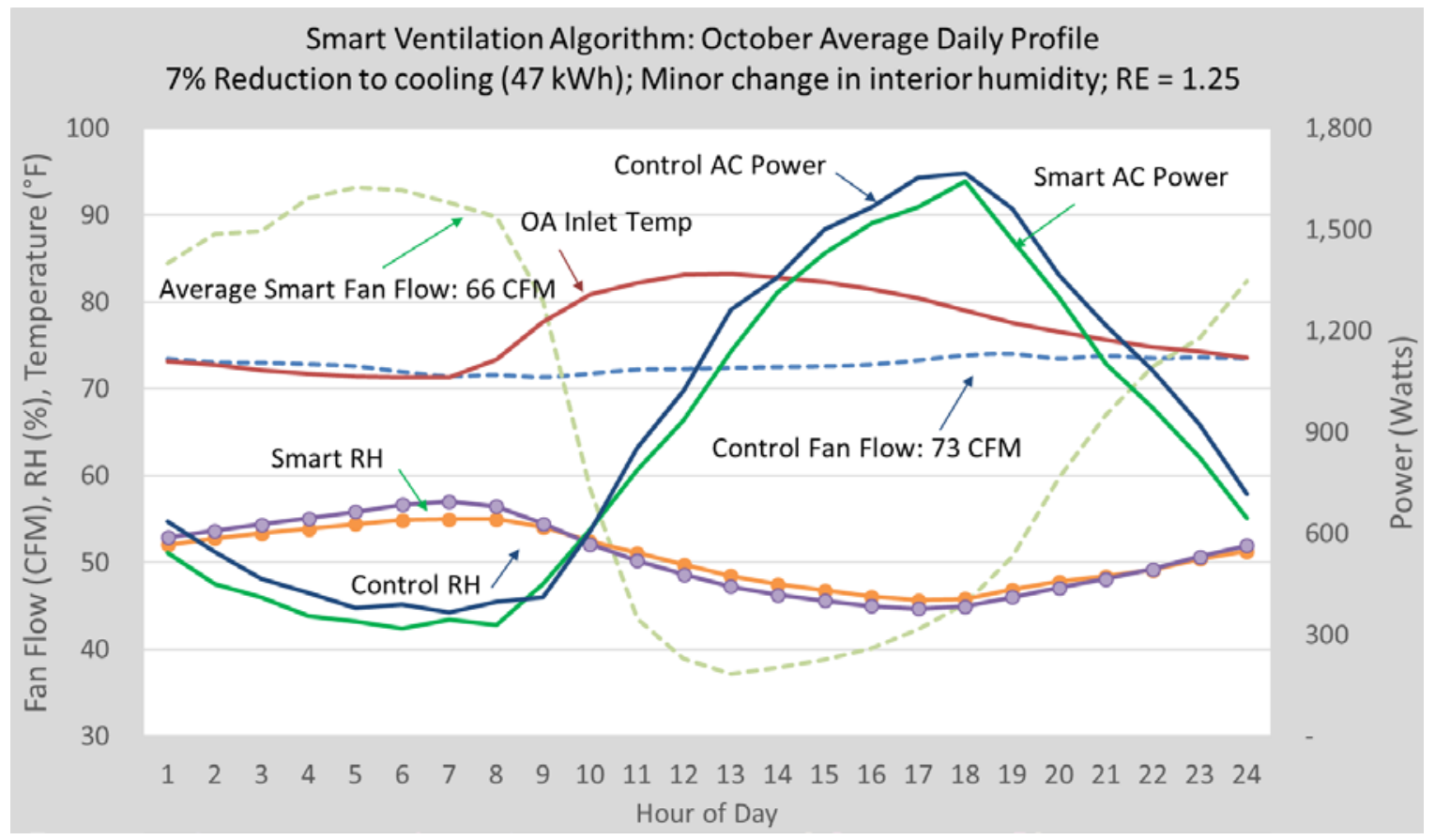

Figure 3-14. October average daily profile, displaying smart building AC power (green line), control building AC power (blue line), smart fan flow (green dash), constant control fan flow (blue dash), smart building interior RH (purple dots), control building interior RH (orange dots), and outside air inlet temperature (red line) 
The smart ventilation scheme fan flow increases between 11 p.m. and 9 a.m., when the outdoor temperature is lowest, and drops well below that of the control building during the remaining hours. However, regardless of the amount of flow, the smart building AC energy is consistently lower than that of the control building. Meanwhile, indoor RH is fairly comparable between the two buildings, with the smart ventilation building's humidity slightly higher in the early morning hours, but slightly lower by mid-day. Average RE for the month was 1.25 .

\subsubsection{Phase I Results: 2017 Heating Period}

A mild 2017 winter in Central Florida provided little data for the smart ventilation heating evaluation, offering only a handful of days with no cooling energy use and relatively substantial heating compared to floating hours. Looking at data spanning two brief cold fronts totaling 12 days found that the average fan flow for the smart ventilation building $(88 \mathrm{cfm})$ exceeded that of the control $(75 \mathrm{cfm})$, and RE was 0.95 given copious floating hours when the smart ventilation fan had a more aggressive flow target. Overall energy saving during these two cold fronts was $-1 \%$, with no savings with fan energy considered. Figure 3-15 depicts conditions during a January cold front, showing the outside air inlet temperature (blue), control and smart building ventilation flows (red and green), and the control and smart air hander energy use (purple and orange). The last three days of the cold front had a considerable number of floating hours. With the Phase I smart ventilation scheme, the mild winter generated no savings, but provided high levels of fan flow during floating hours, helping to balance the annual RE.

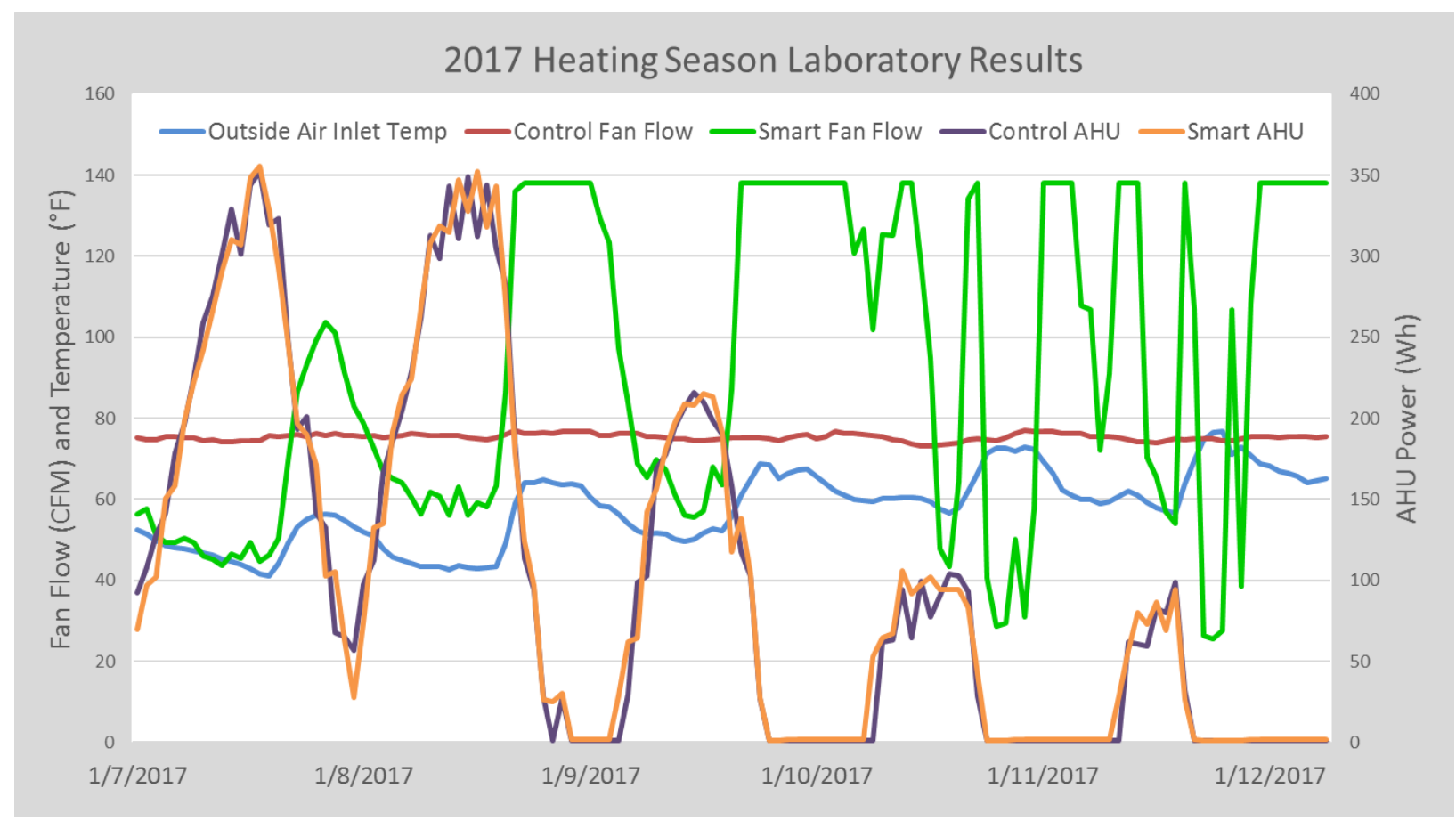

Figure 3-15. Smart ventilation heating (orange) versus control building heating (purple). Smart ventilation heating savings observed during a January cold front.

\subsection{Phase II Scheme Description and Simulation Results}

In effort to achieve reduced RE, better energy savings, and improved indoor comfort conditions from the smart ventilation system, changes were made prior to the onset of the 2017 cooling season. The goal of the revised scheme was to reduce RE and indoor RH, while maximizing cooling energy savings. First, a more powerful fan (Fantech FR 160 series fans) with a maximum installed flow of $209 \mathrm{cfm}$ (tested in situ) was installed to allow greater ventilation flow during moderate outdoor conditions, and the simulation tool was revisited to test additional integrative schemes with added parameters. The power use of the larger fan increased from 59.4 
Watts to 113.8 Watts in the Phase II scheme. While it is expected that this increase in fan energy will negatively impact overall savings, the primary intent of the experiments are to investigate impact of ventilation flow modulation. In practice, fan energy use will need to be optimized, and relative impact will ultimately depend on the baseline system chosen for comparison. Based on 2016 experiences, ventilation during the hottest periods with a limited cooling system capacity led to elevated interior temperatures that would likely not be considered favorable in a functional ventilation system. Thus, a key evaluated parameter included a fan override (flow lockout) above a specified outdoor air temperature. Scheme alterations included a variety of methods to reduce indoor RH, including altering delta-T and delta-W weights. Ultimately, the simulation suggested the best reductions in indoor RH while maintaining savings and an annual RE of 1.00 was to create a second floating period fan flow target when outdoor conditions rose above a specified amount of outdoor moisture.

The chosen Phase II scheme input values include cooling and heating period flow targets of $75 \mathrm{cfm}$, and a floating period target of $209 \mathrm{cfm}$; a fan override to stop fan flow when inlet air temperatures exceed $88^{\circ} \mathrm{F}$; a threshold for lowing floating period fan flow from 209 to $75 \mathrm{cfm}$ when outdoor moisture reaches $15 \mathrm{~g} / \mathrm{m}^{3}$, and the definition of a heating hour was redefined as $<50^{\circ} \mathrm{F}$ outdoor temperature. A complete list of the Phase II scheme parameters, including the outdoor temperature ranges defining the varying flow periods is shown adjacent to the Phase I scheme in Table 3-7.

Given the lessons learned about the impact of outdoor air source on the ventilation air temperature, the algorithm was modified to trigger a fan override and reduce fan flow to $0 \mathrm{cfm}$ when the TMY 3 reaches $84^{\circ} \mathrm{F}$ and the inlet air temperature is assumed to be TMY $3+4^{\circ} \mathrm{F}$, or $88^{\circ} \mathrm{F}$. This was implemented to true-up the simulation with the laboratory experience described in Section 3.5. For the laboratory implementation, the fan is shut off when the outdoor air inlet temperature reaches $88^{\circ} \mathrm{F}$.

Table 3-7. Phase I versus Phase II Scheme Values

\begin{tabular}{c|c|c|c}
\hline $\begin{array}{c}\text { Period } \\
\text { (defined by } \\
\text { hourly avg. } \\
\text { outdoor } \\
\text { Temp.) }\end{array}$ & Parameter & $\begin{array}{c}\text { Phase I Scheme } \\
\text { Values }\end{array}$ & $\begin{array}{c}\text { Phase II Scheme } \\
\text { Values }\end{array}$ \\
\hline \multirow{2}{*}{ Cooling } & Outdoor temp. range for cooling period target & $>71.5^{\circ} \mathrm{F}$ & $>71.5^{\circ} \mathrm{F}$ \\
\cline { 2 - 4 } & Cooling period target fan flow & $55 \mathrm{cfm}$ & $75 \mathrm{cfm}$ \\
\cline { 2 - 4 } & Outdoor temp. range for fan override $(0 \mathrm{cfm})$ & $\mathrm{n} / \mathrm{a}$ & $>=88^{\circ} \mathrm{F}$ \\
\hline \multirow{2}{*}{ Heating } & Outdoor temp. range for heating period target & $<60^{\circ} \mathrm{F}$ & $<50^{\circ} \mathrm{F}$ \\
\cline { 2 - 4 } & Heating period target fan flow & $75 \mathrm{cfm}$ & $75 \mathrm{cfm}$ \\
\hline \multirow{2}{*}{ Floating } & Outdoor temp. range for floating period target & $<=71.5^{\circ} \mathrm{F} ;>=60^{\circ} \mathrm{F}$ & $<=71.5^{\circ} \mathrm{F} ;>=50^{\circ} \mathrm{F}$ \\
\cline { 2 - 4 } & Floating period target fan flow & $138 \mathrm{cfm}(\mathrm{fan}$ limit) & $209 \mathrm{cfm}(\mathrm{fan} \mathrm{limit})$ \\
\cline { 2 - 4 } & Outdoor W range to adjust floating period & $\mathrm{n} / \mathrm{a}$ & $>=15 \mathrm{~g} / \mathrm{m} 3$ \\
\cline { 2 - 4 } & target & $\mathrm{n} / \mathrm{a}$ & $75 \mathrm{cfm}$ \\
\hline \multirow{2}{*}{ All } & Floating period target adjusted for W & $64.4^{\circ} \mathrm{F}$ & $64.4^{\circ} \mathrm{F}$ \\
\cline { 2 - 4 } & Indoor temp. $(\mathrm{T})$ & 2 & 2 \\
\cline { 2 - 4 } & Delta-temp. weight $\left(\mathrm{X}_{\mathrm{T}}\right)$ & $12 \mathrm{~g} / \mathrm{m} 3$ & $12 \mathrm{~g} / \mathrm{m} 3$ \\
& Indoor moisture $(\mathrm{W})$ & 1 & 1 \\
\hline
\end{tabular}

\subsubsection{Phase II Simulation Results}

Simulation results for the Phase II smart ventilation scheme with TMY3 Orlando weather data suggested 96 $\mathrm{cfm}$ average annual fan flow, an increase from that of the Phase I smart ventilation scheme of $79 \mathrm{cfm}$. Total 
annual ventilation averaged $98 \mathrm{cfm} .{ }^{5}$ Along with the increased flow, results suggested an improved annual RE, which averaged 1.01 and reached a maximum of 3.63 for a single hour, still below the 5.00 threshold suggested by ASHRAE 62.2-2016. This compares with the Phase I simulation results of 1.08 and 2.09 for annual average and maximum RE, respectively.

Phase II Scheme simulation results are displayed graphically in Figure 3-16 with hourly fan flow of the smart ventilation plotted in light blue and average daily RE in red. The black line represents the alternative continuous fan flow at $75 \mathrm{cfm}$ and associated RE of 1.00 .

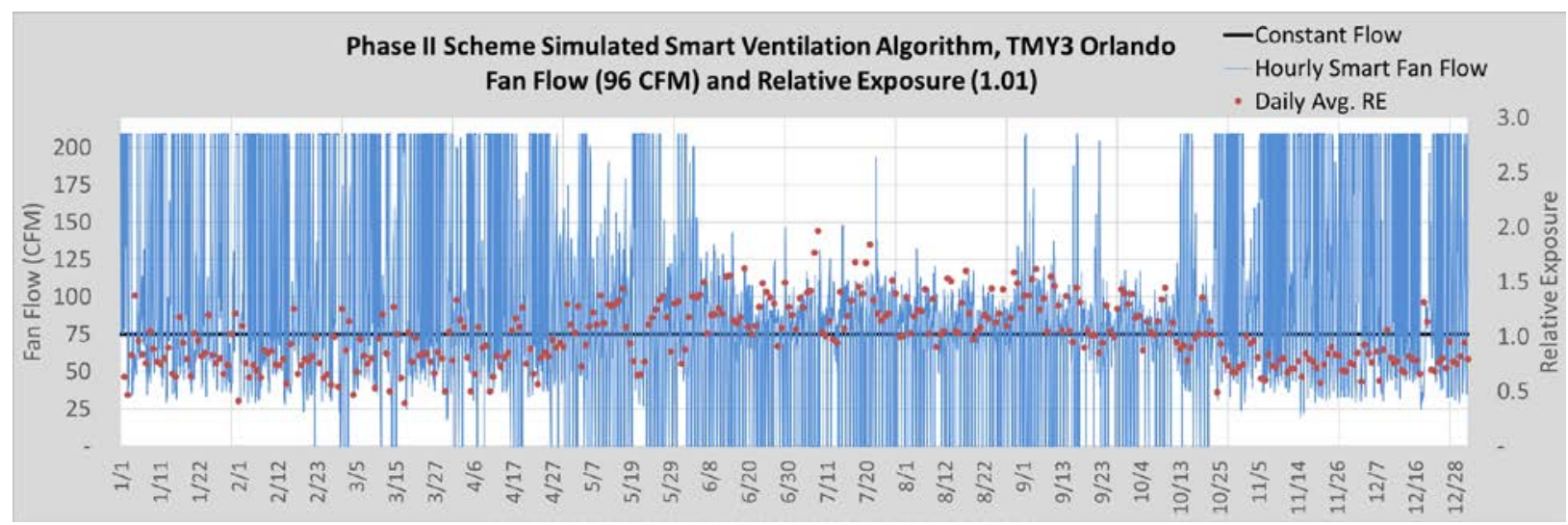

Figure 3-16. Phase II smart ventilation scheme simulated fan flow and RE

One difference between this simulation and the Phase I version is that during the floating period, RE is more frequently below 1.00. However, a more notable difference is that during the summer season (May through October), the fan is frequently shut off. Figure 3-17 magnifies results for August, which illustrates the diurnal fan cycling and that the $88^{\circ} \mathrm{F}$ fan cutoff as being implemented almost daily during this hot summer month.

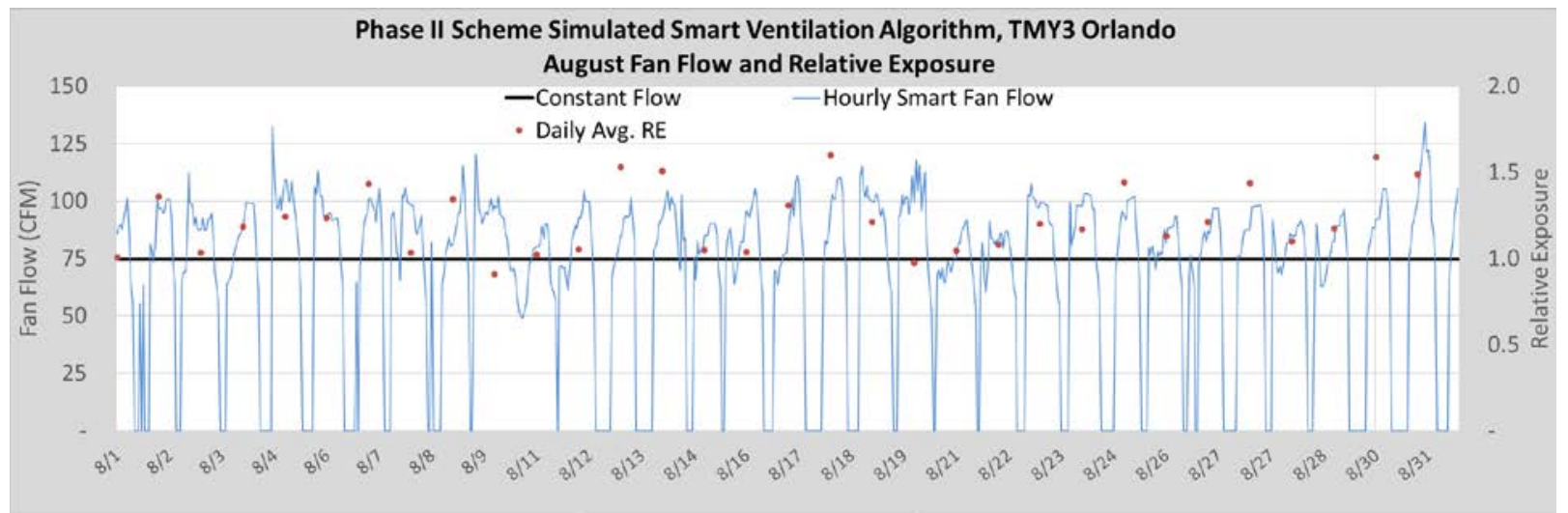

Figure 3-17. Phase II smart ventilation scheme simulated fan flow and RE for month of August

Simulated seasonal differences in the sensible and latent ventilation loads between the constant fan and the Phase II smart ventilation scheme are presented in Table 3-8. This simulation suggests the revised smart ventilation scheme reduces sensible cooling load by $0.33 \mathrm{kBtu} / \mathrm{h}$ and moisture load by $0.08 \mathrm{lb} / \mathrm{h}$ during the summer, and by $0.12 \mathrm{kBtu} / \mathrm{h}$ and $0.09 \mathrm{lb} / \mathrm{h}$, respectively, during the remaining non-summer cooling hours. The Phase II simulation also shows $0.55 \mathrm{kBtu} / \mathrm{h}$ less sensible heat removed during the heating period (reducing heating load) while more heat is removed during the floating period. While Phase II scheme does result in

\footnotetext{
${ }^{5}$ This includes the addition of the modified natural infiltration to the fan component, according to the ASHRAE Standard 62.2-2016 Appendix C, formulas C7 \& C8 for unbalanced mechanical ventilation (ASHRAE 2016).
} 
moisture removal during the floating period (unlike Phase I that showed moisture addition), it is still simulated to be less moisture removal on average than the fixed scheme.

Table 3-8. Hourly Average Phase II Simulated Seasonal Sensible and Latent Loads, and Fan Energy for the Constant Flow (Fixed) Versus Smart Ventilation

\begin{tabular}{|c|c|c|c|c|c|c|c|c|c|c|c|}
\hline \multirow[t]{2}{*}{$\begin{array}{c}\text { Season/ } \\
\text { Period }\end{array}$} & \multicolumn{3}{|c|}{ Sensible (kBtu/h) } & \multicolumn{3}{|c|}{ Latent (lb/h) } & \multicolumn{3}{|c|}{$\begin{array}{c}\text { Fan Power } \\
\text { (Average Watts) }\end{array}$} & \multicolumn{2}{|c|}{ Average } \\
\hline & Fixed & Smart & $\Delta$ & Fixed & Smart & $\Delta$ & Fixed & Smart & $\Delta$ & $\begin{array}{l}\text { Flow } \\
\text { (cfm) }\end{array}$ & RE \\
\hline Summera & 0.25 & $(0.08)$ & 0.33 & 1.88 & 1.80 & 0.08 & 40 & 41 & $(1.38)$ & 76 & 1.19 \\
\hline $\begin{array}{l}\text { Non-Summer } \\
\text { Coolingb }\end{array}$ & 0.14 & 0.02 & 0.12 & 0.40 & 0.30 & 0.09 & 40 & 28 & 11.88 & 51 & 1.15 \\
\hline $\begin{array}{l}\text { Non-Summer } \\
\text { Floating }\end{array}$ & $(0.92)$ & $(1.72)$ & 0.80 & $(0.06)$ & $(0.02)$ & $(0.05)$ & 40 & 80 & $(40.46)$ & 147 & 0.66 \\
\hline Heatingc & $(2.04)$ & $(1.50)$ & $(0.55)$ & $(1.80)$ & (1.34) & $(0.46)$ & 40 & 30 & 9.97 & 55 & 1.25 \\
\hline Annual & & & & & & & & & & 96 & 1.01 \\
\hline
\end{tabular}

a The period between May 1 and Oct. 31.

b The hours outside of the summer period when the outdoor air temperature falls within set parameters - Cooling $>71.5^{\circ} \mathrm{F}$;

Floating $\leq 71.5^{\circ} \mathrm{F}, \geq 50^{\circ} \mathrm{F}$.

${ }^{\mathrm{c}}$ The hours when the outdoor air temperature falls below $50^{\circ} \mathrm{F}$.

The changes in ventilation loads are converted into $\mathrm{kWh}$ using the same procedure as described for Phase I and shown in Table 3-9 along with fan energy.

Table 3-9. Estimated Space Conditioning Energy Use and Savings for Phase II Scheme

\begin{tabular}{|c|c|c|c|c|c|c|c|c|c|c|c|}
\hline \multirow{2}{*}{$\begin{array}{c}\text { Season/ } \\
\text { Period }\end{array}$} & \multicolumn{3}{|c|}{ Sensible (kWh) } & \multicolumn{3}{|c|}{ Latent (kWh) } & \multicolumn{3}{|c|}{ Fan (kWh) } & \multicolumn{2}{|c|}{ Total Savings } \\
\hline & Fixed & Smart & Savings & Fixed & Smart & Savings & Fixed & Smart & Savings & (kWh) & $\%$ \\
\hline Summera & 140 & (46) & 186 & 397 & 380 & 17 & 175 & 181 & (6) & 196 & 28 \\
\hline $\begin{array}{c}\text { Non-Summer } \\
\text { Coolingb }\end{array}$ & 20 & 3 & 17 & 21 & 16 & 5 & 44 & 123 & (78) & (56) & -65 \\
\hline $\begin{array}{l}\text { Non-Summer } \\
\text { Floating }\end{array}$ & & & & & & & 117 & 352 & (235) & (235) & -200 \\
\hline Heatingc & 232 & 170 & 62 & & & & 12 & 131 & (119) & (57) & -23 \\
\hline Annual & 392 & 128 & 264 & 418 & 396 & 22 & 349 & 787 & (438) & (152) & -13 \\
\hline
\end{tabular}

a The period between May 1 and Oct. 31.

$\mathrm{b}$ The hours outside of the summer period when the outdoor air temperature falls within set parameters - Cooling $>71.5^{\circ} \mathrm{F}$; Floating $\leq 71.5^{\circ} \mathrm{F}, \geq 50^{\circ} \mathrm{F}$.

${ }^{c}$ The hours when the outdoor air temperature falls below $50^{\circ} \mathrm{F}$.

Floating period sensible load can again be ignored, as described in the Phase I discussion. Summer sensible savings are $190 \mathrm{kWh}$ - an increase over the Phase I arrangement. The largest change in the Phase II arrangement is the increase in fan power, which has a deleterious impact on annual simulated savings although the impact on RE is considerably improved. The negative impact of increased fan power on the savings of the scheme suggests that the use of permanent magnet motors with much lower power would be highly beneficial to both the ability to modulate flow over periods, rather than utilize a fixed fan speed for varying amounts of time, as well as to reduce fan electric power consumption. 


\subsection{Phase II Laboratory Results: 2017 Cooling Period}

The Phase II scheme was implemented into the FRTF smart-controlled building May 1, 2017. The thermostats in both buildings were raised $2^{\circ} \mathrm{F}$ to $77^{\circ} \mathrm{F}$ since both mechanical systems had trouble meeting load demands during the hottest summer days in Phase I. The adjusted set points will allow the mechanical capacity for both laboratories to better meet demand during these warmest hours. Measured monthly energy savings are provided in Table 3-10, and average fan flow, RE, and interior and exterior conditions in Table 3-11. Results have been projected into 30-day bins, as a full month of data were not available because of internal gains issues - either disparities between the two buildings or limited generation in both.

Table 3-10. Phase II Scheme Average Monthly Measured Smart Ventilation AC Savings

\begin{tabular}{c|c|c|c|c|c|c|c|c|c|c}
\hline Month & \multicolumn{3}{|c|}{ Cooling Energy $(\mathrm{kWh})$} & \multicolumn{3}{c|}{ Fan Energy $(\mathrm{kWh})$} & \multicolumn{4}{c}{ Total Energy (kWh) } \\
\hline $\begin{array}{c}(\mathrm{n}=\text { days of } \\
\text { good data) }\end{array}$ & Fixed & Smart & Savings & Fixed & Smart & Savings & Fixed & Smart & Savings & $\begin{array}{c}\% \\
\text { Savings }\end{array}$ \\
\hline May $(\mathrm{n}=22)$ & 719 & 630 & 89 & 29 & 36 & $(7)$ & 748 & 666 & 82 & $11.0 \%$ \\
Jun $(\mathrm{n}=22)$ & 822 & 749 & 73 & 29 & 20 & 8 & 851 & 770 & 81 & $9.5 \%$ \\
Jul $(\mathrm{n}=26)$ & 1,012 & 924 & 88 & 29 & 26 & 2 & 1,040 & 950 & 90 & $8.6 \%$ \\
Average & 851 & 768 & 83 & 29 & 27 & 1 & 880 & 795 & 84 & $9.6 \%$ \\
\hline
\end{tabular}

Table 3-11. Phase II Scheme Average Monthly Measured Fan Flow, RE, and Interior and Exterior Conditions

\begin{tabular}{c|c|c|c|c|c|c|c|c}
\hline $\begin{array}{c}\text { Month }(\mathrm{n}= \\
\text { days of good } \\
\text { data) }\end{array}$ & $\begin{array}{c}\text { Smart } \\
\text { Flow } \\
(\mathrm{cfm})\end{array}$ & $\begin{array}{c}\text { Smart } \\
\text { RE }\end{array}$ & $\begin{array}{c}\text { Outdoor OA } \\
\text { Inlet Temp. } \\
\left({ }^{\circ} \mathrm{F}\right)\end{array}$ & $\begin{array}{c}\text { Control } \\
\text { Indoor } \\
\text { Temp. }\left({ }^{\circ} \mathrm{F}\right)\end{array}$ & $\begin{array}{c}\text { Smart Vent } \\
\text { Indoor } \\
\text { Temp. }\left({ }^{\circ} \mathrm{F}\right)\end{array}$ & $\begin{array}{c}\text { Outdoor Air } \\
\text { Inlet Dew } \\
\text { Point }\left({ }^{\circ} \mathrm{F}\right)\end{array}$ & $\begin{array}{c}\text { Control } \\
\text { Indoor } \\
\mathrm{RH}\end{array}$ & $\begin{array}{c}\text { Smart Vent } \\
\text { Indoor RH }\end{array}$ \\
\hline May $(\mathrm{n}=22)$ & 91 & 0.99 & 76.4 & 76 & 75.9 & 39.6 & 49.1 & 50.4 \\
\hline Jun $(\mathrm{n}=22)$ & 71 & 1.10 & 80.3 & 76 & 76.2 & 60.0 & 52.3 & 52.4 \\
Jul $(\mathrm{n}=26)$ & 67 & 1.27 & 83.0 & 76 & 76.1 & 61.3 & 49.0 & 49.3 \\
\hline
\end{tabular}

Although the results are limited to three months, the smart ventilation algorithm with the modified scheme and more powerful fan delivered savings far superior to the prior scheme, generating measured $12.4 \% \mathrm{AC}$ savings in May $(89 \mathrm{kWh} /$ month, $3.0 \mathrm{kWh} /$ day), $8.8 \%$ in June $(73 \mathrm{kWh} /$ month, $2.4 \mathrm{kWh} /$ day), and $8.7 \%$ in July ( 88 $\mathrm{kWh} /$ month, $2.9 \mathrm{kWh}$ /day), averaging $9.8 \%$ AC savings for the total period. Factoring in fan energy use, the savings are reduced slightly to $9.6 \%(84 \mathrm{kWh} /$ month, $2.8 \mathrm{kWh} /$ day $)$. While the months of measured data varied between phases, the cooling energy saving for three months under the Phase II scheme averaged 9.6\%, whereas the average cooling energy savings for three months under Phase I was only $2.9 \%$. These savings are compared in Figure 3-18. 


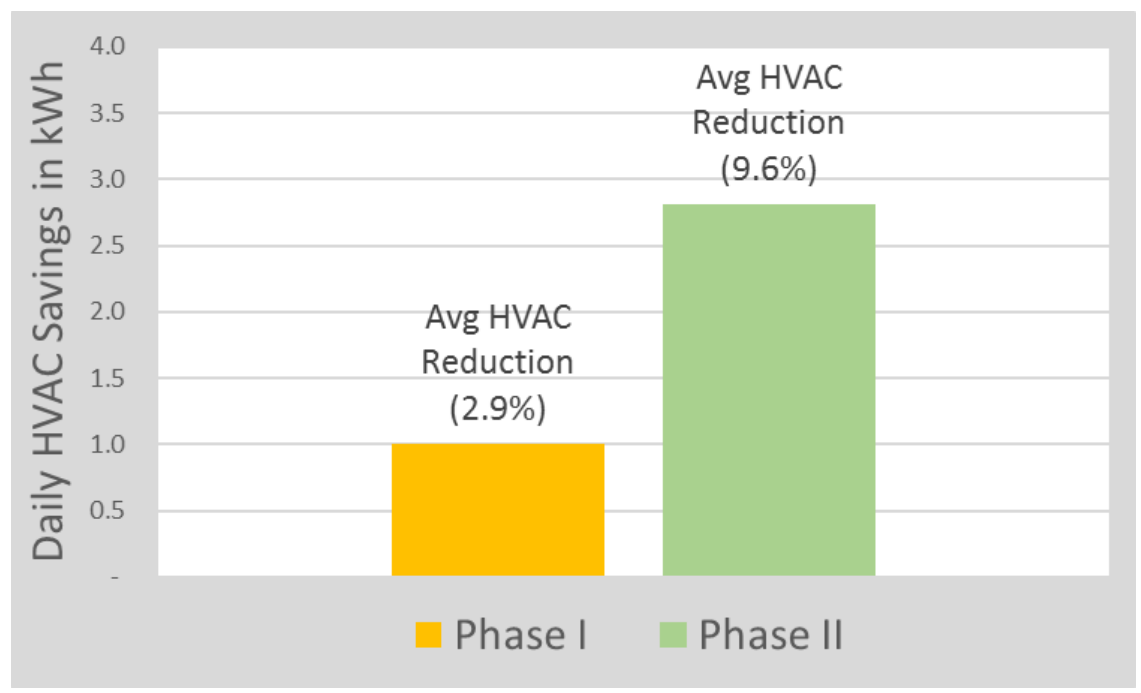

Figure 3-18. Average measured HVAC savings for Phase I (August-October) versus Phase II (May-July)

The average monthly fan flow for the smart ventilated building in May was $91 \mathrm{cfm}$, exceeding the constant fixed flow of 74, and average RE was 0.99 . Average flow during June was reduced to $71 \mathrm{cfm}$ in response to warmer conditions and the average RE rose to 1.10. Average flow during July was reduced slightly further to $67 \mathrm{cfm}$ and the average RE rose to 1.27. Average indoor temperature in the control and smart ventilation buildings are closely aligned. The average indoor RH in May was slightly higher in the smart building than the control, but overall the RH in the smart ventilation building was more closely aligned with that in the constant flow building than it was in Phase I. Still, floating season, when the RH difference between the buildings was greatest during Phase I, has yet to be analyzed. Similarly, a full year of data would be needed to evaluate how well the Phase II scheme actually succeeded in attaining the ASHRAE 62.2-2016 RE target, which was achieved using synthetic data.

The average daily profile for June is highlighted in Figure 3-19, with ventilation scheme savings at 11.3\%, displaying air conditioning power, fan flow, and indoor RH for both buildings along with outside air inlet temperature. The increased fan flow in the smart ventilation building during the morning hours has little impact on RH while still achieving impressive energy savings. The AC energy savings of the smart ventilation scheme are more pronounced during midday, when the outdoor temperature rises and the smart fan flow is greatly reduced. 


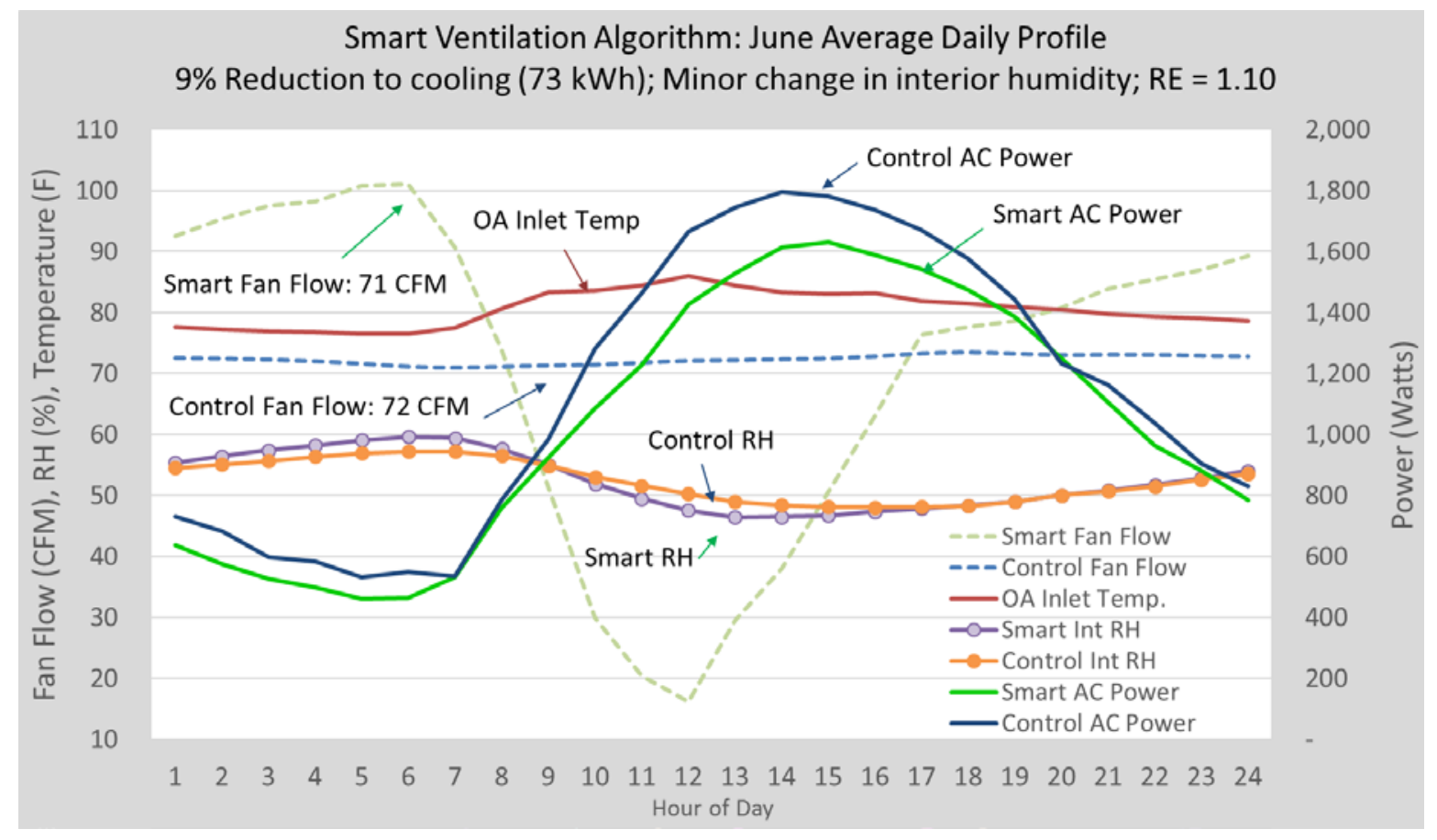

Figure 3-19. June average daily profile, displaying smart building AC power (green line), control building AC power (blue line), smart fan flow (light green dash), constant control fan flow (light blue dash), smart building interior RH (purple dots), control building interior RH (orange dots), and outside air inlet temperature (red line). 


\section{Conclusions from Experimental and Simulation-Based Analysis of Smart Ventilation Performance}

Three approaches to smart ventilation control were investigated as part of the research described in this report, utilizing a combination of energy simulation and experimental approaches. Differing numbers and types of control variables were explored, and implemented for demonstration purposes with varying levels of sophistication. Some controls were simple, while others were quite complex. In all cases, simulations and experiments showed potential to achieve heating and cooling energy savings, while maintaining indoor comfort. All control strategies, except for OTSVC, showed the ability to achieve objectives while maintaining RE to continuous ventilation specified in ASHRAE 62.2-2016. The OTSVC case is unique in that it explored $\mathrm{RE}$ with a different fundamental assumption for how pollutant emission rate may vary with occupancy, as discussed in the next section.

Experimental testing utilized sensor-based measurements of occupancy and weather parameters collected at the actual test homes, but commercialized systems could leverage both broadband weather data available from internet connected devices such as smart thermostats, as well as occupied/unoccupied signals from internetconnected security systems, thermostats, etc. One lesson learned is that differing choices for the physical location of a weather sensor to be located at a home could have an effect on resulting ventilation system operation, but also may more accurately reflect actual ventilation air conditions than data from an airport weather station. If broadband weather data is used as an element of control, algorithms may need to be tuned to correct for local anomalies.

Seasonal Temperature-Based Smart Ventilation Control (STSVC): A low-cost, prototype STSVC that shut off the mechanical ventilation fan below a pre-determined outdoor temperature $\left(57^{\circ} \mathrm{F}\right)$ was implemented in an occupied existing home in the heating dominated, marine climate zone of Olympia, Washington. In order to achieve an equivalent RE to continuous ventilation, above $57^{\circ} \mathrm{F}$, the fan operated at more than two times the rate determined by ASHRAE 62.2-2016 for continuous ventilation. While this arrangement kept the fan off for much of the winter, natural infiltration during periods of high indoor to outdoor temperature difference was modeled as sufficient to prevent unacceptable acute exposure to target pollutants. Simulation results show hourly RE remains below 1.5 and an annual average RE of 0.84 .

Energy simulations indicated potential for 9\% heating and cooling savings for the STSVC approach vs. continuous mechanical ventilation, and analysis of monitored data showed no negative impact on indoor moisture. Analysis of monitored data also showed that while indoor $\mathrm{CO}_{2}$ concentration was slightly higher on average with the STSVC approach compared to the continuous ventilation approach, other factors such as occupancy, air mixing, and changes to air exchange via window opening affect indoor $\mathrm{CO}_{2}$ concentration in similar proportion. Further study regarding other contaminants, particularly during long fan-off periods, is warranted. An evaluation of indoor RH showed that comfortable conditions are being maintained. An analysis of absolute moisture found that only minor differences exist between the continuous and STSVC schemes and health and durability are not impacted.

An investigation into the operation of the $\$ 20$ fan controller used for the experiment found the controller worked as expected, though leads to a suggestion for fan manufactures to evaluate a slightly longer delay period on the controller to reduce occurrences of fan cycling within the 1-minute time step.

Occupancy Timer-Based Smart Ventilation Control (OTSVC): In the same Olympia, Washington, occupied residence, an OTSVC system that varied operation of a mechanical ventilation fan in response to whether the home was occupied or vacant was tested. The simple, and low-cost time clock control assumed no occupancy during a typical workday schedule, seven days each week, where the mechanical ventilation fan was not operated. The scheme is not compliant with the ASHRAE 62.2-2016 standard, but was tested to evaluate control implications related to accuracy of occupancy detection. The imperfect control resulted in periods of 
time when the ventilation system was operating during unoccupied periods, and vice versa. To examine effects of imperfect control, actual occupancy was tracked with sensors and logs. Monitored data and subsequent analysis determined that indoor conditions were wetter during OTSVC with less ventilation air creating less drying potential, but not so wet as to degrade comfort, IAQ or durability. Monitored $\mathrm{CO}_{2}$ data showed that the average concentrations maintained during continuous ventilation $(659 \mathrm{ppm})$ were lower than OTSVC (759 ppm). Differences in monitored VOC concentrations between schemes were not significant. Findings were similar when more perfect occupancy detection was simulated by filtering data for ventilated unoccupied records and non-ventilated occupied periods. An evaluation on absolute moisture suggests that the OTSVC scheme would not generate mold-related IAQ or durability issues.

Energy simulations to estimate heating and cooling energy savings from OTSVC show a range of potential savings that can vary by a factor of 10 or more, yielding as much as $289 \mathrm{kWh} /$ year savings, depending on a number of factors including climate, occupancy schedule, how the schedule corresponds with heating/cooling loads, and the amount of ventilation air reduction provided by the OTSVC strategy.

Real-Time Weather-Based Smart Ventilation Control (RTWSV): An algorithm was developed that interprets measurements of current and 24-hour historical outdoor temperature and moisture and varies ventilation to minimize sensible and latent load impacts. Simulations were conducted to tune the algorithm with differing flow targets and seasonal adjustment factors to maximize heating and cooling energy savings compared to continuous ventilation, maintain similar indoor RH, and achieve RE with respect to ASHRAE 62.2-2016. The second of two RTWSV schemes evaluated suggested that compliant annual average and acute RE could be maintained with $73 \%$ sensible and $9 \%$ latent load reductions during cooling conditions. To achieve these savings, ventilation flow is reduced during cooling weather, and elevated ventilation airflow during the floating period is necessary to maintain annual average RE. Simulations show this approach is likely to increase net moisture addition during the floating period over continuous ventilation; however, experimentation indicates the impact on indoor $\mathrm{RH}$ during this time is minor.

A ventilation system controlled by the algorithm was implemented in a laboratory home and tested side by side with an identical home operating with continuous mechanical ventilation. Average cooling energy savings of $10 \%$ were measured during the first three months of evaluation due to the reduction in sensible and latent load created by the advanced system. A fan with a maximum capacity nearly three times greater than the continuous fan was required to achieve these savings, and added fan energy needs to be carefully considered so as not to erode potential cooling savings. The negative impact of increased fan power on the savings of the scheme suggests that the use of permanent magnet motors with much lower power would be highly beneficial to both the ability to modulate flow over periods, rather than utilize a fixed fan speed for varying amounts of time, as well as to reduce fan electric power consumption. 


\section{Industry Considerations for Commercialization of Smart Ventilation Controls}

The results presented in this report show potential for SVC; however, currently only a small selection of smart ventilation systems is on the market, including from manufacturers such as AprilAire, QuFresh, and AirCycler. Each manufacturer's system is able to suspend ventilation according to user-entered values for outdoor temperature and, in some cases, outdoor moisture, though no systems can automatically adjust flow to remain in compliance with ASHRAE 62.2 from an RE perspective. Commercially available calculators are just emerging that would enable a designer to implement a simple form of SVC, such as STSVC, by modifying a steady-state design flow using TMY3 data, to achieve RE with ASHRAE 62.2-2016. Therefore, to enable savings and IAQ improvements from SVCs, a concerted commercialization effort needs to be undertaken by manufacturers and other stakeholders such as builders, contractors, and standards organizations. During the course of the research, Building America Partnership for Improved Residential Construction (BA-PIRC) worked with manufacturers and other stakeholders to increase awareness of the potential of SVC and prime the industry for eventual device development and implementation.

The potential market size for SVC is growing, and justifies the need for commercially available products. Market research shows that the annual market for ventilation systems could be as high as 600,000 to 700,000 homes per year, as follows:

- New site-built code homes: Our research suggests that 23 states have adopted International Residential Code (IRC) 2012 and have built roughly 500,000 new units in 2014 where whole-house ventilation system installations were required. Many more states are expected to adopt these IRC previsions in the future (Stevens 2015).

- New Housing and Urban Development-code manufactured homes: Whole-house ventilation systems installed as part of the Manufactured Housing Construction Safety Standards. Approximately 60,000 homes were built in 2015 (Starkey 2015).

- Newly weatherized low-income units in U.S. DOE programs: Approximately 100,000 energy-efficiency retrofits were conducted in 2015 as part of DOE weatherization efforts (Francisco 2015).

\subsection{Stakeholder Outreach}

During 2015-2017, the BA-PIRC team worked with stakeholders to convene an advisory group and solicit input via emails, phone conversations, and in person at meetings and conferences. Core members of this advisory group included representatives from ASHRAE 62.2 committee, Lawrence Berkeley National Laboratory, the Building America Partnership for Advanced Residential Retrofit, The Energy Conservatory, Residential Energy Dynamics, Nest Labs, Panasonic, AirCycler, Johnson Controls, and AirAdvise.

Additional stakeholder outreach efforts were conducted by convening informal discussions and leveraging conference presentations at venues including RESNET-2016, ACI-2016, Energy OutWest 2016, Westford Symposium 2016, and Building Thermal Envelopes XIII 2017. At these events, team members solicited feedback from homebuilders, home performance contractors, low-income weatherization contractors, and manufacturers of ventilation systems. In addition, an SVC expert meeting at FSEC on Jan. 28, 2016, provided an additional opportunity to discuss SVC commercialization with Building America industry stakeholder partners.

\subsection{General Opportunities and Challenges}

Various opportunities have been identified for manufacturers to consider when it comes to commercializing SVCs. Stakeholder feedback suggests that for SVC commercialization to transform the market, it should: 
- Be a cost-effective solution with a savings-to-investment ratio of 1.0, which saves energy while maintaining acceptable IAQ.

- Meet the value proposition to consumers and others (energy, health, safety, durability).

- Comply with codes and standards such as ASHRAE 62.2-2016.

- Have a large enough demand in the new and existing home markets.

- Be perceived by SVC manufacturers as a profitable product development venture.

- Be perceived by builders and home performance contractors as profitable to include.

- Be incorporated into Energy Rating Indexes such as Home Energy Rating System, Home Energy Score, or ASHRAE 90.2 metrics; and be an added functionality of modeling tools (such as BEopt and EnergyGuage) to model these typical time-varying systems.

Some identified gaps that need resolution include:

- Determine if SVC is appropriate for very tight envelopes with heat recovery ventilation such as required in Passive House. This represents a small but growing sector of the potential SVC market.

- Define "occupancy away" for machine learning SVC associated with connected thermostat "black box" algorithms.

- Ensure that operation and maintenance $(\mathrm{O} \& \mathrm{M})$ is as intended by incorporating O\&M into SVC to ensure that the design, installation, commissioning, and inspection are in compliance with ASHRAE 62.2 Section 4.5 and Appendix C - Variable Mechanical Ventilation. The new emerging market of residential IAQ monitors (FOBOT, AirAdvise, etc.) that advise occupants about IAQ issues in their home may also be part of O\&M SVC to encourage occupants about the importance of IAQ and the O\&M of their ventilation system. If the whole-house ventilation system is not operated or maintained by the occupants as intended, SVC will not be cost-effective.

Additional discussion of some of these opportunities and challenges follows.

\subsection{Systems Costs and Emerging Opportunities}

One component of a research-to-market approach for SVCs that examines what it may take for mass market acceptance is to determine manufacturing cost estimates so they can be compared with costs of traditional ventilation systems. The cost premium for SVCs will depend on the complexity of the particular smartventilation approach chosen. For example, a basic smart ventilator that relies on an occupancy timer and/or outdoor temperature will be $\$ 100$ or less if it is integrated into existing smart web-enabled thermostat - also called connected thermostat (CT) - controls or another device that can access weather or occupancy information via the web instead of using local sensors. CT manufacturers are interested in having their CT platforms communicate with ventilation systems in compliance with ASHRAE 62.2-2016. Incorporating SVC algorithms into CT may add almost no incremental cost to the equipment or installation costs. More complex approaches involving sensing operation of other fans and/or occupancy would cost $\$ 100$ to $\$ 150$ due to sensor costs and additional installation labor, unless those signals can also be provided by web-enabled equipment via the internet of things.

\subsection{Industry Standards and the Authorizing Environment}

An important milestone in SVC commercialization was achieved when the "authorizing environment" (in this case, ASHRAE) made changes to ASHRAE Standard 62.2. These efforts resulted in the development of Section 4.5 - Variable Mechanical Ventilation and Normative Appendix C - Relative Exposure, which 
provides additional guidance to stakeholders who are looking to commercialize ASHRAE 62.2-compliant SVC systems. SVC commercialization is expected to accelerate as a result of the new ASHRAE 62.2 guidance.

To introduce the industry to new smart ventilation strategies, an ASHRAE 62.2 user's manual was developed that focused on SVCs that met ASHRAE 62.2-2016 compliance. SVC work described in earlier sections of this report serves as the basis for "real world" examples in the ASHRAE 62.2 user's manual, including Q\&A examples related to:

- STSVC in user manual example c-c: Outdoor temperature cutout

- Occupancy control in user manual example c-b: Mechanical ventilation

- General SVC algorithm development guidance in user manual example c-f: Calculating RE for noncontinuously operating whole-house mechanical ventilation systems.

The current ASHRAE 62.2-2016 always assumes constant contaminant emissions; this assumption may limit potential of realizing energy savings with SVC. Future consideration could be given to the notion that for pollutants of concern, emission rates and pollutant concentrations are typically higher when the home is occupied. A straw poll proposal that sought to separate pollutant contributions of the building and the occupant was proposed at the ASHRAE 62.2 meeting in June 2017. For example, equation 4.1 of ASHRAE 62.2- could be revised to reflect occupancy by eliminating the need for the $7.5 \mathrm{cfm} /$ bedroom +1 when the home is unoccupied. This proposal was generally acceptable to ASHRAE 62.2 members and to other stakeholders. Future discussions of such ideas could result in changes that will help improve energy savings from occupancy controls and support commercialization efforts.

Work also needs to be done to achieve consensus about how to specify occupancy-based systems and components to best ensure that the home is unoccupied when system operation is curtailed. Strategies include one, or a combination, of the following approaches:

- Simple scheduling of occupancy by occupants (like set-back thermostats)

- Geofencing using smart phones

- Adding occupancy sensors with and without machine-learning algorithms

- Using $\mathrm{CO}_{2}, \mathrm{VOC}$, and other pollutant sensors as a surrogate for occupancy

- Allowing the emerging smart home CT technology marketplace to issue specifications, not ASHRAE 62.2

- Developing standards that help define an "occupants away" signal for occupancy-based systems.

\subsection{Gaps in System Design, Installation, and Commissioning}

As manufacturers develop SVCs, consideration has to be given to the design, installation, and commissioning of such systems. Identified gaps include:

- Software tools based on ASHRAE 62.2-2016 Appendix C and the user's manual are needed to help designers and verifiers ensure compliance and to credit SVC approaches for code compliance and ratings.

- Onboard fault detection and diagnosis is needed to alert homeowners/contractors to failures, which is an often-overlooked feature of a smart ventilation system. 
- As ventilation and other systems get smarter, equipment will likely rely on the internet to send and receive input from the cloud or from other devices. When a new home is built, stakeholders must take into account how it will be commissioned prior to occupancy, considering that internet access is typically set up by the occupants after they move in.

- Who will be trained to commission a potentially vast array of smart ventilation systems? Considering that their operation will vary over time according to a number of changing control variables (outdoor temperature, etc.), how can they be commissioned during a single visit?

- Smart ventilation systems likely need to be set up by the builder (and contractors) because most occupants are not likely to do it themselves due to its complexity. But if systems connect to and receive information from other devices (clothes dryers for exhaust run time, security system to sense occupancy, etc.), the builder may have to provide a package that includes a complete suite of gadgets so the system can be set up ahead of time. Also consider real-life issues such as when occupants replace their dryer with an incompatible model.

- Consistency of communication among "smart" devices is essential so they can be leveraged as part of a SVC system. Some single-manufacturer platforms have devices that talk to each other. Partnerships have emerged among manufacturers to use the same communication platform to enable cross-cutting communication. However, different platforms are currently in use, including HomeKit (Apple) and Brillo/Weave (Google).

\subsection{Stakeholder Discussions on Commercialization}

The Building America Partnership for Improved Residential Construction worked with various industry partners to identify what sort of SVC development they are currently engaged in, further define what must be achieved to commercialize SVC, and extract general sentiments on the future of residential mechanical ventilation in general.

\subsubsection{Nest}

The Works with Nest program allows ventilation system manufacturers to partner by providing a "Nest away" signal to the ventilation system that may allow for occupancy-based controls. Nest away is determined by occupancy sensors at the thermostat that incorporate machine-learning algorithms. The Nest smoke/carbon monoxide alarms option (which also has occupancy sensors) can provide a higher degree of reliability associated with the Nest away signal when installed.

Nest can also provide these Works with Nest partners with local outdoor temperatures to facilitate commercialization of temperature-based controls. Information available via $\mathrm{CT}$ about local pollen count, high ozone, forest fires, and other extraordinary events could also be options for SVC when ventilation is undesirable. Information from web-based CT like Nest may allow SVC to also communicate mission-critical O\&M information to the occupant to help ensure operation per ASHRAE 62.2, like the Nest green leaf currently does to encourage energy-efficient behavior at home. A similar concept (healthy house icon) could be employed on the CT display to encourage habits that ensure a healthier indoor environment. This is critical given the challenges documented by Building America and others to "ventilate right when building tight."

\subsubsection{Panasonic}

Panasonic has been developing a platform that allows for communication between the whole-house, intermittent exhaust ventilation systems, range hoods, and/or other smart appliances, such as clothes dryers and home security systems. The platform may provide the ability to communicate through the internet with weather sites to determine outside temperature for employing SVC. Occupancy sensors and geofencing, as well as monitoring key appliances, may help to determine occupancy conditions for occupancy-based systems. 
The following insights provided by Russell Pope illustrate a general confusion on the part of builders and contractors, stemming from a lack of consistent guidance about proper specification of ventilation systems:

These are all things that we have heard on at least once-exhaust this, supply that, use the air handling unit for distribution, but only if it has an efficient motor. No, you don't want to do THAT! That is too much air and will waste electricity. That is not enough air, the people will get sick! Infiltration credit - how do I calculate that?

\subsubsection{AirCycler}

The AirCycler has been around for many years as a smart control feature called the TempGuard. This device is installed in the fresh air supply duct and disables the whole-house supply ventilation system when the outside temperature is below $35^{\circ} \mathrm{F}$ or above $95^{\circ} \mathrm{F}$. The control ensures that no cold outside air is supplied to the furnace to prevent thermal shock to the heat exchanger and reduce draft-related occupant comfort complaints. These complaints can cause occupants to override controls and shut off the ventilation, which will not turn back on without occupant intervention. This lockout could employ the guidance in ASHRAE 62.2-2016 Appendix $\mathrm{C}$ to adjust the ventilation flow rate in compliance with requirements for annual exposure if the climate, outside temperature at site, measured air leakage, and stack height are known. Calculators could be developed that may help determine the correct flow rate for any lockout temperature, as allowed in ASHRAE 62.2 Appendix C and user's manual.

The following insights about the AirCycler are provided by Jason Wolfson:

The future of ventilation: The ideal ventilation system would have a feedback loop and would control ventilation rates based on pollutants present in the home. But, at least for now, that's not possible. The list of pollutants is both long and undefined. Even if they were defined, the sensors required to monitor all possible pollutants, all tied back to a central controller, would be too expensive to purchase and install.

If you visit AirCycler.com and play with the Ventilation Cost Calculator, you'll see the cost to ventilate the average home is under $\$ 200$ year. If the goal is to reduce ventilation cost by $20 \%$ - an ambitious goal-you're only saving \$40/year. Anything you do to achieve that savings can't cost much to purchase and install or the return on investment isn't there. Since pollutants can't be accurately or efficiently measured, it's important to measure what causes most of them: the occupants. The future of ventilation uses the same solution that's used for so much these days - The Internet of Things. Using the Internet of Things to determine occupancy is simple. Systems could use IP sniffing for cell phones, geofencing, or interacting with other devices in the home like a Nest thermostat. The incremental cost of adding a Wi-Fi transceiver to the ventilation controller is under $\$ 5$ and installation cost is minimal, if any. Using this functionality, ventilation rates can automatically ramp up and down based on how the home is used, operating when it matters most and with no input from the occupants. And finally, once you're tied to the web, endless climate data becomes available and allows for a host of additional capabilities.

\subsubsection{Residential Energy Dynamics}

The following insights about SVC design tools are provided by Rick Karg of Residential Energy Dynamics (RED):

Residential Energy Dynamics (RED) has the software and capability now for the design of controls and real-life examples of smart ventilation devices and scenarios, all based on ASHRAE 62.2-2016, Section 4.5 and Appendix C. RED currently offers a free online calculation aid for determining many of the variables involved with smart ventilation, including outdoor temperature. The Advanced Infiltration tool can be found at http://www.residentialenergydynamics.com/REDCalcFree/Tools/AdvancedInfiltration. In the near future, RED will make a smart ventilation application program interface available to interested research organizations and businesses. Additionally, RED will provide web-based 
calculation tools for smart ventilation temperature cut-off and diurnal, or longer-term, variable ventilation rates, suitable for controlling ventilation based on time-of-use electric rates or home/away schedules. 


\section{References}

ASHRAE. 2016. Standard 62.2-2016 Ventilation and Acceptable Indoor Air Quality in Low-Rise Residential Buildings.

Building America Program. 2015. "Building America Research to Market Plan." https://energy.gov/eere/buildings/downloads/building-america-program-research-market-plan

Francisco, P. and Rose, W. 2010. "Temperature and Humidity Measurements in 71 Homes Participating in an IAQ Improvement Program.” In Proceedings of Thermal Performance of Exterior Envelopes of Whole Buildings XI, Florida, USA, December.

Less, Brennan and Walker, Iain. 2016, Smart Ventilation Control of Indoor Humidity in High Performance Homes in Humid U.S. Climates. Ernest Orlando Lawrence Berkeley National Laboratory. LBNL-1006980.

Less, B., Walker, I., and Tang, Y. 2014. "Development of an Outdoor Temperature Based Control Algorithm for Residential Mechanical Ventilation Control.” Lawrence Berkeley National laboratory, Berkeley, CA.

Martin, E. for Building Science Corporation, Florida Solar Energy Center, and IBACOS. 2014. Impact of Residential Mechanical Ventilation on Energy Cost and Humidity Control. Golden, CO. National Renewable Energy Laboratory. NREL/SR-5500-60675, January 2014.

Offerman, F. J. 2009. "Ventilation and Indoor Air Quality in New Homes." PIER Collaborative Report, California Energy Commission \& California Environmental Protection Agency Air Resources Board.

Parker, D., Cummings, J., Vieira, R., Fariey III, P., Sherwin, J., Withers Jr., C., Hoak, D., and Beal, D. 2014.Flexible Residential Test Facility: Impact of Infiltration and Ventilation on Measured Cooling Season Energy and Moisture Levels. Golden, CO. National Renewable Energy Laboratory. NREL/SR-5500-61012, January 2014.

Sherman, M. H., Matson, N.E. 2002. “Air Tightness of New U.S. Houses: A Preliminary Report.” Lawrence Berkeley National Laboratory, Berkeley, CA. (LBNL-48671).

Sherman, M. H.; Walker, I.S. 2011. "Meeting Residential Ventilation Standards through Dynamic Control of Ventilation Systems.” Energy and Buildings, 43(8), 1904-1912. doi:10.1016/j.enbuild.2011.03.037.

Sherman, M. H., Walker, I.S., Logue, J.M. 2012. "Equivalence in ventilation and indoor air quality." HVAC\&R Research, 18(4), 760-773.

Turner, W.J.N. and Walker, I.S. 2012. "Advanced Controls and Sustainable Systems for Residential Ventilation." Lawrence Berkeley National Laboratory, Berkeley, CA. Retrieved from http://eetd.lbl.gov/sites/all/files/publications/lbnl-5968e.pdf. (LBNL-5968E).

Vieira, R, D. Parker, P. Fairey III, J. Sherwin, C. Withers, and D. Hoak. 2013. Flexible Residential Test Facility: Impact of Infiltration and Ventilation on Measured Heating Season Energy and Moisture Levels. Golden, CO. National Renewable Energy Laboratory, September 2013.

Walker, Iain, Sherman, Max, and Less, Brennan. 2014. Houses are Dumb without Smart Ventilation. Lawrence Berkeley National Laboratory. LBNL-6747E. 
Office of

ENERGY EFFICIENCY \& RENEWABLE ENERGY
For more information, visit: buildingamerica.gov

DOE/EE-1701 · January 2018 